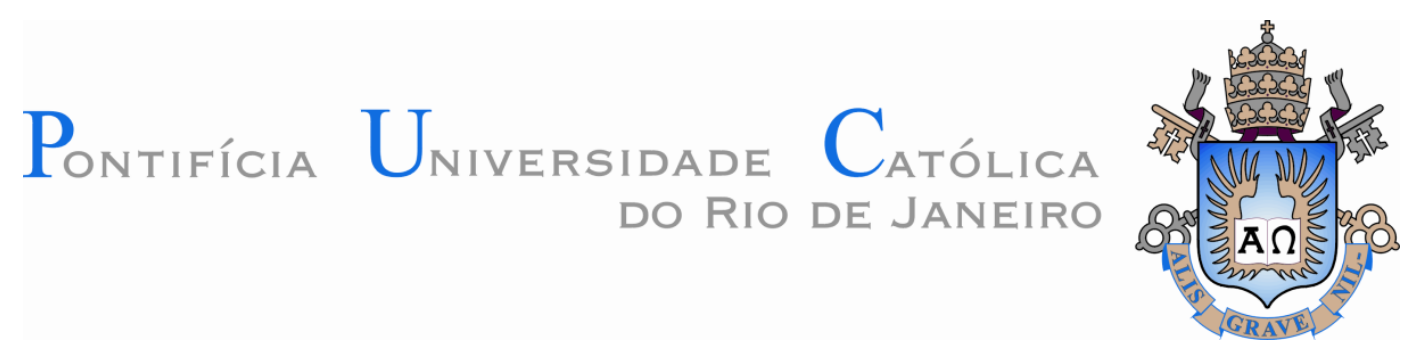

Eric Arthur de Freitas Penedo

\title{
Prova de Carga Instrumentada em um Cais apoiado sobre Estacas
}

Dissertação apresentada como requisito parcial para obtenção do título de Mestre pelo Programa de PósGraduação em Engenharia Civil do Departamento de Engenharia Civil do Centro Técnico Científico da PUCRio.

Orientador: Prof. Pedricto Rocha Filho 
Eric Arthur de Freitas Penedo

\section{Prova de Carga Instrumentada em um Cais apoiado sobre Estacas}

Dissertação apresentada como requisito parcial para obtenção do grau de Mestre pelo Programa de Pós-Graduação em Engenharia Civil do Departamento de Engenharia Civil do Centro Técnico Científico da PUC-Rio. Aprovada pela Comissão Examinadora abaixo assinada.

Prof. Pedricto Rocha Filho Orientador

Departamento de Engenharia Civil - PUC-Rio

Prof. Celso Romanel Departamento de Engenharia Civil - PUC-Rio

Prof. Giuseppe Barbosa Guimarães Departamento de Engenharia Civil - PUC-Rio

Prof. Fernando Saboya de Albuquerque Júnior Departamento de Engenharia Civil - UENF

Prof. José Eugenio Leal

Coordenador Setorial do Centro Técnico Científico - PUC-Rio

Rio de Janeiro, 10 de agosto de 2012 
Todos os direitos reservados. É proibida a reprodução total ou parcial do trabalho sem autorização da universidade, do autor e do orientador.

\section{Eric Arthur de Freitas Penedo}

Graduou-se em Engenharia Civil pela Pontifícia Universidade Católica do Rio de Janeiro, em 2009. Ingressou no mestrado em Engenharia Civil (Geotecnia) na Pontifícia Universidade Católica do Rio de Janeiro em 2010, desenvolvendo dissertação na linha de pesquisa de Geotecnia experimental.

Ficha Catalográfica

Penedo, Eric Arthur de Freitas
Prova de Carga Instrumentada em um Cais
apoiado sobre Estacas / Eric Arthur de Freitas Penedo ;
orientador: Pedricto Rocha Filho. - 2012.
104 f. il. (color.) ; $30 \mathrm{~cm}$
Dissertação (mestrado)-Pontifícia Universidade
Católica do Rio de Janeiro, Departamento de Engenharia
Civil, 2012.
Inclui bibliografia
1. Engenharia civil - Teses. 2. Instrumentação.
3. Eletroníveis. 4. Prova de carga. 5. Grupo de estacas. I.
Rocha Filho, Pedricto. II. Pontifícia Universidade Católica
do Rio de Janeiro. Departamento de Engenharia Civil. III.
Título.




\section{Agradecimentos}

Ao professor Pedricto Rocha Filho pela orientação neste trabalho e pela contribuição essencial para a minha formação.

À equipe que participou da realização do teste, composta por Giuseppe, Gusmão, Francisco, Euclides e José Nilson.

À CAPES, FAPERJ e à PUC-Rio.

À PMMR e à EBSE pela oportunidade para a aplicação desta pesquisa experimental neste trabalho.

À minha família, em especial aos meus pais Evaldo e Tereza, pelo apoio necessário para a minha formação.

À Mariana Paiva por estar ao meu lado durante a realização deste trabalho.

Aos meus amigos que de alguma forma foram importantes para este trabalho.

Aos funcionários do departamendo de Engenharia Civil. 


\section{Resumo}

Penedo, Eric Arthur de Freitas; Rocha Filho, Pedricto. Prova de Carga Instrumentada em um Cais apoiado sobre Estacas. Rio de Janeiro, 2012. 104 p. Dissertação de Mestrado - Departamento de Engenharia Civil, Pontifícia Universidade Católica do Rio de Janeiro.

Esta dissertação apresenta os dados de um teste de carga instrumentado em um cais, enfatizando a importância da instrumentação de campo para melhor compreender o comportamento da estrutura durante o teste. Dentro desta abordagem, foi realizada uma revisão sobre o comportamento de grupo de estacas, direcionada à influência do espaçamento entre estacas na interação entre as mesmas, e da rigidez do bloco na distribuição de carga entre as estacas, no fator de segurança das mesmas e das distorções angulares do bloco. Em seguida, foram descritas as caratcerísticas geométricas e geotécnicas do cais testado, e foram apresentadas as características da instrumentação utilizada, composta por extensômetros elétricos, eletroníveis e nível topográfico, desde sua montagem e calibração, até a sua instalação em campo. Foi destacada a utilização dos eletroníveis, que apesar de pouco utilizados na prática da engenharia geotécnica, são instrumentos versáteis, precisos e podem ser reutilizados. O procedimento do teste de carga foi realizado de modo a simular a situação real da maneira mais próxima da realidade, onde foram monitoradas as deformações em quatro estacas, a rotação e o recalque da laje do cais. A estrutura apresentou bom desempenho durante o teste, com baixo nível de deformação nas estacas, distorção angular desprezível e baixos valores de recalque total e residual.

\section{Palavras-chave}

Instrumentação; Eletroníveis; Prova de carga; Grupo de estacas. 


\section{Abstract}

Penedo, Eric Arthur de Freitas; Rocha Filho, Pedricto. Instrumented Load Test carried out in a Piled Quay Structure. Rio de Janeiro, 2012. 104 p. MSc. Dissertation - Departamento de Engenharia Civil, Pontifícia Universidade Católica do Rio de Janeiro.

This dissertation presents the data of an instrumented load test in a wharf, emphasizing the importance of field instrumentation to analyze the behavior of the structure during the load test. First, a review was carried out on the behavior of pile groups, focusing on the influence of pile spacing in the interaction factors. It also considered the influence of the raft stiffness on the load distribution and factor of safety of the piles. The main characteristics of the wharf were presented, such as, geometry, dimensions, deformability and strength properties of the concrete. The geological and geotechnical subsoil profile have been presented, indicating a soft clay layer resting on a very compact residual soil. The particularities of the instrumentation used on the test, composed by strain gauges, electrolevels and a topographic level, were presented since the assembly and calibration, to the installation on field. Despite its underutilization in geotechnical engineering practice, the use of electrolevels was emphasized, due to its versatility, accuracy and the fact that they can be reutilized. The load test procedure was made to simulate the real situation as close as possible, where strain in four piles, rotation and settlement of the deck were monitored. The structure performanced well during the test, presenting low level of strain in piles, negligible angular distortion of the deck and low values of total and residual settlements.

\section{Keywords}

Instrumentation; Electrolevels; Load test; Pile Group. 


\section{Sumário}

1 Introdução 16

$\begin{array}{ll}\text { 1.1. Comentários gerais } & 16\end{array}$

$\begin{array}{ll}\text { 1.2. Objetivos do trabalho } & 16\end{array}$

$\begin{array}{ll}\text { 1.3. Estrutura do trabalho } & 17\end{array}$

2 Revisão bibliográfica $\quad 18$

2.1. Introdução 18

2.2. Métodos de previsão do recalque de grupos de estacas 18

$\begin{array}{ll}\text { 2.2.1. Teoria da elasticidade e elementos de contorno } & 18\end{array}$

2.2.1.1. Influência da aplicação do fator de interação somente à componente $\begin{array}{ll}\text { elástica do recalque } & 21\end{array}$

2.2.2. Método da superposição 22

2.3. Análise numérica $\quad 24$

2.3.1. Distribuição de carga entre as estacas $\quad 25$

$\begin{array}{ll}\text { 2.3.2. Fator de segurança contra a ruptura } & 27\end{array}$

2.3.3. Distorções angulares 30

2.4. Parâmetros geotécnicos 32

3 Características do cais e da instrumentação utilizada 33

3.1. Características do cais 33

3.1.1. Características geométricas 33

3.1.2. Características geotécnicas $\quad 35$

3.2. instrumentação 36

3.2.1. Concepção geral 36

3.2.2. Eletroníveis 36

$\begin{array}{ll}\text { 3.2.2.1. Princípio de funcionamento } 38 & 38\end{array}$

3.2.2.2. Montagem 40

3.2.2.3. Calibração $\quad 40$

3.2.2.3.1. Eletronível de referência 43

3.2.2.3.2. Eletroníveis EL01 a EL16 44

3.2.2.4. Instalação 45

3.2.3. Extensômetros elétricos 48 
3.2.3.1. Princípio de funcionamento 49

3.2.3.2. Montagem 49

3.2.3.3. Calibração 50

3.2.3.4. Instalação 51

3.2.4. Nivelamento topográfico 52

4 Resultados 53

4.1. Procedimento do teste 54

4.2. Rotações $\quad 57$

4.3. Deformações 58

4.3.1. Deformações devido ao carregamento 59

4.3.2. Deformações devido ao peso próprio da estrutura 62

4.4. Deslocamento vertical 64

4.5. Carga nas estacas 66

5 Conclusões e sugestões para trabalhos futuros 67

5.1. Conclusões 67

5.2. Sugestões para trabalhos futuros 68

$\begin{array}{ll}\text { Referências bibliográficas } & 69\end{array}$

Apêndice 1: Curvas de calibração dos eletroníveis EL01 a EL16 71

Apêndice 2: Leituras dos eletroníveis EL01 a EL16 88 


\section{Lista de figuras}

Figura 2.1 - Grupo de duas estacas. (Poulos e Davis, 1980)

Figura 2.2 - Fator de interação contra espaçamento para diferentes valores do índice de esbeltez, $K=1000$. (Zhemchuzhnikov, 2011)

Figura 2.3 - Efeito da aplicação do fator de interação somente à componente elástica. (Poulos, 2005) 21

Figura 2.4 - Recalques previstos e medidos. (Poulos, 1998)

Figura 2.5 - Deformações do solo observadas e previstas para um grupo de três estacas sob condição de carga igual (a) e recalque igual (b). (Cooke et al., 1979)

Figura 2.6 - Valores observados dos fatores de interação em comparação com as curvas teóricas. (Cooke et al., 1979)

Figura 2.7 - Geometria do modelo utilizado. (Bacelar, 2003) 25

Figura 2.8 - Configurações utilizadas no estudo paramétrico. (Bacelar, 2003) 26 Figura 2.9 - Classificação das estacas em função de sua posição no radier. (Bacelar, 2003)

Figura 2.10 - Distribuição de carga entre as estacas em função do número de estacas para rigidez $K_{R}=0,01$. (Bacelar, 2003)

Figura 2.11 - Distribuição de carga entre as estacas em função do número de estacas para rigidez $K_{R}=1$. (Bacelar, 2003)

Figura 2.12 - Fator de segurança das estacas para $v_{s}=0,5$. (Bacelar, 2003)

Figura 2.13 - Distribuição do módulo de elasticidade do solo proposta por Poulos (1988). 32

Figura 3.1 - Geometria do cais (dimensões em centímetros). 34

Figura 3.2 - Perfil geotécnico local. 35

Figura 3.3 - Locação da instrumentação. 37

Figura 3.4 - Rotação de corpo rígido. 38

Figura 3.5 - Vista do eletronível de quatro pinos. (www.frederickscom.com) 39

Figura 3.6 - Circuito elétrico de conexão dos eletroníveis. (Ramos, 2009) 39

Figura 3.7 - Curva de sensibilidade do eletronível. (www.frederickscom.com) 40

Figura 3.8 - Dimensões em milímetros da cápsula dos eletroníveis. 41

Figura 3.9 - Eletronível posicionado na cápsula antes da resinagem. 41 
Figura 3.10 - Barra de calibração dos eletroníveis. (Ramos, 2009) 42

Figura 3.11 - Calibração dos eletroníveis utilizando o SME. 42

Figura 3.12 - Correlação entre as leituras feitas pelo SME e Mini Data-Logger. 44

Figura 3.13 - Curvas de calibração dos eletroníveis EL01 a EL16 utilizando o

SME. $\quad 45$

Figura 3.14 - Fatores de calibração para os eletroníveis EL01 a EL16. $\quad 46$

$\begin{array}{ll}\text { Figura } 3.15 \text { - Detalhe dos perfis de fixação dos eletroníveis. } & 47\end{array}$

Figura 3.16 - Nivelamento e fixação do eletronível. 48

Figura 3.17 - Extensômetro Elétrico unidirecional simples.

$\begin{array}{ll}\text { (www.excelsensor.com.br) } & 49\end{array}$

Figura 3.18 - Circuito elétrico dos extensômetros elétricos. 49

Figura 3.19 - Detalhe da conexão serial dos extensômetros elétricos. $\quad 50$

Figura 3.20 - Tratamento da superfície de instalação dos extensômetros elétricos. 51

Figura 3.21 - Detalhe da fixação dos cabos. 52

Figura 4.1 - Trailers carregados com placas de aço e tanques de água. $\quad 53$

Figura 4.2 - Estágios de aplicação da carga. 55

Figura 4.3 - Ângulo de rotação da laje do cais em cada estágio. 57

Figura 4.4 - Ângulo de rotação da laje do cais ao longo do tempo. 58

Figura 4.5 - Estaca E2: deformação específica em cada estágio. 60

Figura 4.6 - Estaca E3: deformação específica em cada estágio. 60

Figura 4.7 - Estaca E47: deformação específica em cada estágio. 61

Figura 4.8 - Estaca E48: deformação específica em cada estágio. 61

Figura 4.9 - Deslocamento vertical para cada estágio de carregamento. $\quad 65$

Figura 4.10 - Curva carga x recalque. 65

Figura A1.1 - Curva de calibração do eletronível EL01. 72

$\begin{array}{ll}\text { Figura A1.2 - Curva de calibração do eletronível EL02. } & 73\end{array}$

$\begin{array}{ll}\text { Figura A1.3 - Curva de calibração do eletronível EL03. } & 74\end{array}$

Figura A1.4 - Curva de calibração do eletronível EL04. 75

Figura A1.5 - Curva de calibração do eletronível EL05. 76

Figura A1.6 - Curva de calibração do eletronível EL06. 77

$\begin{array}{ll}\text { Figura A1.7 - Curva de calibração do eletronível EL07. } & 78\end{array}$

Figura A1.8 - Curva de calibração do eletronível EL08. 79

Figura A1.9 - Curva de calibração do eletronível EL09. 80

Figura A1.10 - Curva de calibração do eletronível EL10. 81

Figura A1.11 - Curva de calibração do eletronível EL11. 82 
Figura A1.12 - Curva de calibração do eletronível EL12. 83

Figura A1.13 - Curva de calibração do eletronível EL13. 84

Figura A1.14 - Curva de calibração do eletronível EL14. 85

Figura A1.15 - Curva de calibração do eletronível EL15. 86

Figura A1.16 - Curva de calibração do eletronível EL16. 87

Figura A2.1 - Leituras do eletronível EL01. 89

Figura A2.2 - Leituras do eletronível EL02. 90

Figura A2.3 - Leituras do eletronível EL03. 91

Figura A2.4 - Leituras do eletronível EL04. 92

Figura A2.5 - Leituras do eletronível EL05. 93

Figura A2.6 - Leituras do eletronível EL06. 94

Figura A2.7 - Leituras do eletronível EL07. 95

Figura A2.8 - Leituras do eletronível EL08. 96

$\begin{array}{ll}\text { Figura A2.9 - Leituras do eletronível EL09. } & 97\end{array}$

Figura A2.10 - Leituras do eletronível EL10. 98

Figura A2.11 - Leituras do eletronível EL11. 99

$\begin{array}{ll}\text { Figura A2.12 - Leituras do eletronível EL12. } & 100\end{array}$

$\begin{array}{ll}\text { Figura A2.13 - Leituras do eletronível EL13. } & 101\end{array}$

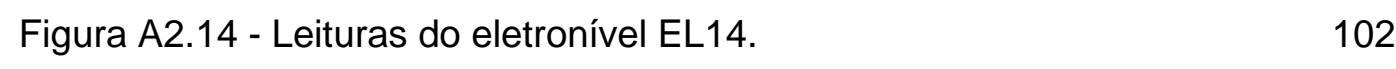

$\begin{array}{ll}\text { Figura A2.15 - Leituras do eletronível EL15. } & 103\end{array}$

$\begin{array}{ll}\text { Figura A2.16 - Leituras do eletronível EL16. } & 104\end{array}$ 


\section{Lista de tabelas}

Tabela 2.1 - Distorções angulares máximas na seção A-A em função da rigidez do radier para $v_{s}=0,5$ e $\mathrm{L} / \mathrm{d}=25$. (Bacelar, 2003)

Tabela 2.2 - Distorções angulares máximas na seção A-A em função do comprimento relativo das estacas para $v_{s}=0,5$ e $L / d=25$. (Bacelar, 2003) 30 Tabela 3.1 - Fatores de calibração para os eletroníveis EL01 a EL16. 46 Tabela 4.1 - Estágios de aplicação de carga. Tabela 4.2 - Ângulo máximo e distorção angular medida pelos eletroníveis. 59 Tabela 4.3 - Deformação nas estacas devido ao peso próprio da estrutura. $\quad 64$ Tabela 4.4 - Carga atuando nas estacas devido ao carregamento. 66 Tabela 4.5 - Carga total atuando nas estacas. 


\section{Lista de Símbolos}

\section{Romanos}

A

$A_{S}$

d

$\mathrm{d}_{\text {eq }}$

$\mathrm{E}$

$\mathrm{E}_{\mathrm{Cm}}$

$E_{P}$

$E_{R}$

$E_{S}$

$E s_{A V}$

$E s_{m}$

$\mathrm{F}_{\mathrm{ck}}$

$\mathrm{F}_{\mathrm{cm}}$

$F_{S}$

FC

$\mathrm{FC}_{\mathrm{REF}}$

$\mathrm{FC}_{\mathrm{ML}}$

$\mathrm{FC}_{\text {SME }}$

$\mathrm{h}$

$\mathrm{K}$

$\mathrm{K}_{\mathrm{R}}$

$\mathrm{k}$

L

$\mathrm{n}$

$\mathrm{N}$

$\mathrm{P}$
Área da seção transversal da estaca

Área efetiva

Diâmetro da estaca

Diâmetro equivalente da estaca

Módulo de elasticidade

Módulo de elasticidade médio do concreto

Módulo de elasticidade da estaca

Módulo de elasticidade do radier

Módulo de elasticidade do solo

Módulo de elasticidade médio do solo

Módulo de elasticidade do solo entre estacas

Resistência característica do concreto

Resistência à compressão média do concreto

Fator de segurança

Fator de calibração dos eletroníveis

Fator de calibração do eletronível de referência

Fator de calibração dos eletroníveis para leituras do Mini Data Logger

Fator de calibração dos eletronpiveis para leituras do SME

Espessura da camada de solo

Rigidez relativa da estaca

Rigidez do radier

"Gage factor"

Comprimento da estaca

Lado da seção transversal da estaca quadrada

Número de elementos da estaca

Número de golpes de SPT

Carga axial aplicada no topo da estaca 


$\begin{array}{ll}\mathrm{P}_{0} & \text { Carga total no topo das estacas de determinado tipo } \\ \mathrm{P}_{\mathrm{AV}} & \text { Carga total no radier dividida pelo número total de estacas } \\ \mathrm{P}_{\mathrm{P}} & \text { Carga na estaca devido ao peso próprio da estrutura } \\ \mathrm{P}_{\mathrm{Q}} & \text { Carga na estaca devido ao carregamento } \\ \mathrm{P}_{\mathrm{T}} & \text { Carga total na estaca } \\ \mathrm{q} & \text { Carga distribuída sobre o radier } \\ \mathrm{Q} & \text { Carga aplicada sobre o cais } \\ \mathrm{R} & \text { Raio do radier } \\ \mathrm{R}_{0} & \text { Resistência elétrica inicial } \\ \mathrm{S} & \text { Espaçamento entre estacas } \\ \mathrm{t} & \text { Espessura do radier } \\ \mathrm{U}_{\mathrm{A}} & \text { Tensão de saída da ponte de Wheatstone } \\ \mathrm{U}_{\mathrm{E}} & \text { Tensão de entrada da ponte de Wheatstone } \\ \mathrm{y} & \text { Deflexão }\end{array}$




\section{Gregos}

$\begin{array}{ll}\beta & \text { Distorção angular } \\ \mathrm{B}_{0} & \text { Distorção angular para o radier sem estacas } \\ \Delta \mathrm{L} & \text { Variação de leitura dos eletroníveis } \\ \Delta \mathrm{L}_{\mathrm{ML}} & \text { Variação da leitura dos eletroníveis no Mini Data Logger } \\ \Delta \mathrm{L}_{\mathrm{SME}} & \text { Variação da leitura dos eletroniveis no SME } \\ \Delta \mathrm{R} & \text { Variação de resistência elétrica } \\ \varepsilon & \text { Deformação } \\ \varepsilon_{\mathrm{p}} & \text { Deformação das estacas devido ao peso próprio da estrutura } \\ \varepsilon_{\mathrm{q}} & \text { Deformação das estacas devido ao carregamento } \\ \varepsilon_{\mathrm{t}} & \text { Deformação total das estacas } \\ \theta & \text { Ângulo de rotação } \\ \mathrm{V}_{\mathrm{P}} & \text { Coeficiente de Poisson das estacas } \\ \mathrm{V}_{\mathrm{R}} & \text { Coeficiente de Poisson do radier } \\ \mathrm{V}_{\mathrm{S}} & \text { Coeficiente de Poisson do solo } \\ \sigma & \text { Tensão } \\ \sigma_{\mathrm{p}} & \text { Tensão nas estacas devido ao peso próprio da estrutura } \\ \sigma_{\mathrm{q}} & \text { Tensão nas estacas devido ao carregamento } \\ \sigma_{\mathrm{t}} & \text { Tensão total nas estacas }\end{array}$




\section{1 Introdução}

\section{1.}

\section{Comentários Gerais}

Segundo Rocha Filho (2000), constata-se atualmente um grande distanciamento entre o refinamento, sofisticação e versatilidade dos métodos numéricos e computacionais de análise e previsão do comportamento de obras geotécnicas em relação à qualidade até mesmo representatividade das informações oriundas de programas observacionais de engenharia geotécnica. Surge, então, a necessidade de se intensificarem os esforços no sentido de desenvolver técnicas mais precisas e abrangentes do monitoramento do comportamento de obras geotécnicas.

Tratando-se de grupo de estacas especificamente, existem diversos métodos para obter a interação entre estacas, subdivididos em teóricos, semiempíricos e empíricos, além de dados experimentais presentes na literatura, contemplando uma variedade de abordagens e variáveis geométricas e geotécnicas.

Segundo Poulos (1999), apesar dos avanços significantes no conhecimento geotécnico, particularmente durante as três últimas décadas, pouco esforço foi feito na avaliação da aplicabilidade de alguns dos métodos de análise comumente utilizados. Afigura-se que o estado da prática em áreas tradicionais da engenharia de fundações está defasado do estado da arte. Pressões relacionadas a custo e tempo frequentemente impedem a aplicação de técnicas modernas de análise e projeto de fundações, e resultam na continuação do uso de procedimentos empíricos ultrapassados, cujos fundamentos podem ser duvidosos.

\section{2.}

\section{Objetivos do trabalho}

Foi realizado um teste de carga com a finalidade de averiguar a capacidade de um cais, localizado em Itaguaí no estado do Rio de Janeiro, em suportar com segurança a passagem de um módulo de compressão de gás de 
$927 \mathrm{tf}$, transportado por dois trailers que, juntos, pesam $126 \mathrm{tf}$, totalizando 1053 tf.

A partir das informações coletadas por um sistema de aquisição de dados, será feita uma análise sobre o comportamento do grupo de estacas que compõe a fundação do cais, com ênfase no conceito do fator de interação entre estacas, além da apresentação dos resultados do desempenho da estrutura durante o teste de carga em si.

\section{3.}

\section{Estrutura do trabalho}

O presente trabalho foi subdividido em cinco capítulos, abordando os seguintes tópicos:

Capítulo 1 - apresenta uma introdução sobre a necessidade da instrumentação no monitoramento do desempenho de estruturas, mencionando a relevância da pesquisa e seus objetivos principais;

Capítulo 2 - apresenta uma breve revisão sobre comportamento de grupo de estacas, abordando a influência do espaçamento entre estacas, rigidez do bloco e parâmetros geotécnicos;

Capítulo 3 - dedicado à descrição das características do cais e da instrumentação utilizada, justificando sua escolha e detalhando as etapas de montagem e instalação;

Capítulo 4 - apresentação e interpretação dos dados obtidos no monitoramento do cais durante a prova de carga;

Capítulo 5 - inclui as conclusões resultantes deste trabalho e proposta para temas de trabalhos futuros.

E por último são apresentadas as referências bibliográficas deste trabalho e dois apêndices. 


\section{2 \\ Revisão bibliográfica}

\section{1. Introdução}

Conforme mencionado anteriormente, existem diversos métodos de previsão do comportamento de grupos de estacas disponíveis na literatura, subdivididos em teóricos, semi-empíricos e empíricos.

Uma prática utilizada em linhas de pesquisa direcionadas a este assunto tem sido a coleta de dados provenientes de experimentos de campo ou de análises numéricas para realizar análises paramétricas com os métodos presentes na literatura, visando mensurar a aplicabilidade dos mesmos.

Este trabalho segue esta abordagem, portanto será apresentada neste capítulo uma revisão de métodos com embasamento teórico, análises numéricas e dados experimentais.

\section{2. \\ Métodos de previsão do recalque de grupos de estacas}

Zhemchuzhnikov (2011) realizou uma análise comparativa dos diversos métodos de previsão do recalque de grupos de estacas no meio homogêneo, abrangendo métodos empíricos, semi empíricos, teóricos baseados na teoria da elasticidade e elementos de contorno, das camadas finitas, das camadas fictícias e o método baseado na aproximação de Winkler.

As principais conclusões sobre a aplicabilidade dos métodos mais relevantes obtidas neste trabalho estão apresentadas a seguir.

\subsection{1.}

\section{Teoria da elasticidade e elementos de contorno}

O método proposto por Poulos e Davis (1968) baseado na Teoria da Elasticidade linear utilizando o método dos elementos de contorno utiliza fatores de interação para quantificar a influência entre estacas.

São necessárias algumas simplificações, tais como, o solo é considerado elástico e a aderência entre o solo e a estaca é perfeita. Além disso, considera- 
se que a tensão cisalhante é uniformemente distribuída ao longo da circunferência da estaca.

O grupo é composto por duas estacas flutuantes idênticas, cada uma dividida em $n$ elementos (Figura 2.1). Os deslocamentos das estacas são obtidos através da integração das equações de Mindlin para deslocamento vertical em um espaço semi homogêneo sob carregamento interno vertical. Desta forma, os fatores de interação foram obtidos por Poulos e Mattes (1971) e são representados em gráficos em função do espaçamento adimensional (s/d), da rigidez relativa da estaca $(\mathrm{K})$ e do índice de esbeltez da estaca $(\mathrm{L} / \mathrm{d})$.

$A$ rigidez relativa da estaca $(K)$ é definida pela Equação 2.1, onde $A_{S}$ é a razão entre a área sólida da estaca e a área da circunferência. Logo, para estacas maciças $A_{S}=1$ e para estacas vazadas $A_{S}<1$.

$$
K=\frac{E_{P}}{E_{S}} \times A_{S}
$$

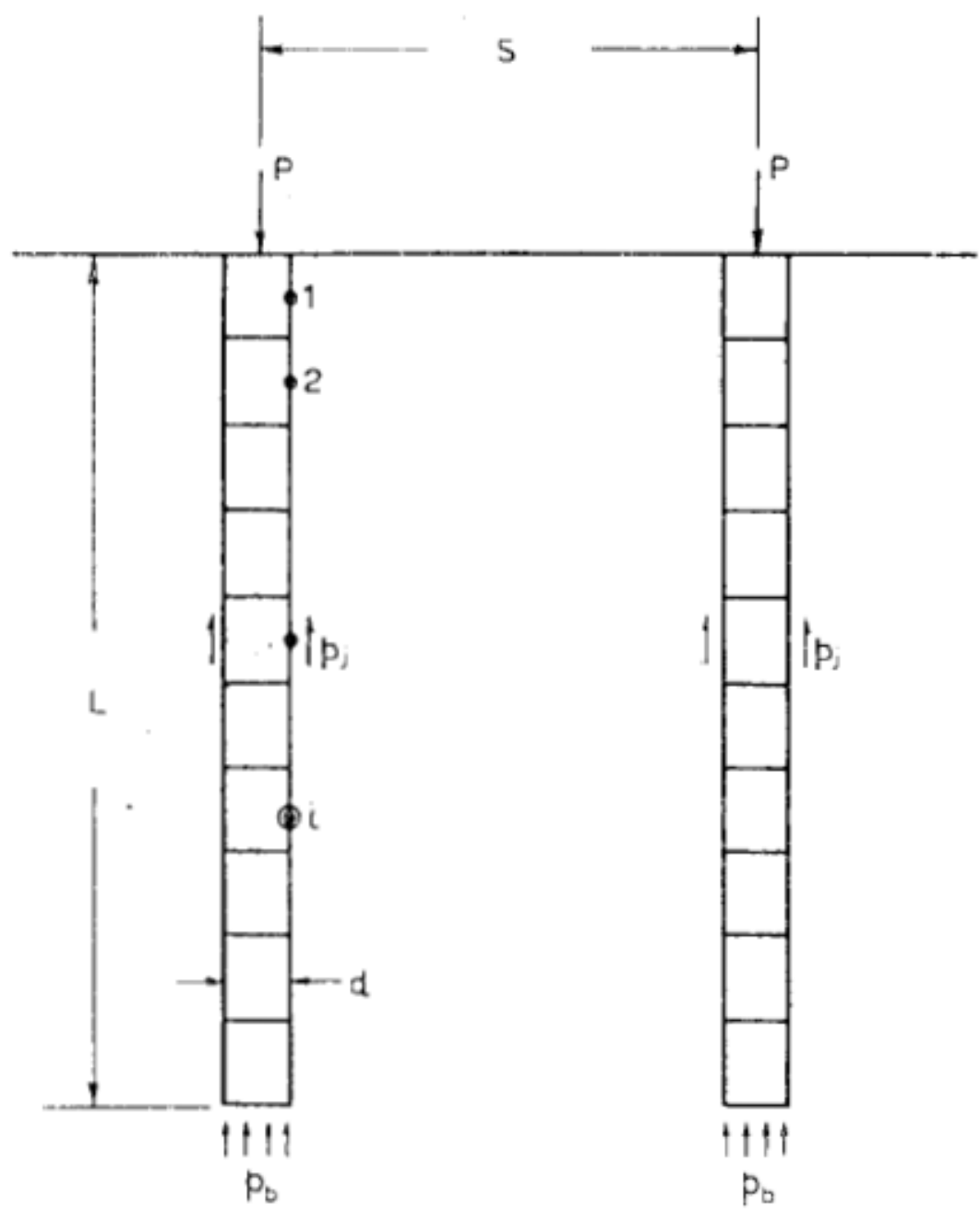

Figura 2.1 - Grupo de duas estacas (Poulos \& Davis, 1980). 
A Figura 2.2 mostra a variação do fator de interação em função do espaçamento relativo entre estacas, para vários índices de esbeltez (L/d) com rigidez relativa $K=1000$. Observa-se que os fatores de interação continuam significantes mesmo para grandes espaçamentos.

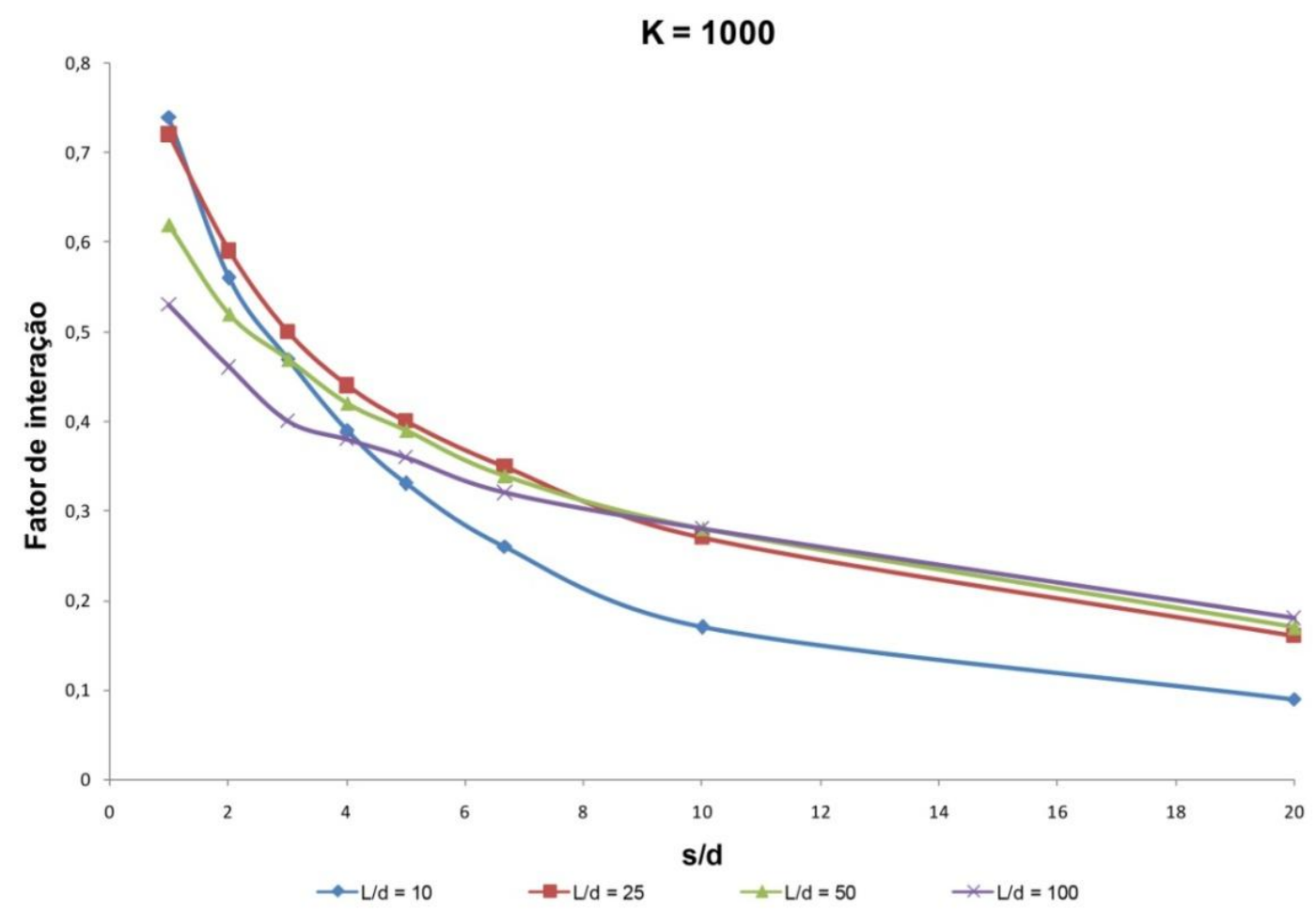

Figura 2.2 - Fator de interação contra espaçamento para diferentes valores do índice de esbeltez, K=1000 (Zhemchuzhnikov, 2011).

Para grupos maiores do que duas estacas, Poulos e Davis (1980) propõem que a análise para o grupo de duas estacas pode ser estendido caso o comportamento das estacas seja idêntico, ou seja, o grupo deve ser simétrico e as estacas devem ter mesma carga e recalque.

Esta solução considera que o recalque adicional de uma estaca causado pelas estacas vizinhas pode ser aproximadamente calculado através da superposição dos fatores de interação individuais. Entretanto, esta consideração ignora o fato de que a adição de uma estaca altera o sistema elástico do conjunto estaca/solo individual, ou seja, assume-se que o meio (solo) mantém as mesmas características após a adição da estaca adjacente. 


\subsubsection{1. \\ Influência da aplicação do fator de interação à componente elástica do recalque}

Mandolini e Viggiani (1997) e Randolph (1994) propuseram a aplicação dos fatores de interação somente à componente elástica do recalque das estacas adjacentes, considerando a parcela plástica um fenômeno isolado que não afeta a interação entre estacas.

A Figura 2.3 mostra o efeito desta proposta nas curvas carga $\mathrm{x}$ recalque teóricas para um grupo de 16 estacas sob carregamento axial.

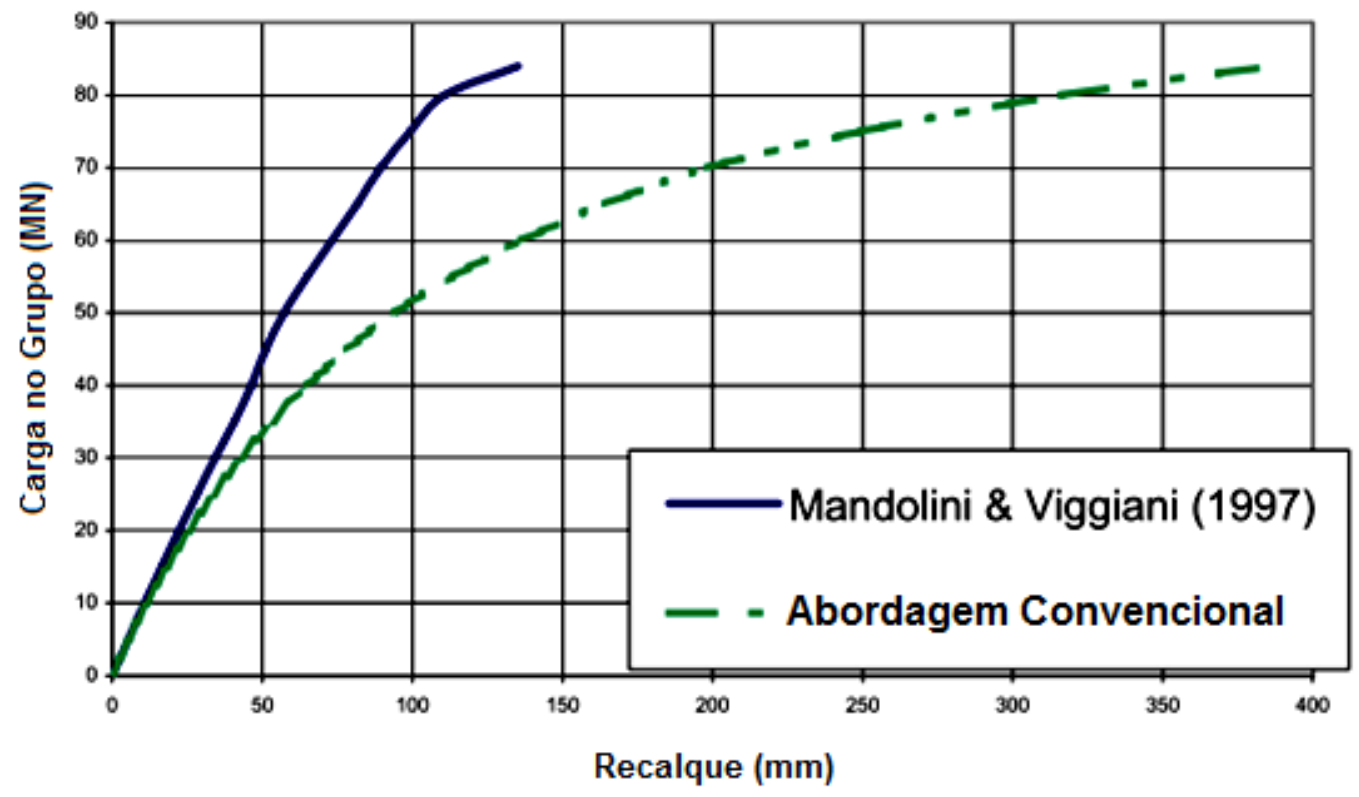

Figura 2.3 - Efeito da aplicação do fator de interação somente à componente elástica (Poulos, 2005).

Para ilustrar a aplicação desta proposta, a seguir é apresentado um estudo de caso realizado por Poulos (1998).

Goosens e Van Impe (1991) apresentaram uma comparação entre os resultados provenientes da análise baseada no método dos elementos de contorno e os resultados medidos em campo para um grande grupo de estacas.

Este caso também foi analisado utilizando a proposta de Mandolini e Viggiani (1997), onde além da aplicação do fator de interação somente à componente elástica do recalque, também foi adotado um espaçamento máximo no qual não ocorre interação entre estacas (raio de influência).

A Figura 2.4 mostra que a análise baseada nos elementos de contorno (identificada como DEFPIG) superestima o recalque, reforçando os conceitos 
apresentados anteriormente de que a extrapolação da interação entre duas estacas para grupos maiores não é aplicável.

Poulos (2005) recomenda a utilização da abordagem proposta por Mandolini e Viggiani (1997), pois apresenta análises mais próximas aos resultados experimentais.

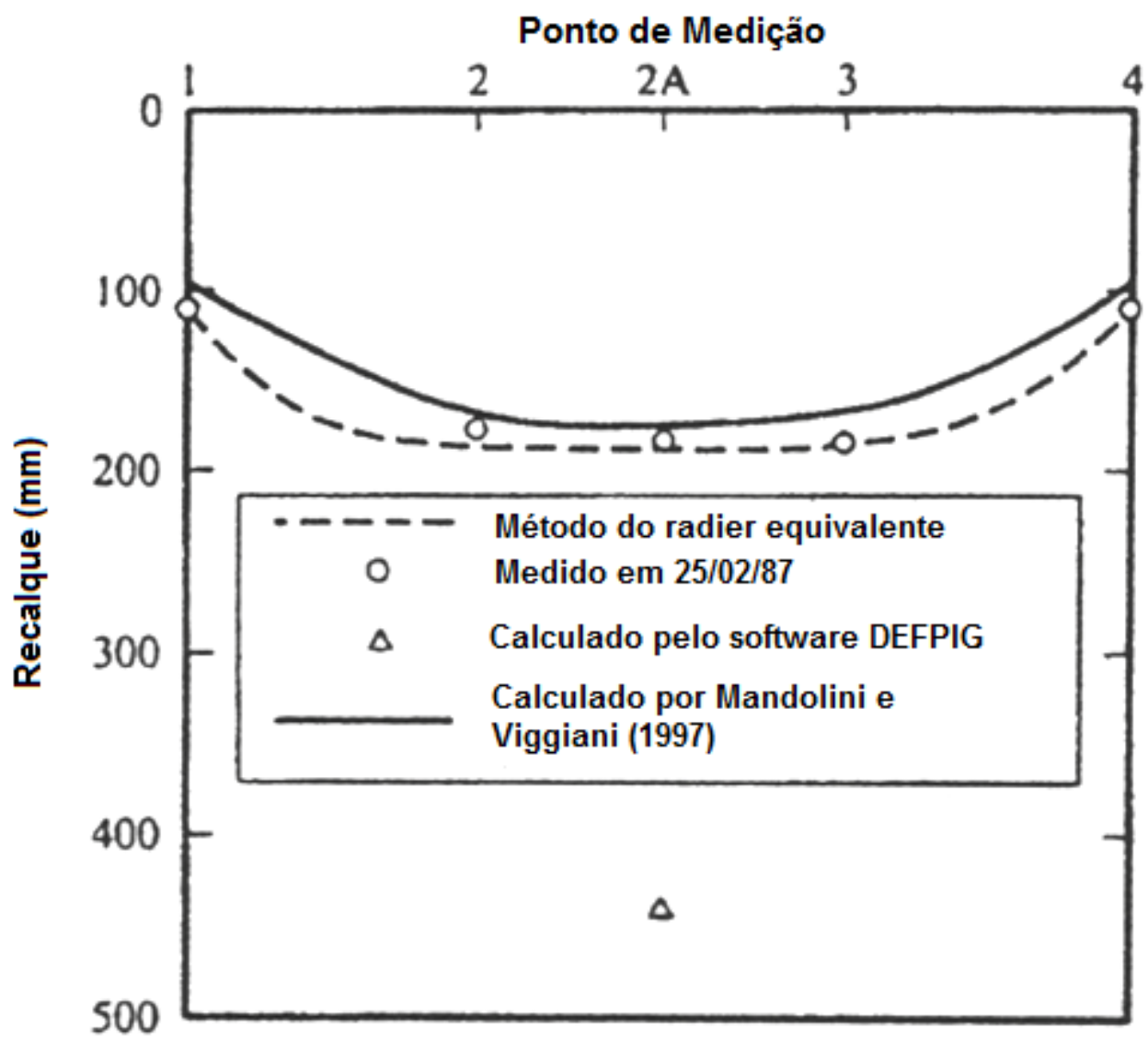

Figura 2.4 - Recalques previstos e medidos (Poulos, 1998).

\subsection{2}

\section{Método da superposição}

O método de superposição baseado no modelo de cilindros concêntricos possibilita a obtenção dos deslocamentos de um grupo de estacas em função do deslocamento de uma estaca isolada.

Resultados de provas de carga instrumentadas em grupos de duas e três estacas foram apresentados por Cooke e Price (1973), Cooke et al. (1979) e Cooke et al. (1980) para verificar a aplicabilidade deste método. 
O deslocamento de um grupo de duas estacas foi calculado satisfatoriamente somando-se o deslocamento da estaca isolada sob metade do carregamento do grupo (caso de bloco flexível) e o deslocamento do solo no local de instalação da estaca adjacente. Além da condição de carga igual (bloco flexível), também foi verificada a condição de recalque igual (bloco rígido) (Figura 2.5).

O método foi aplicado para um grupo de cinco estacas e observou-se que o campo de deslocamento de cada estaca se limita a um raio de aproximadamente dez diâmetros da mesma, ou seja, um raio de influência a partir do qual o deslocamento do solo se torna desprezível.
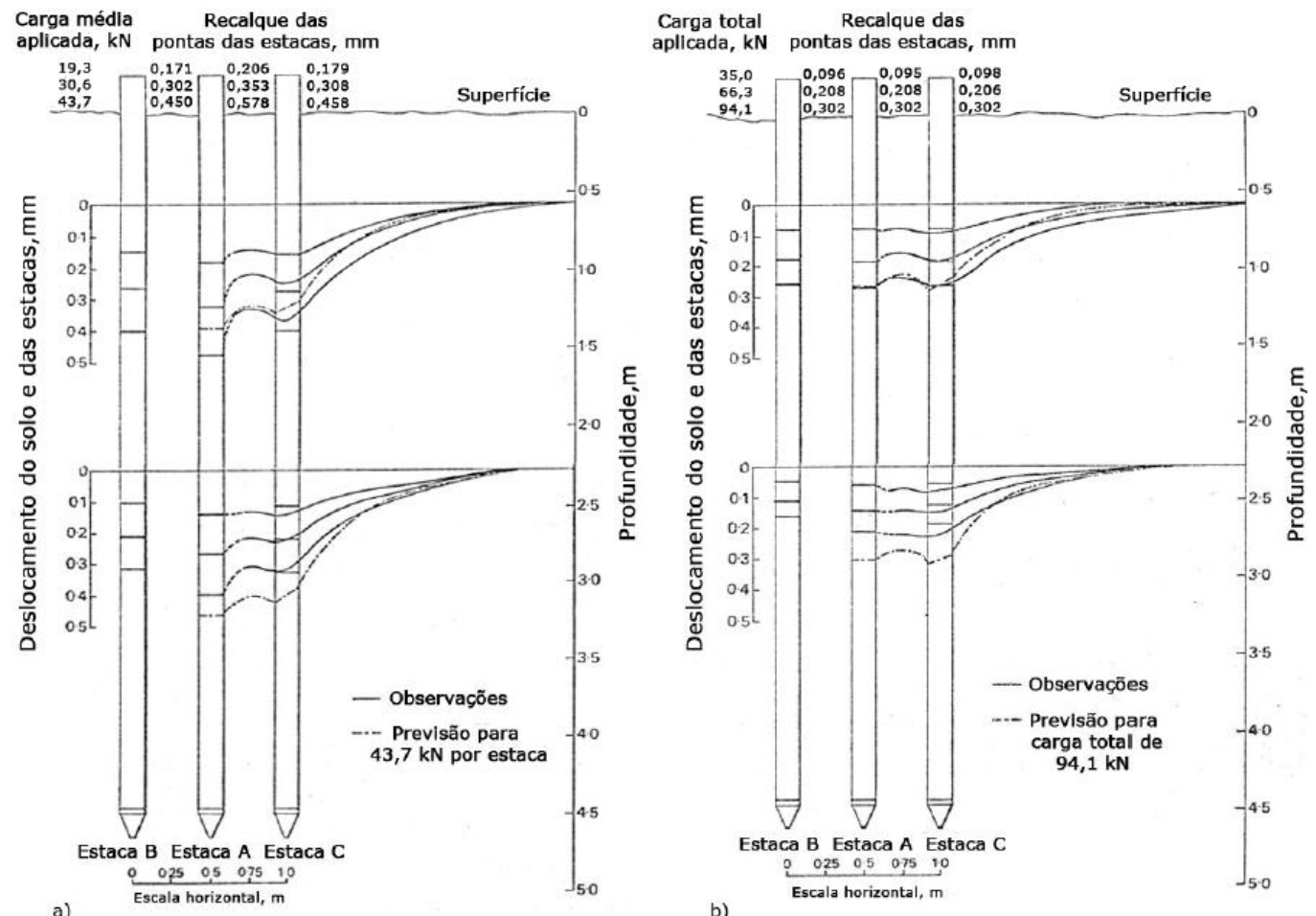

Figura 2.5 - Deformações do solo observadas e previstas para um grupo de três estacas sob condição de carga igual (a) e recalque igual (b) (Cooke et al., 1979).

A Figura 2.6 mostra uma curva comparando os fatores de interação obtidos durante os ensaios e curvas teóricas. Observa-se novamente que o método dos elementos de contorno superestima o fator de interação para grandes espaçamentos.

De acordo com Zhemchuzhnikov (2011), vale ressaltar que este método de precisão dos deslocamentos por superposição foi verificado experimentalmente para grupos de duas e três estacas alinhadas. Portanto, o comportamento observado pode não ser típico para grupos bidimensionais maiores, onde mais 
carregamento é transferido para a base do grupo, e por consequência as características do bloco do solo reforçado pelas estacas podem ser mais relevantes do que o comportamento de uma estaca isolada.

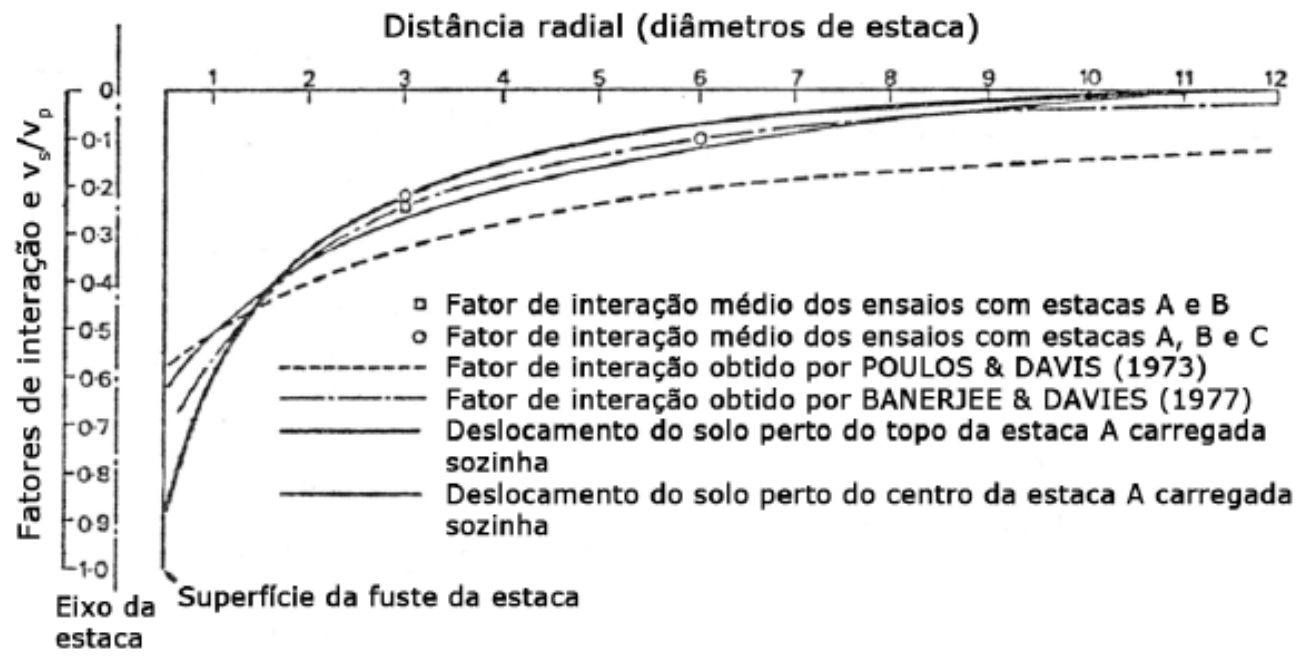

Figura 2.6 - Valores observados dos fatores de interação em comparação com as curvas teóricas (Cooke et al., 1979).

Além disso, as propostas de fator de interação que incluem um raio de influência na análise conforme Cooke (1974) e Mandolini e Viggiani (1997) tendem a fornecer previsões mais realistas e menos conservativas, porém existe dificuldade em encontrar os parâmetros utilizados nestas análises.

\section{3.}

\section{Análise numérica}

Bacelar (2003) realizou uma análise paramétrica para descrever o comportamento de radiers estaqueados utilizando o método dos elementos finitos, onde foram comparadas diversas configurações de grupos de estacas, variando-se o número e a distribuição das estacas.

Além disso, para uma mesma configuração, foram feitas variações em parâmetros como a rigidez do radier $\left(\mathrm{K}_{\mathrm{R}}\right)$, o espaçamento relativo entre estacas (s/d) e o comprimento relativo das estacas (L/d). A rigidez do radier é dada pela Equação 2.2.

$$
K_{R}=\frac{E_{R}\left(1-v_{S}^{2}\right)}{E_{S}}\left(\frac{t}{R}\right)^{3}
$$


O modelo utilizado foi um radier circular uniformemente carregado, conforme mostrado na Figura 2.7. As configurações com as respectivas distribuições de estacas consideradas estão representadas na Figura 2.8.

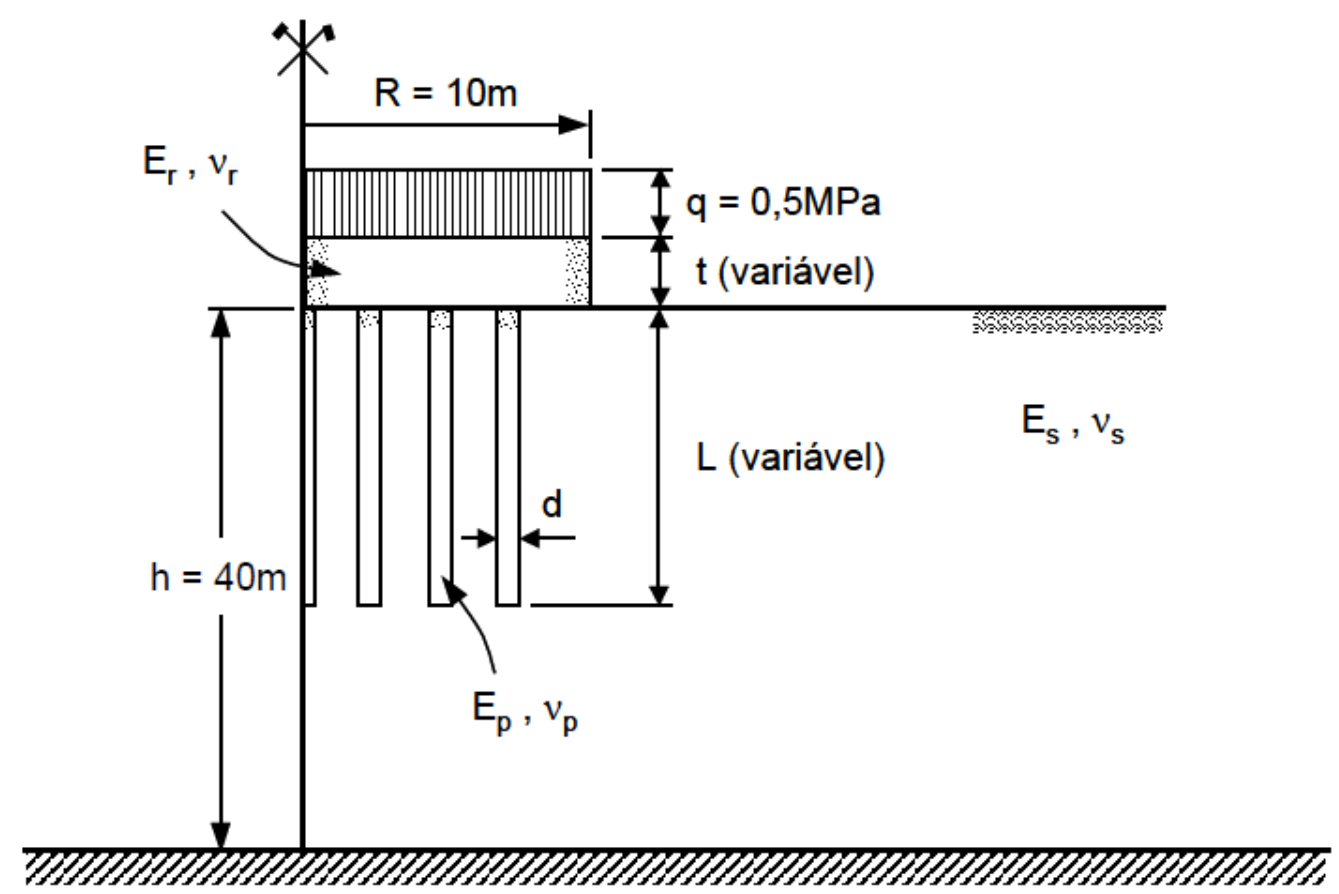

Figura 2.7 - Geometria do modelo utilizado (Bacelar, 2003).

Dentre os diversos resultados observados, destaca-se a influência da rigidez do radier na distribuição de carga nas estacas, no fator de segurança contra a ruptura das estacas e nas distorções angulares.

\subsection{1.}

\section{Distribuição de carga entre as estacas}

Uma análise sobre a distribuição de carga entre as estacas de uma mesma configuração mostra que quanto mais afastada do centro do radier uniformemente carregado, maior será o carregamento no topo da estaca.

As estacas foram classificadas em tipos relacionados com seu posicionamento no grupo conforme mostrado na Figura 2.9.

As Figuras 2.10 e 2.11 apresentam a razão entre a carga total no topo das estacas de cada tipo $\left(\mathrm{P}_{0}\right)$ normalizada pela carga total aplicada no radier dividida pelo número total de estacas $\left(\mathrm{P}_{\mathrm{AV}}\right)$, em função do número de estacas do grupo para diferentes valores da rigidez relativa do radier. 


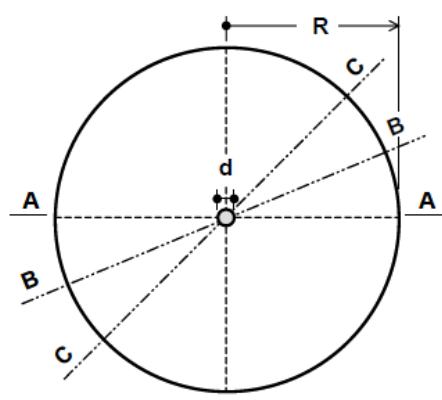

(1) radier com 1 estaca central

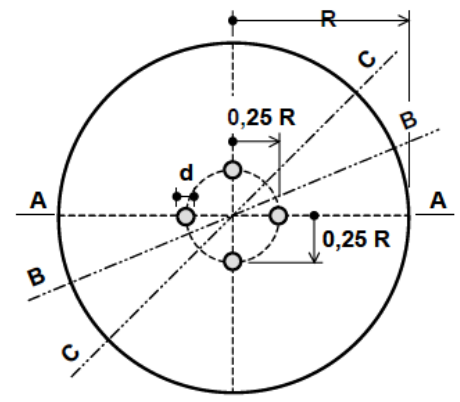

(2) radier com 4 estacas

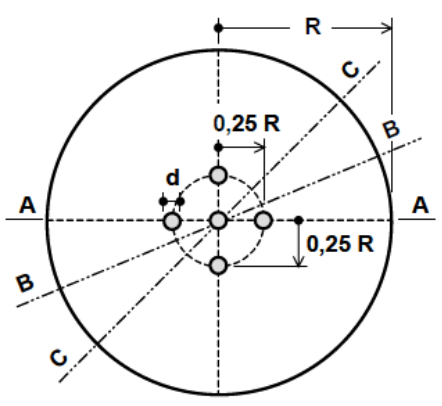

(3) radier com 5 estacas

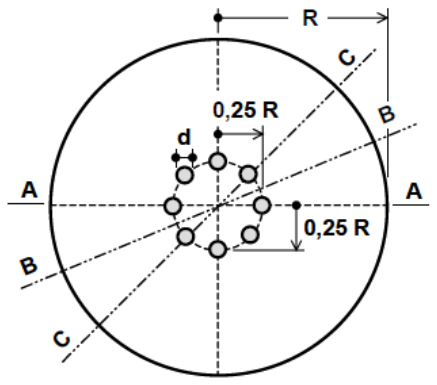

(4) radier com 8 estacas

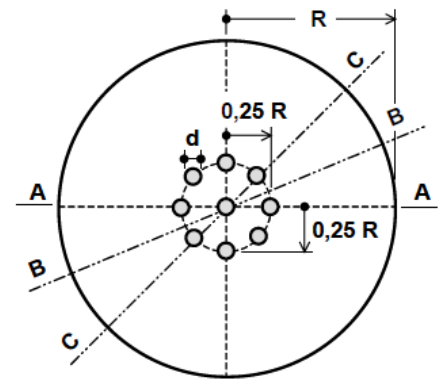

(5) radier com 9 estacas (a)

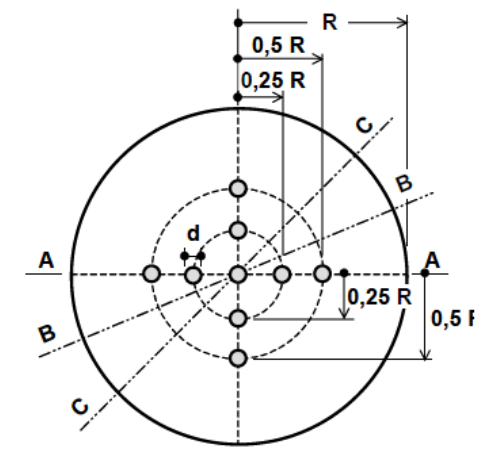

(6) radier com 9 estacas (b)

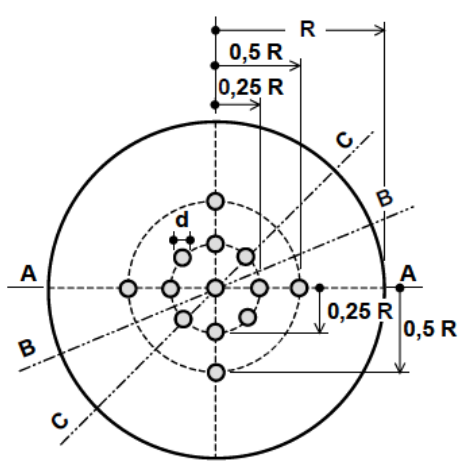

(7) radier com 13 estacas (a)

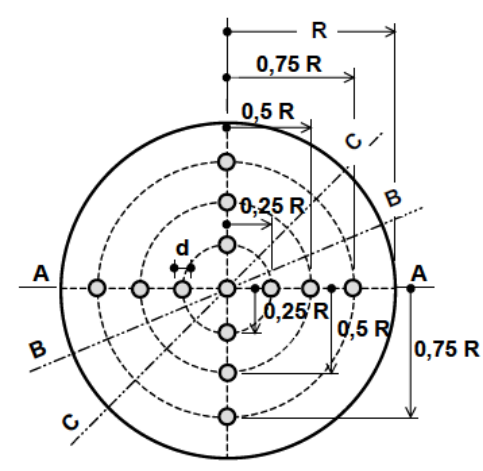

(8) radier com 13 estacas (b)

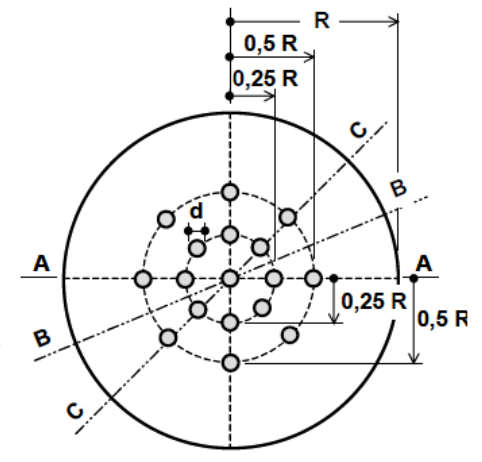

(9) radier com 17 estacas

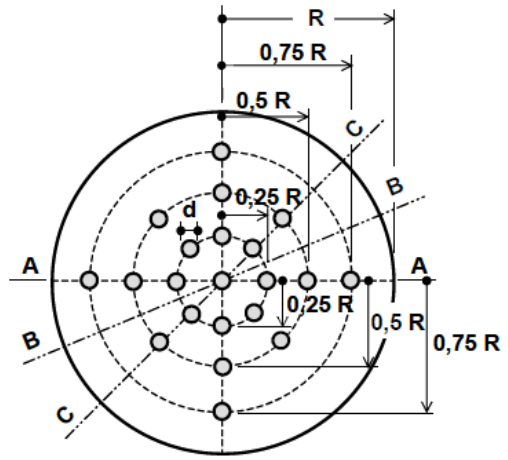

(10) radier com 21 estacas

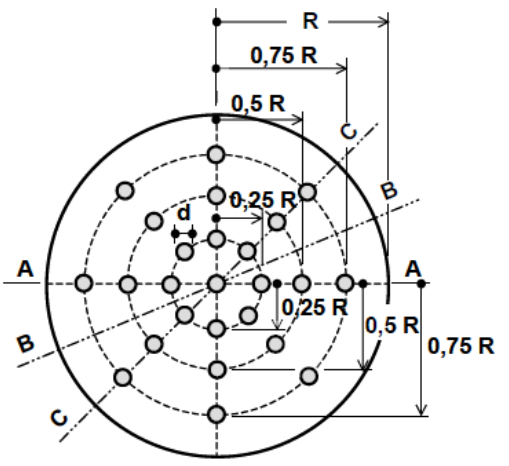

(11) radier com 25 estacas

Figura 2.8 - Configurações utilizadas no estudo paramétrico (Bacelar, 2003). 


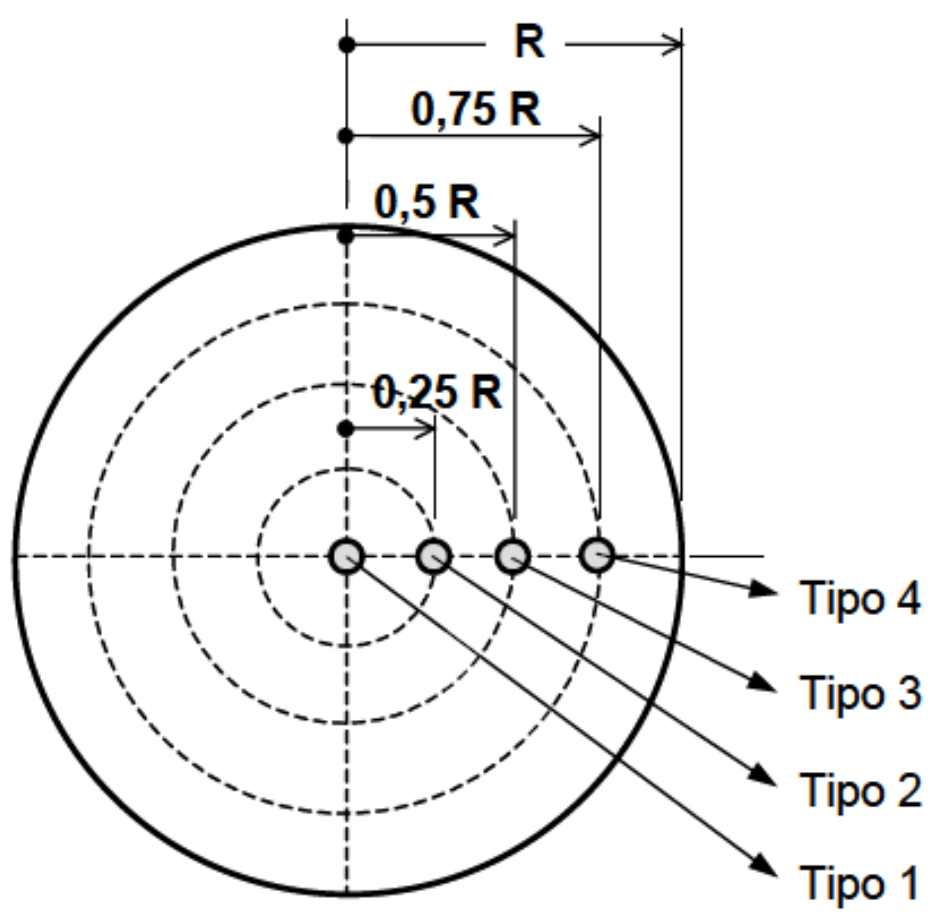

Figura 2.9 - Classificação das estacas em função de sua posição no radier (Bacelar, 2003).

Observa-se que quanto maior o comprimento relativo das estacas e a rigidez relativa do radier, maior será a proporção de carga suportada pelas estacas externas. Além disso, a carga nas estacas tipo 1 e 2 não apresentam variações significativas com o aumento do número de estacas no grupo, assim como as estacas tipo 3 e 4, principalmente para o caso de radier flexível $\left(K_{R}=0,01\right)$.

\subsection{2.}

\section{Fator de segurança contra a ruptura}

Os fatores de segurança contra ruptura das estacas de cada tipo foram obtidos a partir da capacidade de carga estimada e da carga atuante em cada estaca.

A Figura 2.12 mostra que o aumento da rigidez do radier contribui significativamente para o aumento do fator de segurança contra a ruptura das estacas. Adicionalmente, observou-se que quanto maior o comprimento relativo das estacas, maior a proporção de carga suportada pelas estacas externas. 


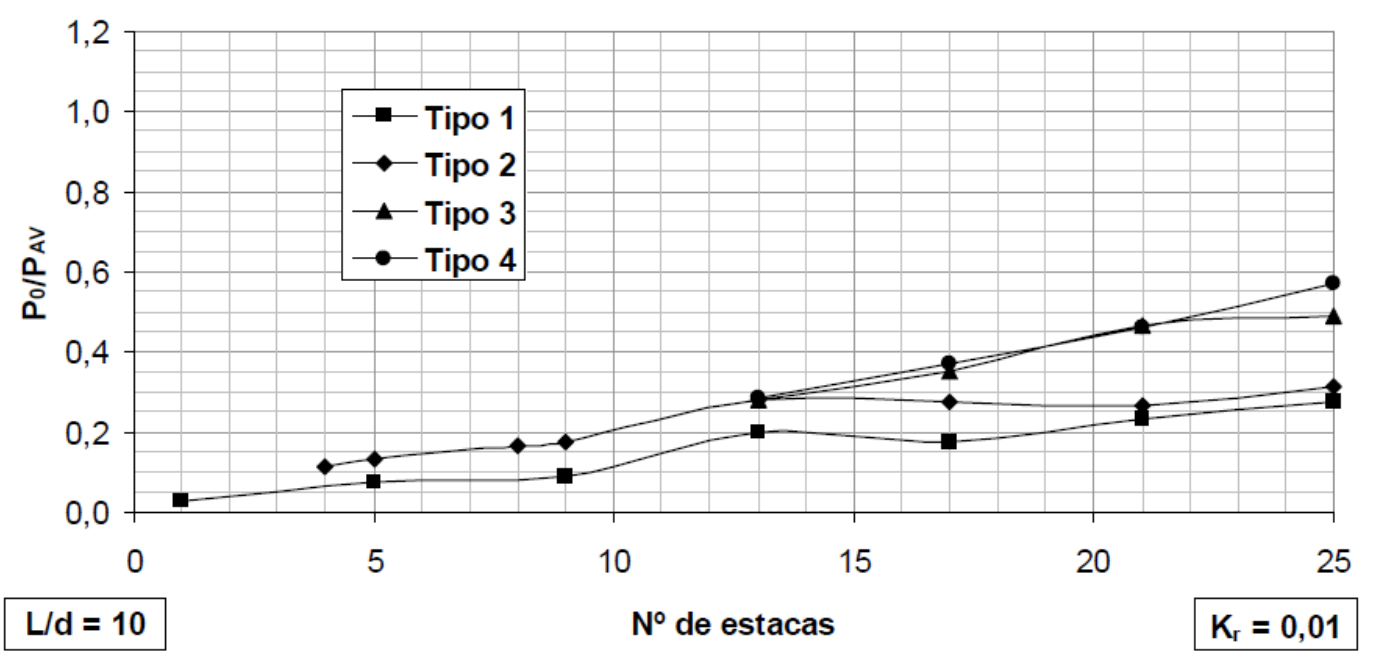

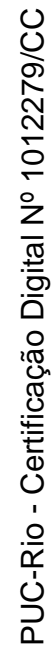
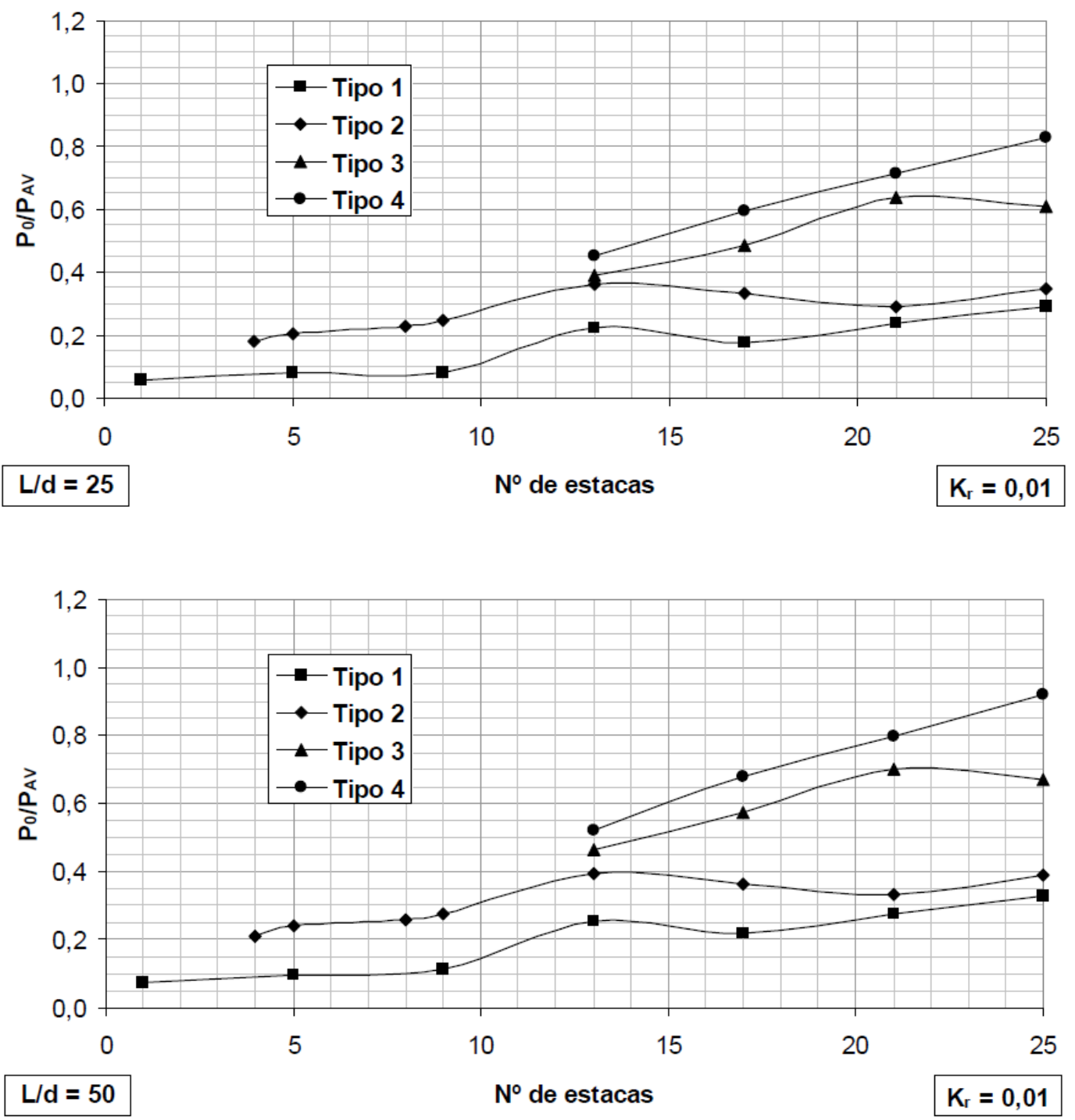

Figura 2.10 - Distribuição de carga entre as estacas em função do número de estacas para rigidez $\mathrm{K}_{\mathrm{R}}=0,01$ (Bacelar, 2003). 


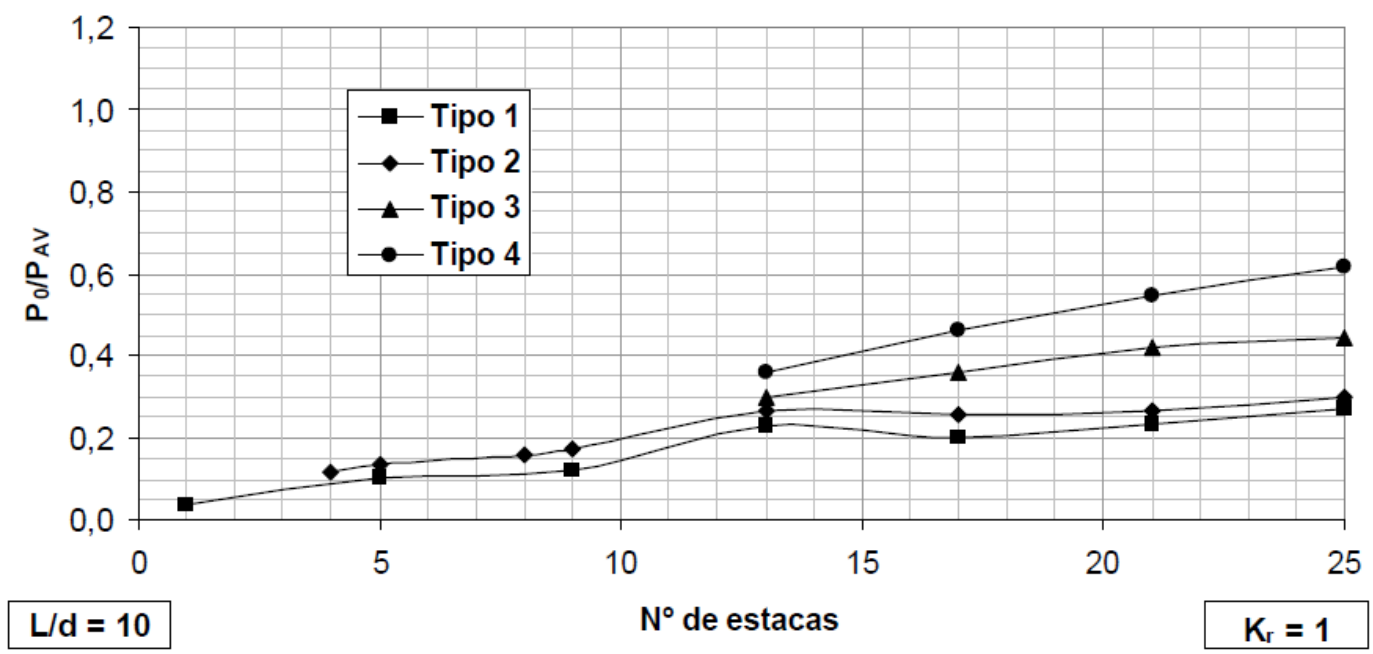

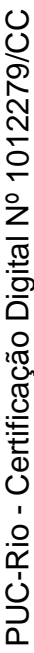
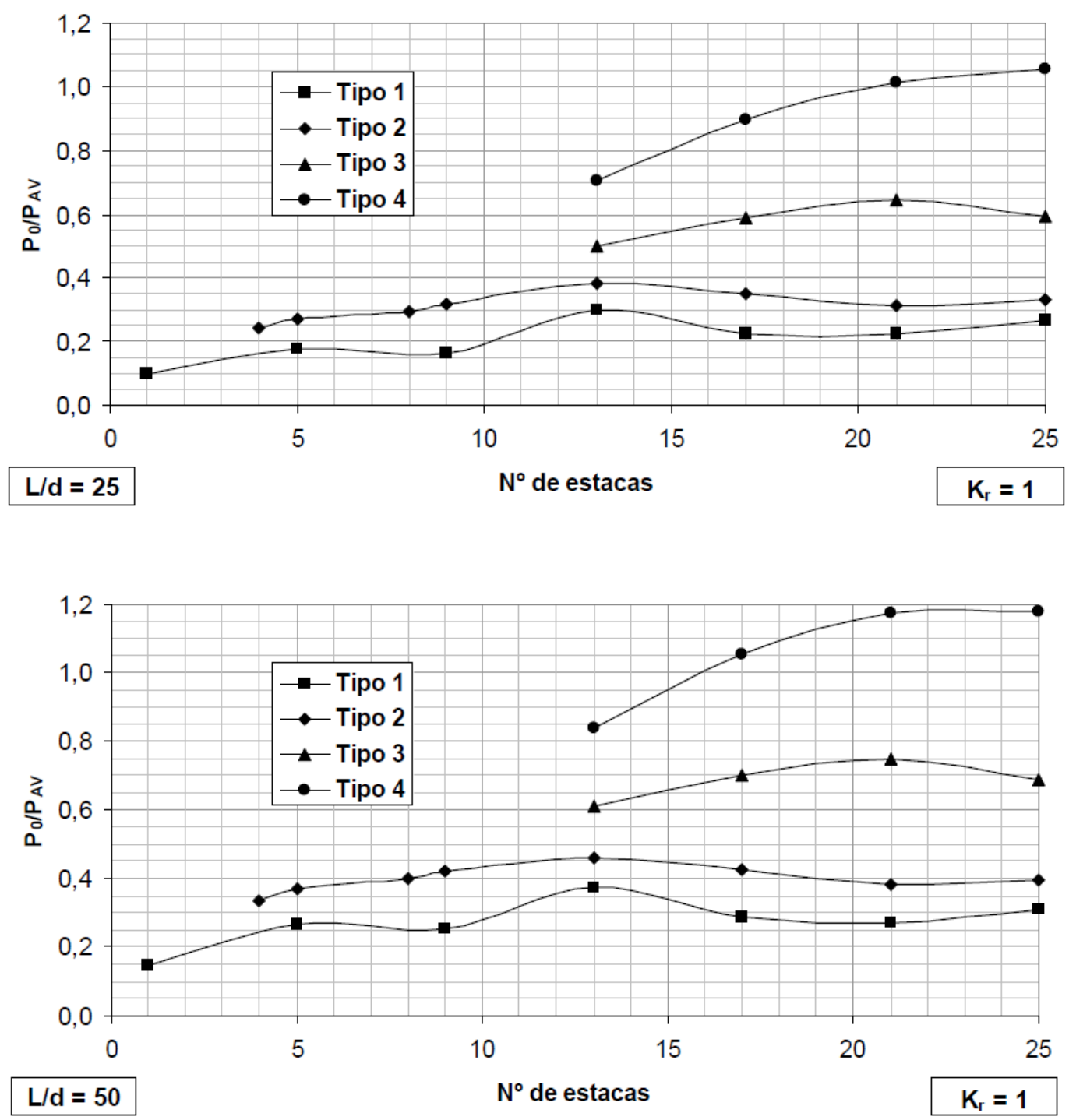

Figura 2.11 - Distribuição de carga entre as estacas em função do número de estacas para rigidez $K_{R}=1$ (Bacelar, 2003). 


\subsection{3. \\ Distorções angulares}

As distorções angulares, ou recalques diferenciais, do radier para cada configuração analisada foram obtidos em três seções (A, B e C) conforme mostrado anteriormente na Figura 2.8.

A Tabela 2.1 mostra a distorção angular máxima em função da rigidez do radier calculada na a seção A-A e a Tabela 2.2 mostra a distorção angular máxima em função do comprimento relativo das estacas calculada na seção A-A.

Observa-se a redução da distorção angular com o aumento da rigidez do radier, o mesmo efeito sendo observado com o aumento do comprimento relativo das estacas.

\begin{tabular}{ccccccc}
\hline $\mathrm{N}^{\circ}$ Estacas & $\mathrm{K}_{\mathrm{r}}=0,01$ & $\beta / \beta_{0}(\%)$ & $\mathrm{K}_{\mathrm{r}}=0,1$ & $\beta / \beta_{0}(\%)$ & $\mathrm{K}_{\mathrm{r}}=1$ & $\beta / \beta_{0}(\%)$ \\
\hline 0 & 0.0459 & - & 0.0272 & - & 0.0103 & - \\
\hline 1 & 0.0416 & 90.55 & 0.0248 & 91.31 & 0.0085 & 82.27 \\
\hline 4 & 0.0525 & 114.35 & 0.0243 & 89.34 & 0.0067 & 64.99 \\
\hline 5 & 0.0515 & 112.18 & 0.0232 & 85.29 & 0.0067 & 64.99 \\
\hline 8 & 0.0517 & 112.61 & 0.0214 & 78.68 & 0.0065 & 63.05 \\
\hline $9(\mathrm{a})$ & 0.0466 & 101.50 & 0.0211 & 77.57 & 0.0065 & 63.05 \\
\hline $9(\mathrm{~b})$ & 0.0371 & 80.78 & 0.0176 & 64.65 & 0.0058 & 55.78 \\
\hline $13(\mathrm{a})$ & 0.0317 & 69.05 & 0.0171 & 62.87 & 0.0060 & 58.20 \\
\hline $13(\mathrm{~b})$ & 0.0371 & 80.88 & 0.0161 & 59.24 & 0.0047 & 45.65 \\
\hline 17 & 0.0329 & 71.66 & 0.0167 & 61.40 & 0.0055 & 53.35 \\
\hline 21 & 0.0320 & 69.70 & 0.0146 & 53.68 & 0.0044 & 42.68 \\
\hline 25 & 0.0423 & 92.14 & 0.0164 & 60.29 & 0.0056 & 54.03 \\
\hline
\end{tabular}

Tabela 2.1 - Distorções angulares máximas na seção A-A em função da rigidez do radier para $v_{s}=0,5$ e $L / d=25$ (Bacelar, 2003).

\begin{tabular}{ccccccc}
\hline $\mathrm{N}^{\circ}$ Estacas & $\mathrm{L} / \mathrm{d}=10$ & $\beta / \beta_{0}(\%)$ & $\mathrm{L} / \mathrm{d}=25$ & $\beta / \beta_{0}(\%)$ & $\mathrm{L} / \mathrm{d}=50$ & $\beta / \beta_{0}(\%)$ \\
\hline 0 & 0.0103 & - & 0.0103 & - & 0.0103 & - \\
\hline 1 & 0.0098 & 95.05 & 0.0085 & 82.27 & 0.0072 & 69.84 \\
\hline 4 & 0.0090 & 87.29 & 0.0067 & 64.99 & 0.0047 & 45.59 \\
\hline 5 & 0.0085 & 82.47 & 0.0067 & 64.99 & 0.0041 & 39.77 \\
\hline 8 & 0.0093 & 89.91 & 0.0065 & 63.05 & 0.0029 & 28.13 \\
\hline $9(\mathrm{a})$ & 0.0091 & 88.26 & 0.0065 & 63.05 & 0.0030 & 29.10 \\
\hline $9(\mathrm{~b})$ & 0.0086 & 83.43 & 0.0058 & 55.78 & 0.0020 & 19.09 \\
\hline $13(\mathrm{a})$ & 0.0090 & 87.29 & 0.0060 & 58.20 & 0.0032 & 31.04 \\
\hline $13(\mathrm{~b})$ & 0.0084 & 81.06 & 0.0047 & 45.65 & 0.0015 & 14.30 \\
\hline 17 & 0.0083 & 80.50 & 0.0055 & 53.35 & 0.0023 & 22.31 \\
\hline 21 & 0.0082 & 79.53 & 0.0044 & 42.68 & 0.0009 & 9.07 \\
\hline 25 & 0.0095 & 92.14 & 0.0056 & 54.03 & 0.0019 & 18.43 \\
\hline
\end{tabular}

Tabela 2.2 - Distorções angulares máximas na seção A-A em função do comprimento relativo das estacas para $\mathrm{v}_{\mathrm{s}}=0,5 \mathrm{e} \mathrm{L} / \mathrm{d}=25$ (Bacelar, 2003). 

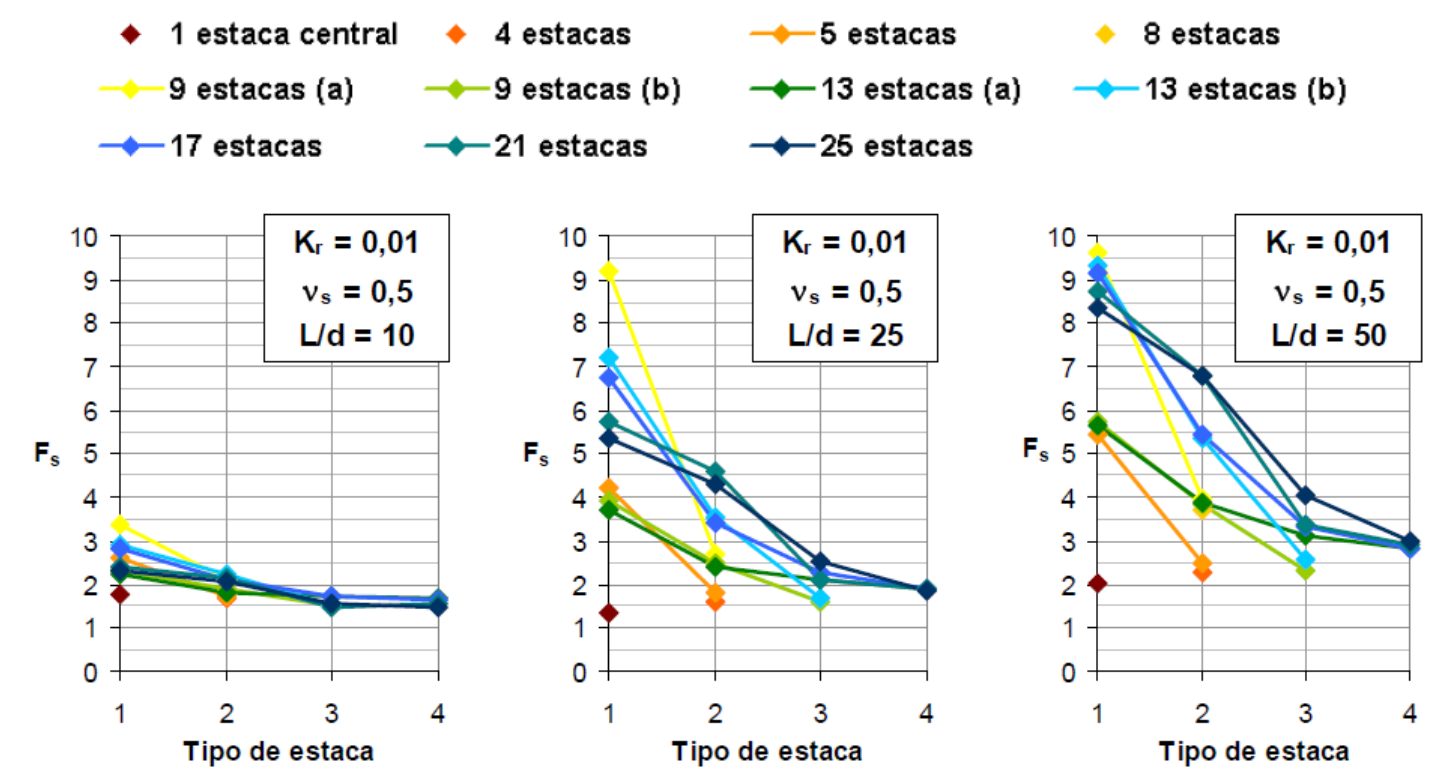

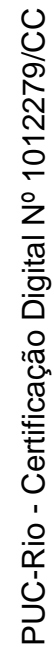
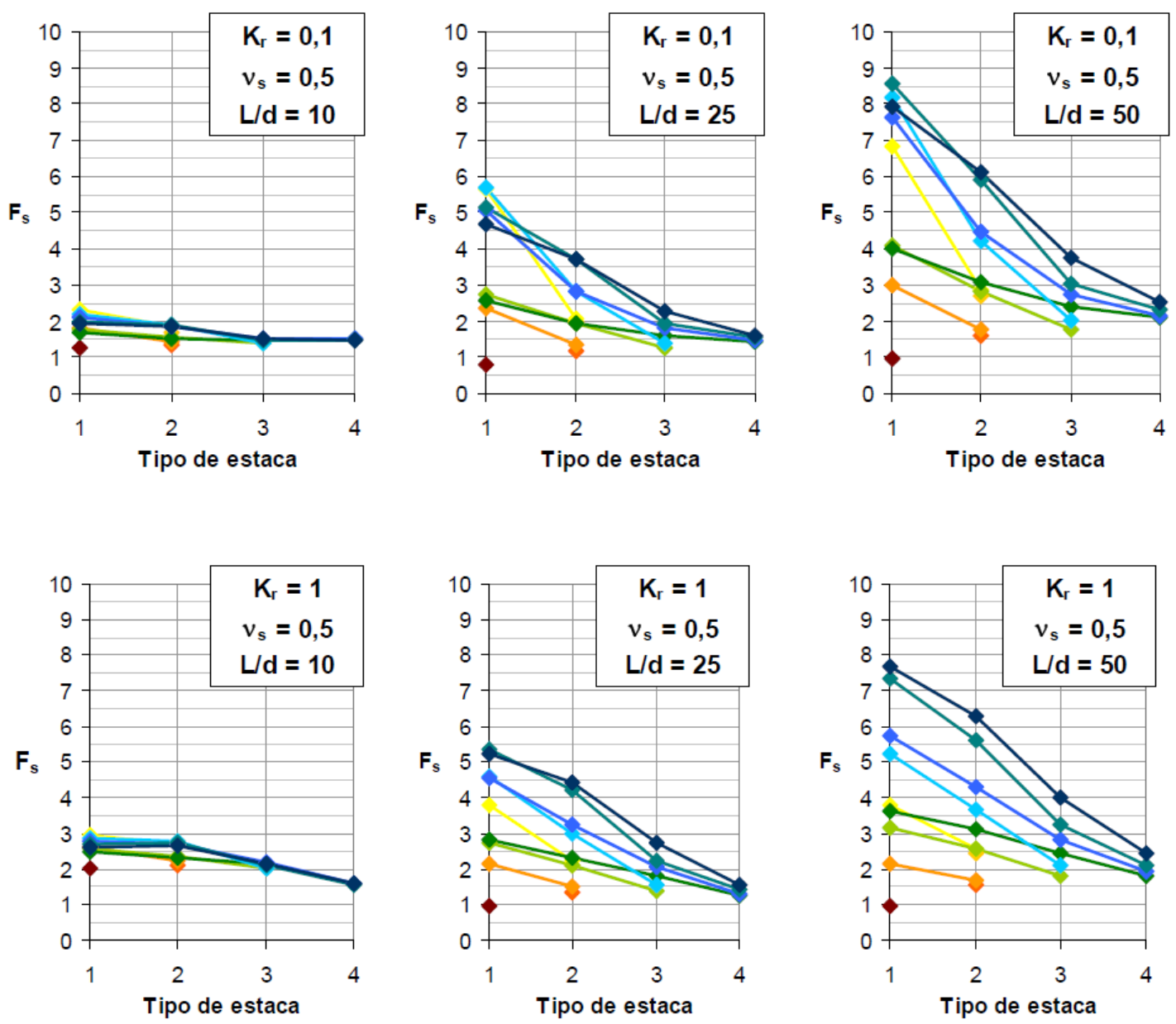

Figura 2.12 - Fator de segurança das estacas para $v_{s}=0,5$ (Bacelar, 2003). 


\section{4 .}

\section{Parâmetros geotécnicos}

Outra abordagem proposta por outros autores é a de majorar os parâmetros elásticos do solo com a finalidade de ajustar os resultados da análise utilizando o método dos elementos de contorno aos resultados experimentais. Entretanto, esta prática não apresenta nenhuma base teórica.

Poulos (1988) sugere uma modificação no cálculo do fator de interação para a análise de grupos de estacas, onde é considerado que o módulo de elasticidade do solo próximo às estacas é inferior ao módulo entre as mesmas. Portanto, o recalque da estaca isolada continua sendo calculado utilizando o módulo de elasticidade próximo à estaca, e o acréscimo de recalque é calculado utilizando o módulo de elasticidade do solo entre estacas.

A Figura 2.13 mostra a distribuição do módulo de elasticidade adotada por Poulos (1988). A razão entre o módulo de elasticidade entre estacas e adjacente à estaca apresenta valores entre 3 e 10, para $s_{t}$ na faixa de 3 a 6 diâmetros.

Rocha Filho e Romanel (1998) apresentaram uma análise do recalque de fundações profundas a partir de retroanálises de provas de carga instrumentadas, ensaios de campo e de laboratório, onde foi mostrado que a obtenção dos parâmetros geotécnicos a partir de uma escolha adequada do tipo de ensaio e do nível de deformação que será causado pelo carregamento é fundamental para sua determinação experimental. Ensaios realizados a baixos níveis de deformação $(\leq 0,1 \%)$ resultaram em valores mais próximos aos computados nas retroanálises.

Segundo Poulos (1999), o sucesso do resultado de uma análise é mais sensível à escolha adequada dos parâmetros geotécnicos do que ao método de análise empregado.

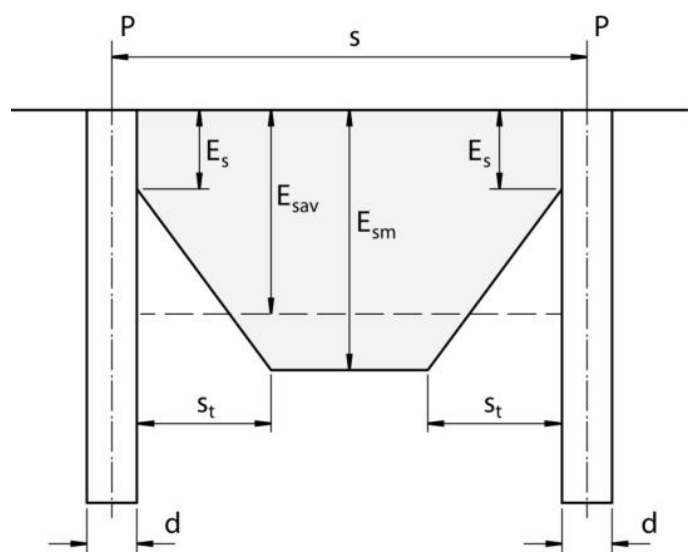

Figura 2.13 - Distribuição do módulo de elasticidade do solo proposta por Poulos (1988). 


\section{3 Características do cais e da instrumentação utilizada}

\section{1.}

\section{Características do cais}

A seguir são apresentadas as principais características do cais testado neste trabalho, detalhando a geometria da estrutura e o perfil geotécnico local. Vale ressaltar que a estrutura foi executada na década de 1980, portanto as informações disponíveis são escassas.

\subsection{1.}

\section{Características da estrutura}

O cais consiste em uma laje retangular de concreto armado com reforço de fibra de carbono com comprimento, largura e altura de 46,0 m, 23,0 m e 0,80 m respectivamente. Esta laje está apoiada sobre 61 estacas pré-moldadas de concreto armado, sendo 32 verticais e 29 inclinadas.

As estacas tem seção transversal quadrada com lado (I) de $54 \mathrm{~cm}$ e comprimento (L) médio de $24,0 \mathrm{~m}$.

O comprimento relativo (L/d) das estacas pode ser obtido a partir do diâmetro equivalente $\left(d_{\text {eq }}\right)$ das estacas, conforme mostrado a seguir.

$$
\begin{gathered}
A=l^{2}=54^{2}=2916 \mathrm{~cm}^{2} \\
A=\frac{\pi d_{e q}^{2}}{4} \therefore \quad d_{e q}=\sqrt{\frac{4 A}{\pi}} \cong 60 \mathrm{~cm} \\
\frac{L}{d_{e q}}=\frac{24}{0,6}=40
\end{gathered}
$$

O espaçamento (s) entre as estacas verticais é de $6,25 \mathrm{~m}$ e $4,50 \mathrm{~m}$ nos sentidos longitudinal e transversal do cais, respectivamente. Logo, o espaçamento relativo (s/d) em cada sentido é obtido conforme mostrado a seguir. 


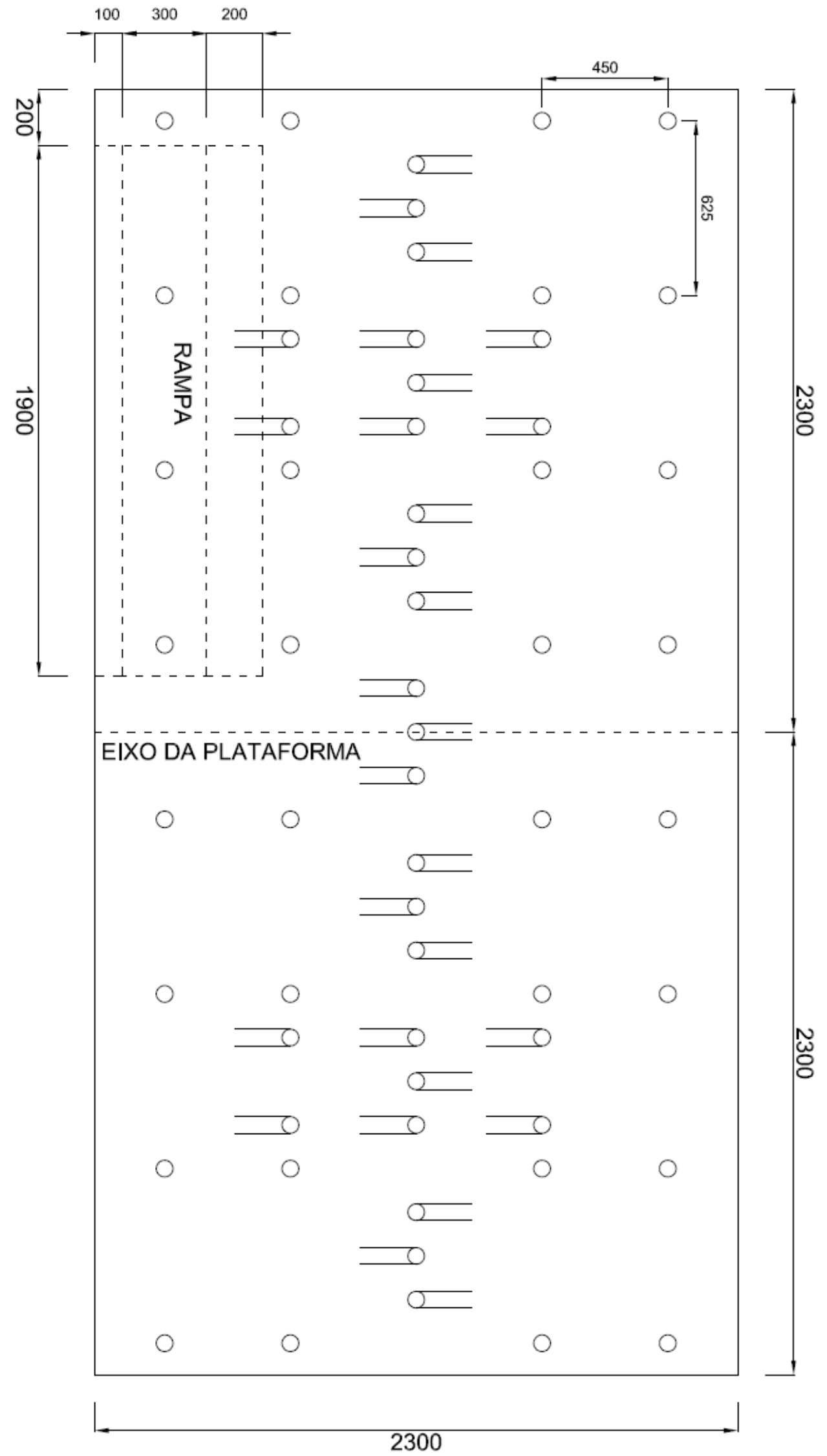

Figura 3.1 - Geometria do cais (dimensões em centímetros). 


$$
\begin{aligned}
& s / d_{L}=\frac{6,25}{0,60} \cong 10 \\
& s / d_{T}=\frac{4,50}{0,60} \cong 7,5
\end{aligned}
$$

A disposição das estacas é simétrica em relação ao eixo do cais, conforme mostrado na Figura 3.1.

A instrumentação foi realizada em metade do cais, na direção da rampa onde as embarcações são atracadas, conforme será detalhado a seguir.

\subsection{2.}

\section{Características geotécnicas}

A geologia local consiste em uma camada de aproximadamente 15,0 m de espessura de argila de consistência mole à média com N SPT variando entre 5 a 15, sobre uma camada de solo residual com N SPT médio de 40 (Figura 3.2). Portanto, conclui-se que as estacas trabalham predominantemente por resistência de ponta.

Não existem dados de investigações de outros parâmetros do local, tais como módulo de elasticidade das camadas de argila e solo residual.

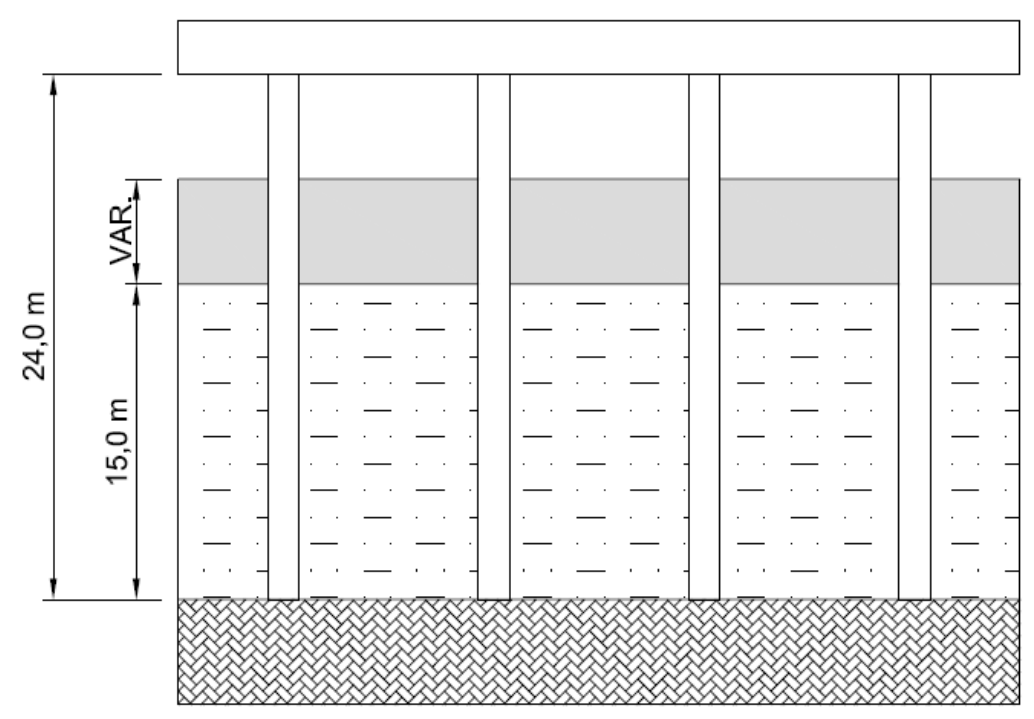

LÂMINA D'ÁGUA

ARGILA MOLE A MÉDIA

SOLO RESIDUAL

Figura 3.2 - Seção esquemática com o perfil geotécnico local. 


\section{2. Instrumentação}

Conforme mencionado anteriormente, existem diversos benefícios na utilização de instrumentação para o monitoramento de estruturas geotécnicas.

De modo a melhor compreender o comportamento do grupo de estacas durante a prova de carga realizada, foi montada uma instrumentação composta por extensômetros elétricos e eletroníveis, ambos com leitura contínua, de modo a monitorar a estrutura durante todo o tempo do teste. $\mathrm{O}$ monitoramento contínuo das deformações e rotação da estrutura além de fornecer leituras para qualquer etapa em que uma análise seja necessária, promove mais segurança ao teste, uma vez que qualquer anomalia nas leituras ou súbito aumento de alguma grandeza pode ser facilmente visualizados. Além disso, foi utilizado nivelamento topográfico para medir os recalques do topo da laje do cais.

\subsection{1.}

\section{Concepção geral}

Foram montados dois sistemas para monitoramento da prova de carga. $\mathrm{O}$ primeiro composto por extensômetros elétricos instalados em quatro estacas e em um ponto da laje com a finalidade de controlar as deformações do concreto e, conseqüentemente, o carregamento sob o qual cada estaca está submetida. O segundo composto por dezesseis eletroníveis distribuídos ao longo de cinco seções (A até $E$ ) sobre a laje do cais com a finalidade de controlar as distorções angulares da estrutura.

Em complemento, foi utilizado nivelamento topográfico em três pontos sobre a laje do cais para medição dos recalques. Estes dados, associados com as rotações da estrutura medidas pelos eletroníveis, fornecem indiretamente 0 recalque dos demais pontos do cais. A Figura 3.3 mostra a locação da instrumentação utilizada na prova de carga.

\subsection{2.}

\section{Eletroníveis}

Os eletroníveis foram desenvolvidos há mais de 60 anos nos Estados Unidos como sensores para a indústria aeronáutica. Porém, sua aplicação em obras geotécnicas diretamente ligadas ao monitoramento de recalques foi feita inicialmente na Inglaterra em 1990, em trabalhos realizados pela Construction Monitoring Control Systems (CMCS), destacando-se o sistema de 
monitoramento instalado na Mansion House objetivando controlar os recalques oriundos da expansão do metrô de Londres.

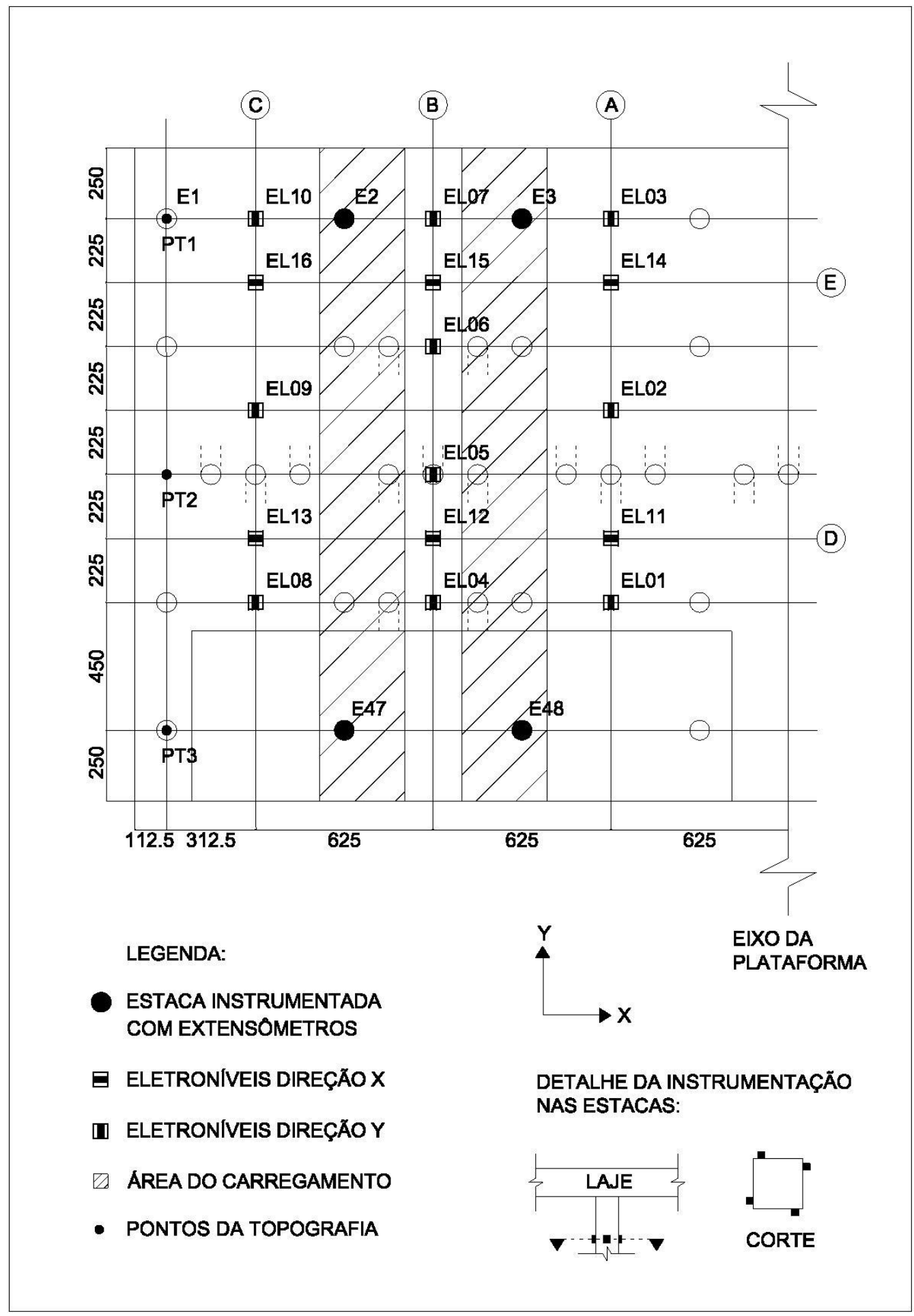

Figura 3.3 - Locação da Instrumentação.

No Brasil esta técnica foi utilizada primeiramente em laboratório na medição de pequenas deformações em ensaios triaxiais instrumentados 
(Marinho, 1986). Em obras geotécnicas, os eletroníveis foram primeiramente aplicados na determinação da deflexão da face de concreto do reservatório da barragem de Xingó (Rocha Filho, 1995).

Além de apresentar precisão da ordem de segundos do arco, esta técnica apresenta baixo custo, portabilidade e registro automático e contínuo dos dados obtidos.

Nesta prova de carga especificamente, foi assumida a hipótese de que a estrutura apresenta rotações de corpo rígido, logo as deflexões podem ser obtidas por simples relações trigonométricas (Figura 3.4), tal que:

$$
y=L \times \tan \varnothing
$$

\section{Eletronível}

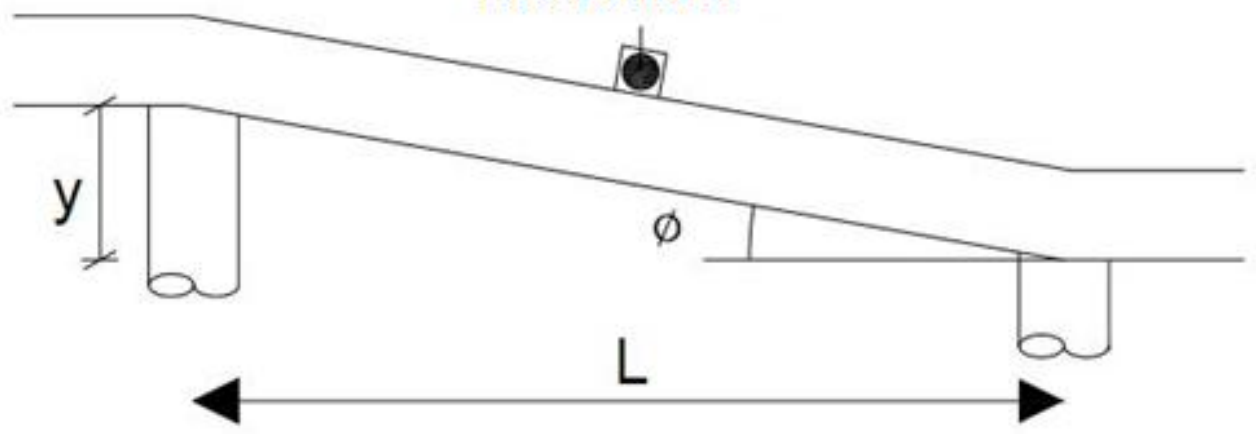

Figura 3.4 - Rotação de corpo rígido.

A partir das leituras das séries de eletroníveis posicionados em cada uma das cinco seções da instrumentação, podem ser obtidas as distorções angulares da estrutura pelo método incremental, que consiste no somatório das deflexões dos trechos considerados rígidos.

\subsubsection{1. Princípio de funcionamento}

Os eletroníveis são sensores que consistem em uma ampola parcialmente preenchida por um fluido eletrolítico, contendo três ou quatro pinos metálicos utilizados para medir a resistência elétrica do conjunto, formando meia ponte de Wheatstone. A resistência elétrica entre dois pinos consecutivos é inversamente proporcional ao volume de líquido entre os mesmos e o volume entre pinos é alterado de acordo com a rotação aplicada ao conjunto. Desta maneira pode-se 
associar a variação da resistência elétrica à rotação do conjunto. Os eletroníveis utilizados no teste são compostos por quatro pinos, o que resulta em maior precisão das leituras devido à menor distância entre pinos. A Figura 3.5 mostra o eletronível utilizado.

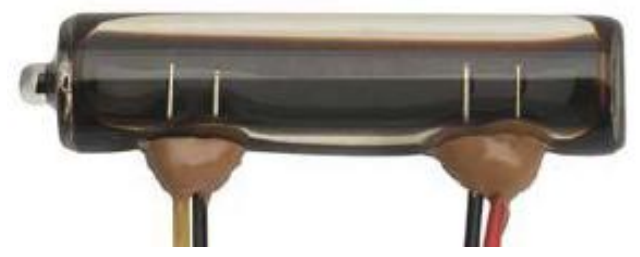

Figura 3.5 - Vista do eletronível de quatro pinos (www.frederickscom.com).

Com o propósito de evitar alterações nas características físicas dos pinos por processos de eletrólise, a excitação não deve ser feita por tensões contínuas, sendo utilizados sinais alternados (ondas quadradas ou senoidais).

O circuito elétrico dos eletroníveis é mostrado na Figura 3.6. Nota-se que o eletronível é utilizado como uma metade de uma ponte de Wheatstone, onde a outra metade é composta por duas resistências. A tensão de saída é tratada por um circuito adicional que fornece a leitura.

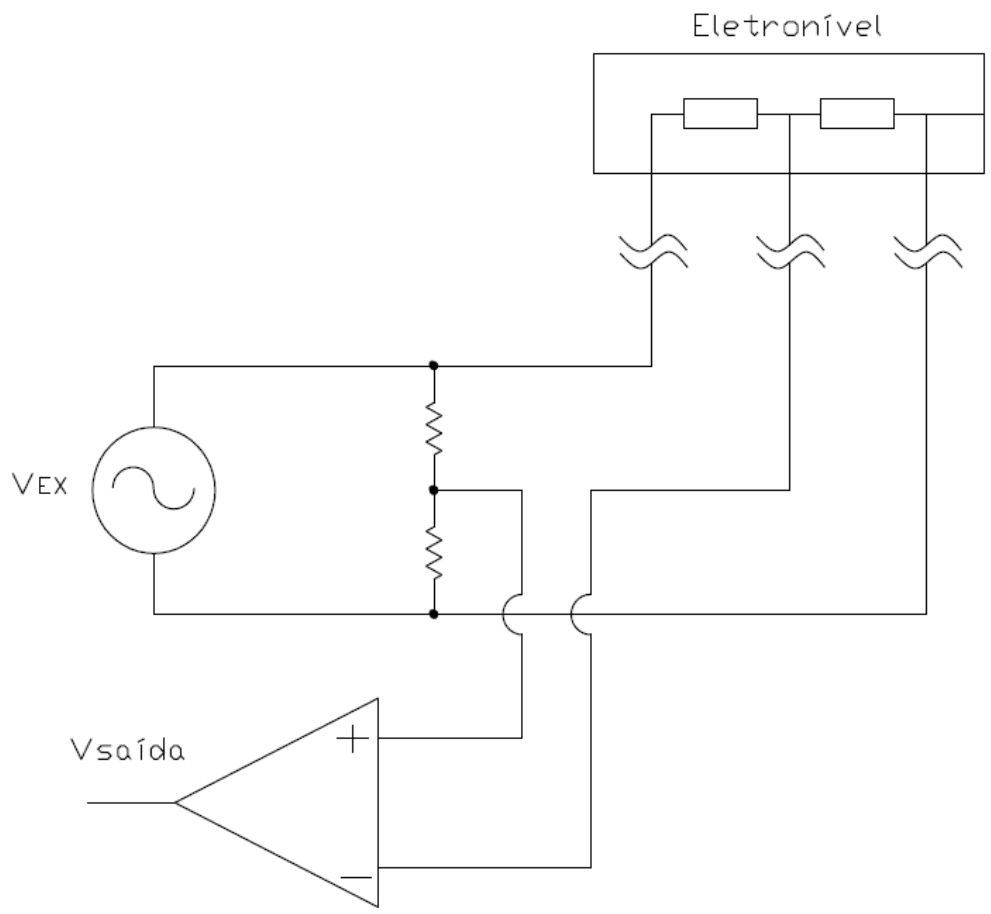

Figura 3.6 - Circuito elétrico de conexão dos eletroníveis (Ramos, 2009). 
Os valores de saída dos eletroníveis utilizados apresentam linearidade na faixa de $\pm 3^{\circ}$, conforme informado pelo fabricante (Figura 3.7).

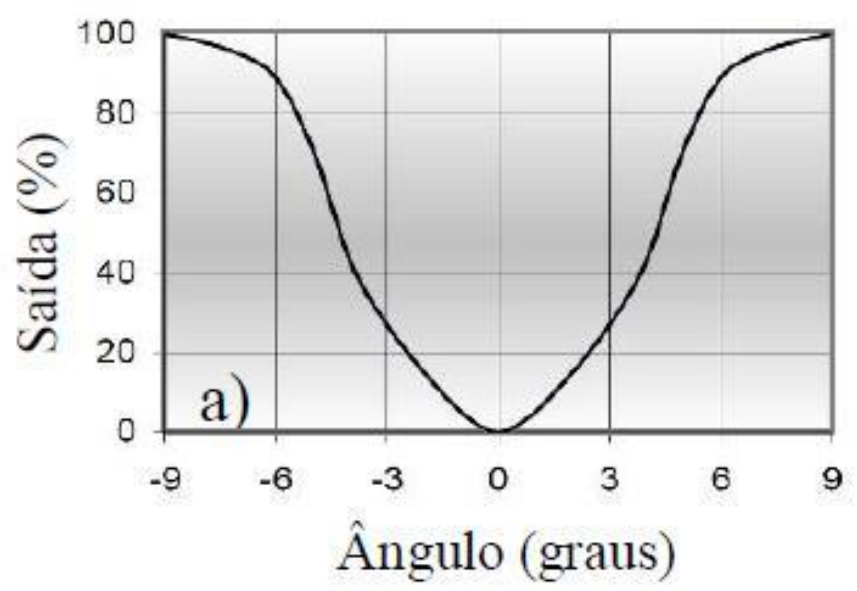

Figura 3.7 - Curva de sensibilidade do eletronível (www.frederickscom.com).

\subsubsection{2. \\ Montagem}

A preparação dos eletroníveis para utilização em campo foi realizada no laboratório de instrumentação geotécnica de campo da PUC-Rio. Esta preparação consiste basicamente da proteção mecânica, fixação e vedação da ampola.

Foi usinada uma cápsula cilíndrica de alumínio com uma cavidade excêntrica onde o eletronível é posicionado e envolto por resina plástica. As cápsulas apresentam uma rosca em uma face para fixação nas cantoneiras metálicas utilizadas para fixar os eletroníveis na estrutura. As Figuras 3.8 e 3.9 mostram o detalhamento da cápsula utilizada e o eletronível posicionado na cápsula antes da aplicação da resina, respectivamente.

\subsubsection{3.}

\section{Calibração}

Assim como a montagem, a calibração dos eletroníveis também foi realizada no laboratório de instrumentação geotécnica de campo da PUC-Rio.

O processo de calibração consiste em determinar para cada eletronível uma curva que relaciona a variação das leituras em função da variação angular. A inclinação de cada curva é o fator de calibração (FC) do respectivo eletronível. 

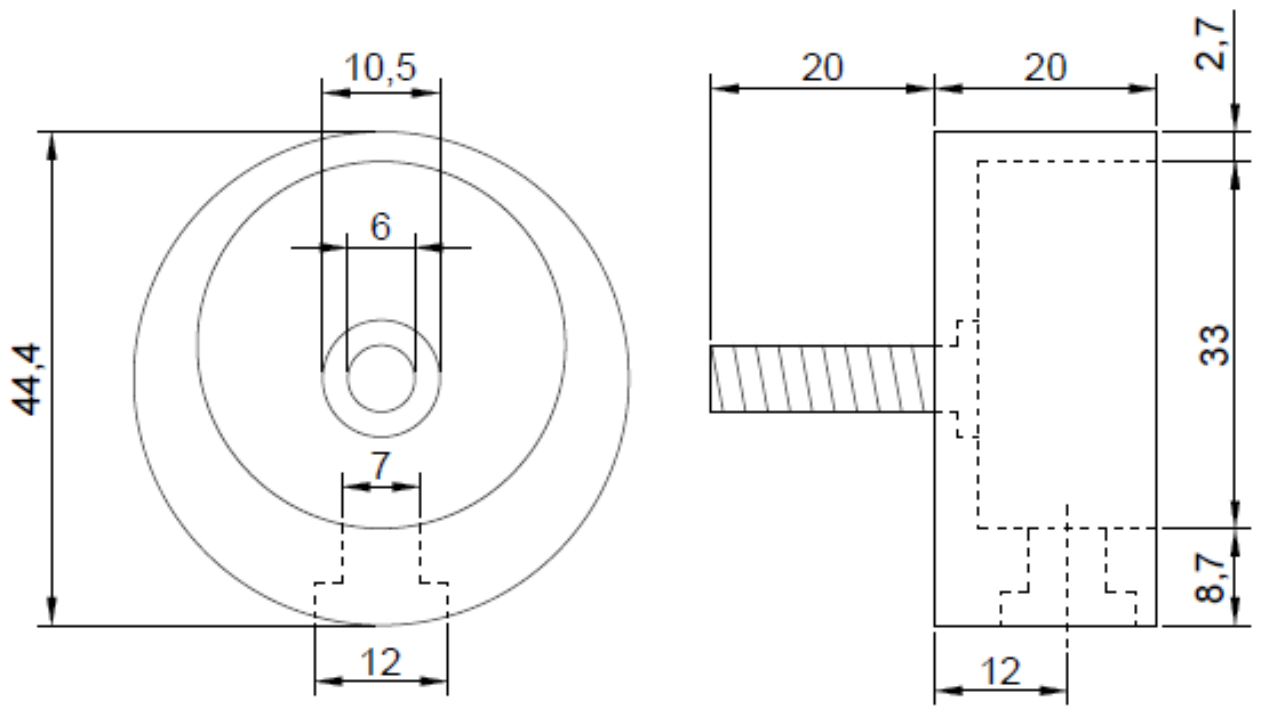

Figura 3.8 - Dimensões em milímetros da cápsula dos eletroníveis.

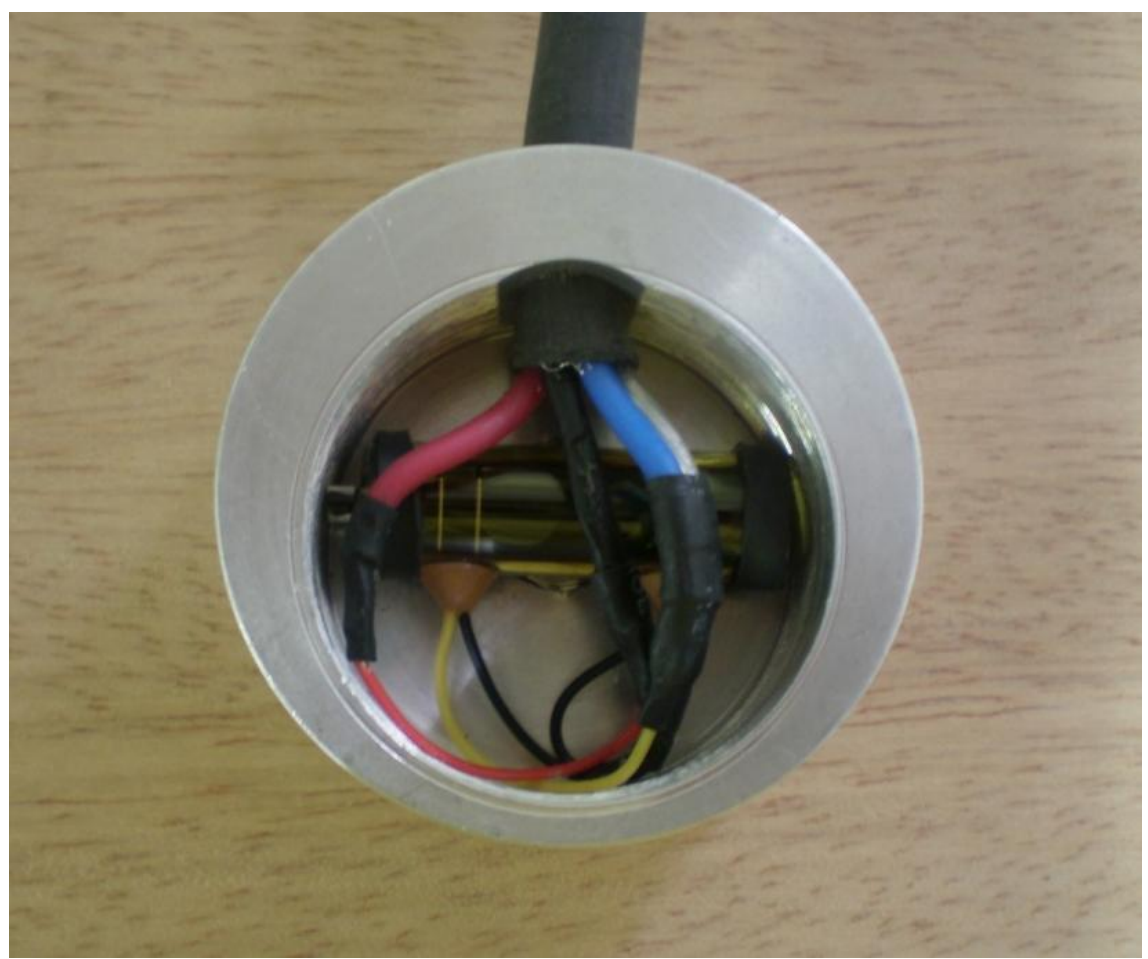

Figura 3.9 - Eletronível posicionado na cápsula antes da resinagem.

Os eletroníveis a serem calibrados são fixados juntamente com um eletronível de referência (com fator de calibração conhecido) em uma barra rígida de comprimento conhecido $L$, rotulada em uma extremidade (B) e livre para deslocamentos verticais na outra $(A)$, proporcionando a rotação desejada 
(Figura 3.10). É possível realizar este procedimento com até dez eletroníveis fixados na barra.

As leituras foram feitas utilizando o SME (Sistema de Monitoramento de Eletroníveis) que fornece as leituras dos eletroníveis em milivolts, e pode fazer leitura de até trinta e dois eletroníveis simultaneamente, conforme a Figura 3.11.

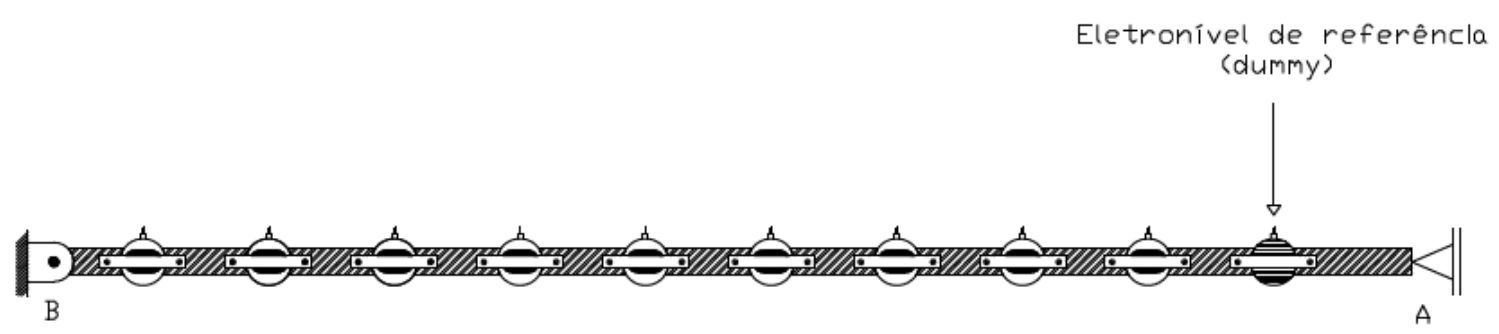

Figura 3.10 - Barra de calibração dos eletroníveis (Ramos, 2009).

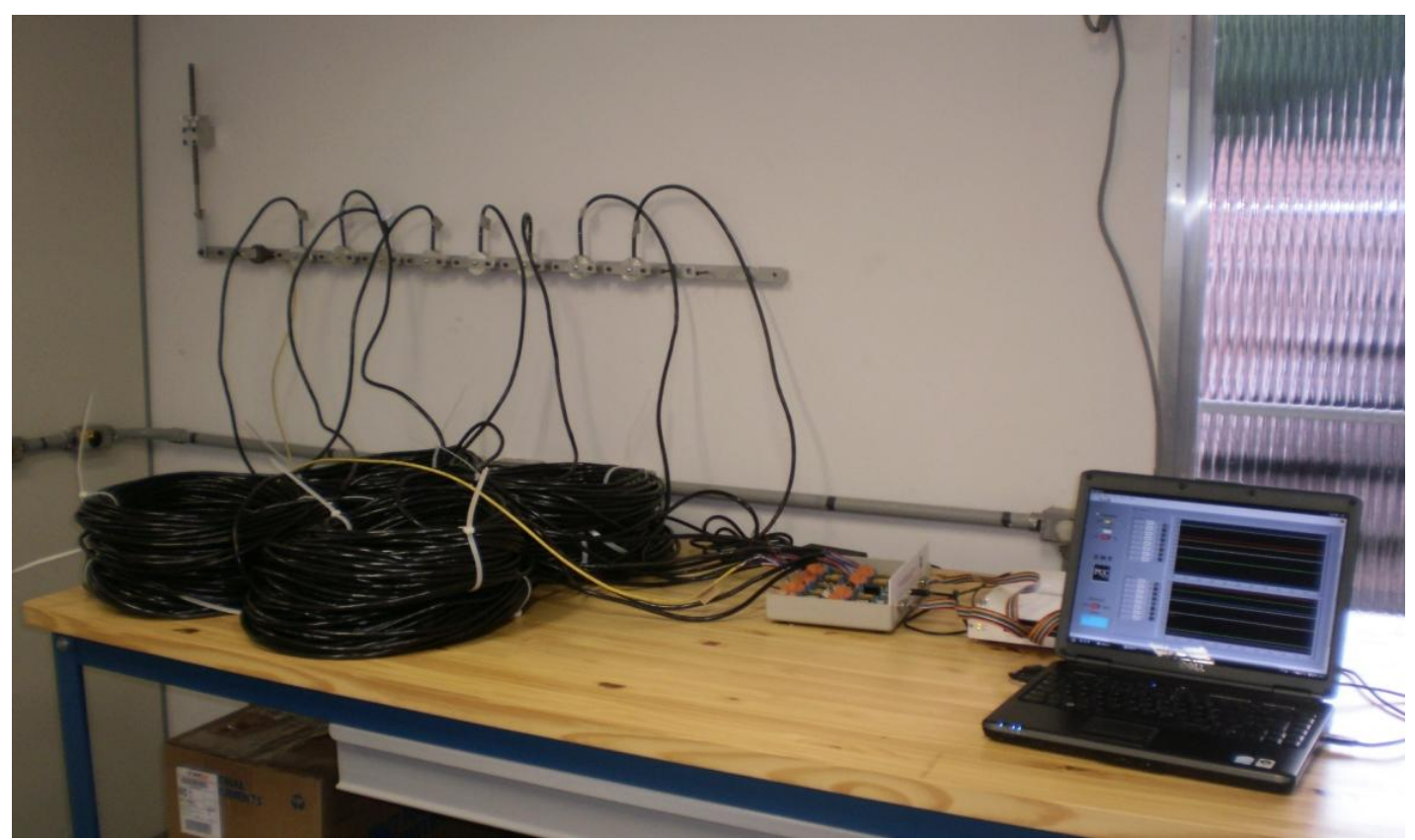

Figura 3.11 - Calibração dos eletroníveis utilizando o SME.

A partir de um deslocamento vertical (y) na extremidade $A$, o ângulo de rotação da barra, e conseqüentemente dos eletroníveis, pode ser obtido através da seguinte expressão:

$$
\theta=\arctan \left(\frac{y}{L}\right)
$$


Logo, o fator de calibração de cada eletronível é obtido de acordo com sua respectiva leitura, segundo a seguinte equação:

$$
F C=\frac{\theta(\text { rad })}{\text { leitura do eletronível }}
$$

Uma vez que a precisão da leitura dos eletroníveis é de uma ordem de grandeza muito pequena, pequenos erros na medição do deslocamento vertical podem resultar em erros grandes no cálculo do fator de calibração. Portanto, os ângulos de rotação da barra são obtidos a partir das leituras $(\Delta \mathrm{L})$ do eletronível de referência e de seu respectivo fator de calibração $\left(\mathrm{FC}_{\mathrm{ref}}\right)$ da seguinte forma:

$$
\theta=F C_{r e f} \times \Delta L
$$

\subsubsection{1.}

\section{Eletronível de referência}

O eletronível de referência possui sensibilidade de $\pm 1,5^{\circ}$, ou seja, a faixa de linearidade de suas leituras tem metade da amplitude dos eletroníveis utilizados na instrumentação.

Como já mencionado anteriormente, durante a calibração as leituras foram feitas utilizando o SME. Uma vez que o eletronível de referência apenas possui fator de calibração para leituras feitas pelo Mini Data-Logger desenvolvido pela CMCS, foi necessário obter um fator de calibração para as leituras do SME. Portanto, para cada posição da barra de calibração correspondente a um ângulo diferente, foram feitas leituras utilizando os dois sistemas conforme a Figura 3.12 .

Logo, a partir da correlação obtida e conhecido o fator de calibração do eletronível de referência para o Mini Data-Logger $\left(\mathrm{FC}_{\mathrm{ML}}\right)$, o fator de calibração para o SME (FC $\left.\mathrm{SME}_{\mathrm{S}}\right)$ foi obtido da seguinte maneira:

$$
\begin{aligned}
& \theta=F C_{M L} \times \Delta L_{M L} \\
& \theta=F C_{S M E} \times \Delta L_{S M E} \\
& F C_{M L}=4,9 \times 10^{-6} \\
& \Delta L_{S M E}=\left(4 \times 10^{-5}\right) \times \Delta L_{M L}
\end{aligned}
$$




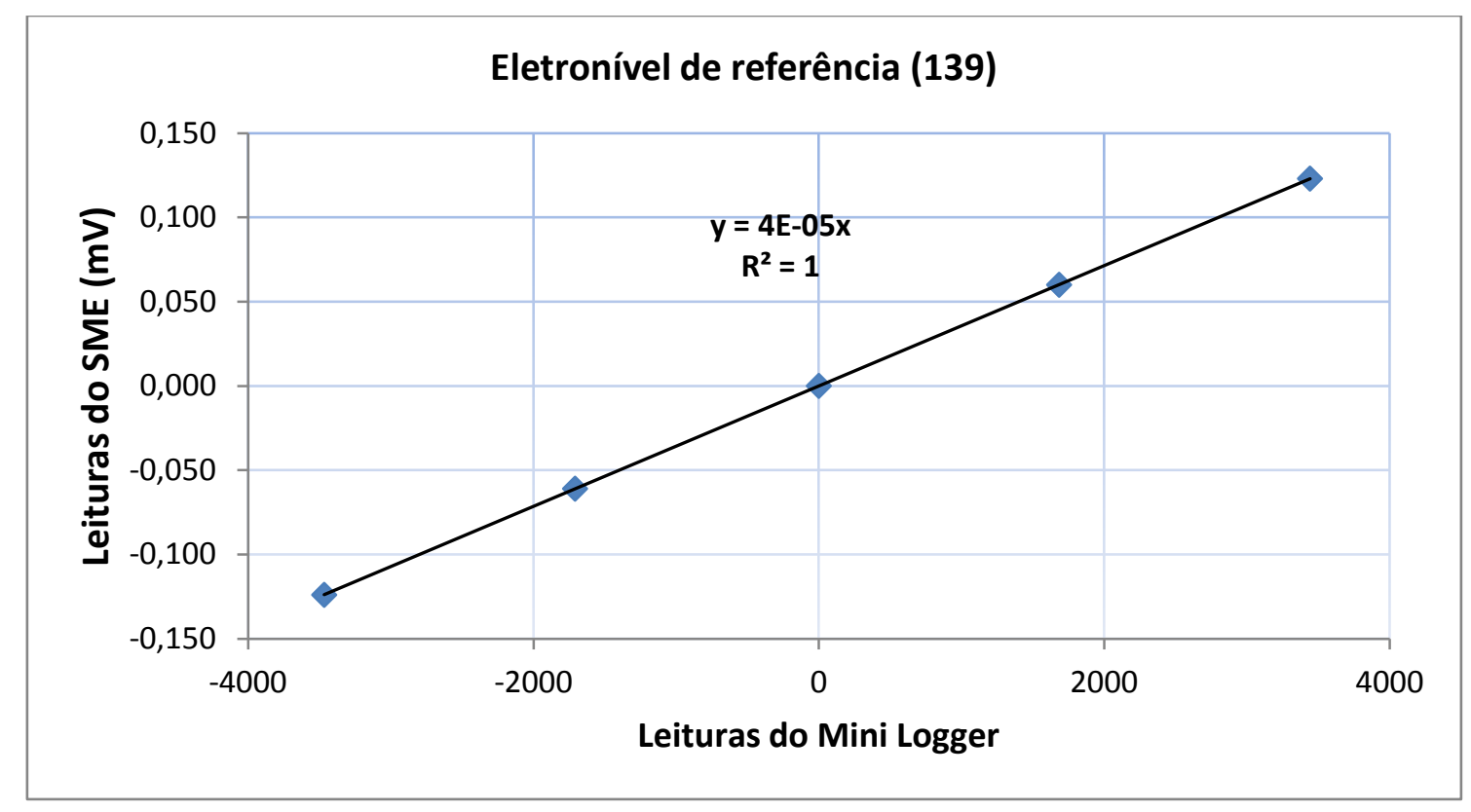

Figura 3.12 - Correlação entre as leituras feitas pelo SME e Mini Data-Logger.

Substituíndo a equação 3.5 na equação 3.6, temos:

$$
F C_{S M E} \times \Delta L_{S M E}=F C_{M L} \times \Delta L_{M L}
$$

Substituindo a equação 3.7 na equação 3.8, temos o fator de calibração do eletronível de referência para leituras feitas pelo SME:

$$
\begin{gathered}
F C_{S M E}=\frac{F C_{M L} \times \Delta L_{M L}}{\Delta L_{S M E}} \\
F C_{S M E}=\left(4,9 \times 10^{-6}\right) \times \frac{\Delta L_{M L}}{\left(4 \times 10^{-5}\right) \times \Delta L_{M L}}=0,1225
\end{gathered}
$$

\subsubsection{2.}

\section{Eletroníveis EL01 a EL16}

Utilizando o fator de calibração do eletronível de referência corrigido para o SME (equação 3.9) na equação 3.4, é possível obter os ângulos corrigidos para a calibração dos dezesseis eletroníveis produzidos para a instrumentação da prova de carga.

Os eletroníveis foram separados em dois grupos com oito eletroníveis novos mais o eletronível de referência, uma vez que a barra de calibração apenas comporta dez elementos. Segundo Ramos (2009), treze variações 
angulares são suficientes para obter a linearidade dos eletroníveis. Foram feitas variações angulares de aproximadamente 0,0075 radianos, resultando em uma amplitude de aproximadamente $\pm 2,6^{\circ}$, abrangendo grande parte da faixa linear dos eletroníveis. A Figura 3.13 mostra o resultado da calibração.
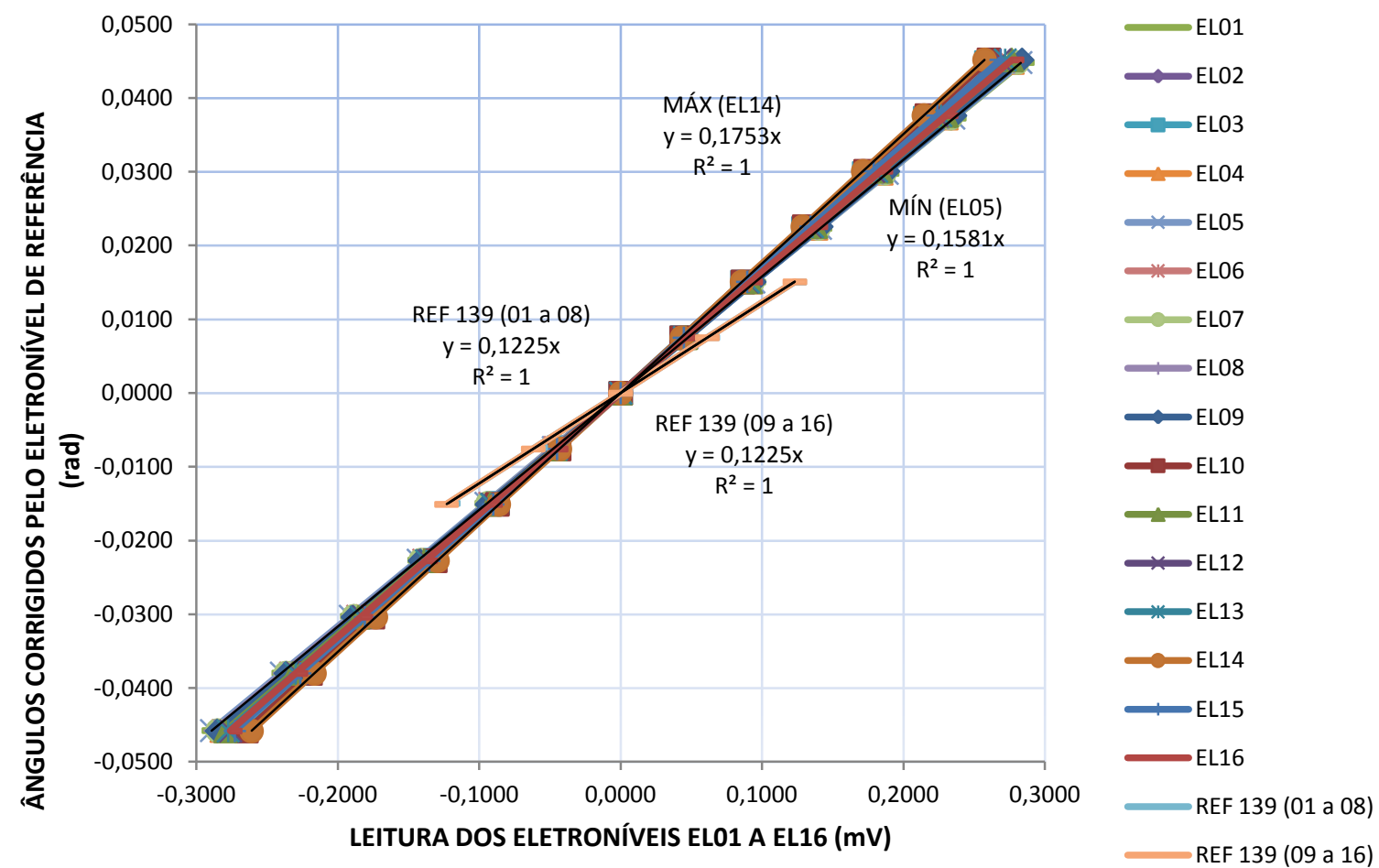

Figura 3.13 - Curvas de calibração dos eletroníveis EL01 a EL16 utilizando o SME.

Observam-se duas curvas do eletronível de referência, que correspondem a cada grupo de eletroníveis calibrados. Os eletroníveis calibrados demonstraram um comportamento similar, cujos valores estão apresentados na Tabela 3.1 e na Figura 3.14.

\subsubsection{4.}

\section{Instalação}

Após o processo de montagem e calibração dos eletroníveis em laboratório, foi realizada sua instalação em campo.

Os eletroníveis foram locados em dezesseis pontos sobre a laje do cais, formando cinco seções conforme mostrado na Figura 3.3. Cada eletronível foi devidamente fixado em uma cantoneira de alumínio, que por sua vez foi fixada à laje do cais por dois parafusos (Figura 3.15). 


\begin{tabular}{|c|c|}
\hline EL01 & 0,1587 \\
\hline EL02 & 0,1600 \\
\hline EL03 & 0,1728 \\
\hline EL04 & 0,1620 \\
\hline EL05 & 0,1581 \\
\hline EL06 & 0,1628 \\
\hline EL07 & 0,1601 \\
\hline EL08 & 0,1602 \\
\hline EL09 & 0,1598 \\
\hline EL10 & 0,1735 \\
\hline EL11 & 0,1637 \\
\hline EL12 & 0,1673 \\
\hline EL13 & 0,1658 \\
\hline EL14 & 0,1753 \\
\hline EL15 & 0,1680 \\
\hline EL16 & 0,1645 \\
\hline MÉDIA & $\mathbf{0 , 1 6 4 6}$ \\
\hline
\end{tabular}

Tabela 3.1 - Fatores de calibração para os eletroníveis EL01 a EL16.

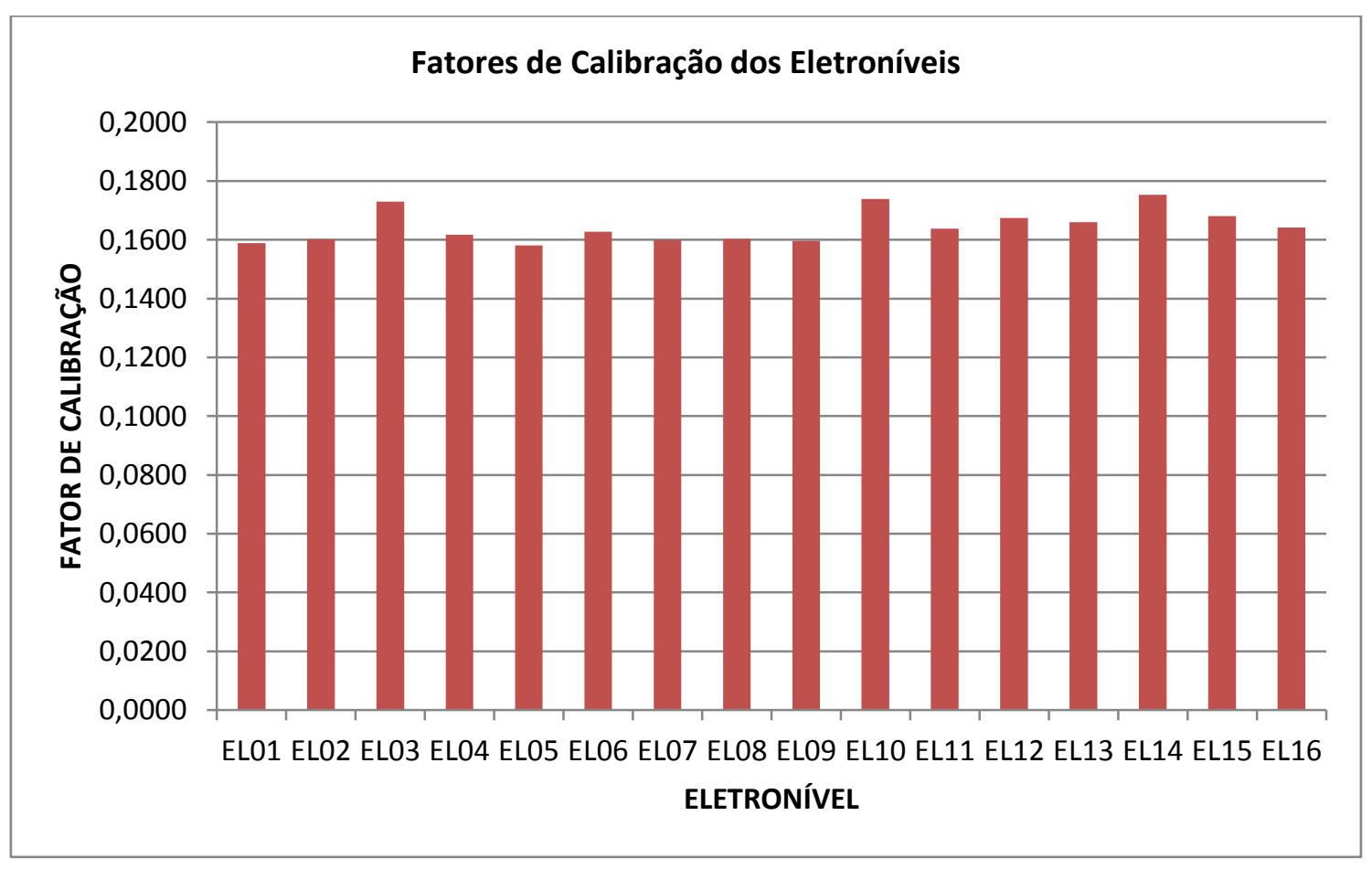

Figura 3.14 - Fatores de calibração para os eletroníveis EL01 a EL16. 

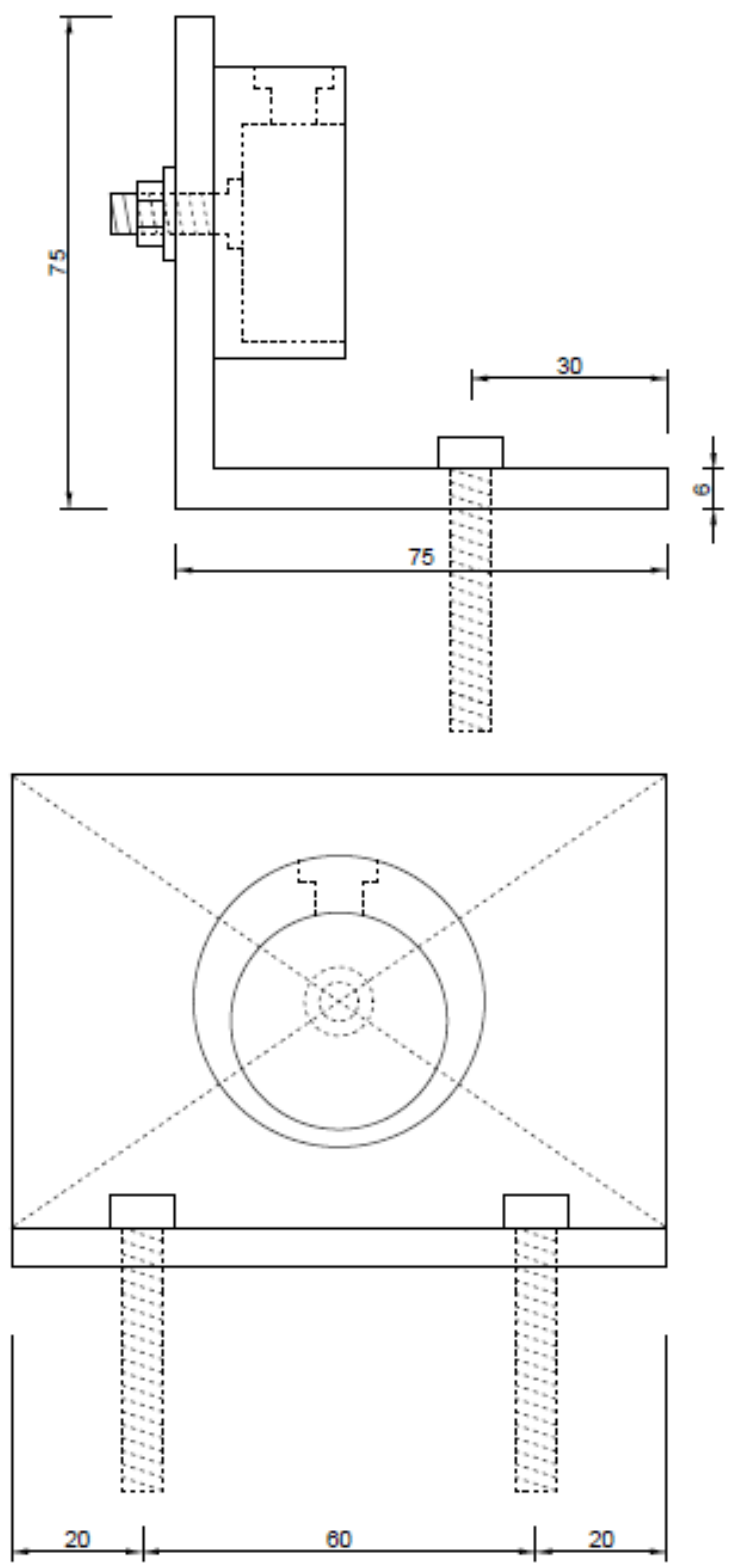

Figura 3.15 - Detalhe dos perfis de fixação dos eletroníveis.

Antes da fixação do eletronível no perfil, este deve estar o mais próximo possível da horizontal, de modo que possa ser aproveitada a mesma amplitude de leituras para rotação em ambos os lados. Este processo de nivelamento (Figura 3.16) é realizado utilizando o Mini Data-Logger, por sua facilidade de conexão e portabilidade. Este aparelho fornece uma leitura adimensional, associada à rotação do eletronível, que varia entre \pm 19999 , onde o valor 0 equivale à um ângulo de $0^{\circ}$ entre o eletronível e a superfície de fixação.

Após o nivelamento de cada eletronível, visando impossibilitar a rotação da cápsula em torno do eixo da rosca, sua fixação foi feita utilizando arruela de pressão e, após o aperto da porca, foi aplicada resina epóxi sobre o conjunto rosca-arruela-porca. 
Finalizada a instalação e fixação dos eletroníveis, os cabos foram ligados ao sistema de aquisição de dados.

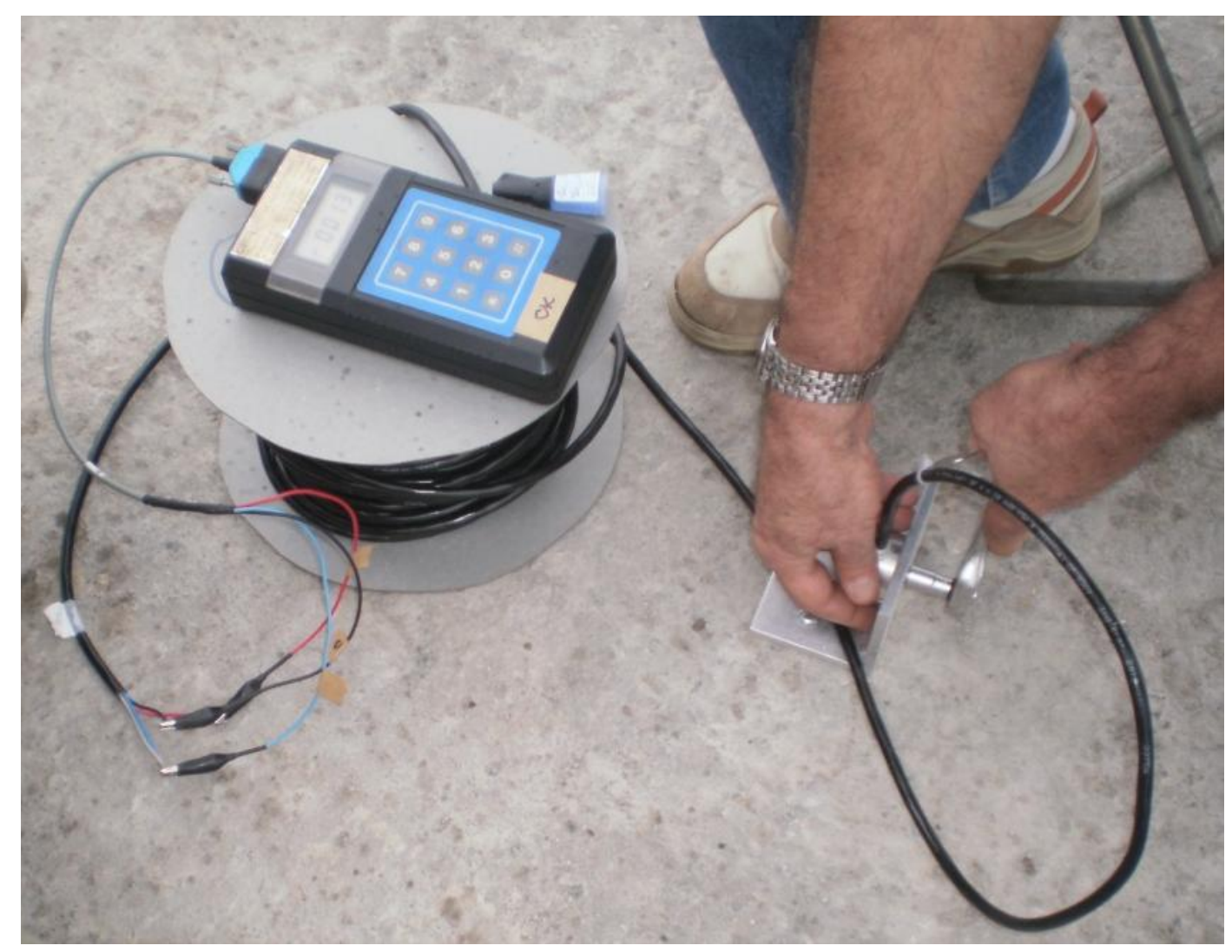

Figura 3.16 - Nivelamento e fixação do eletronível.

\subsection{3.}

\section{Extensômetros elétricos}

Os extensômetros elétricos utilizados para medir as deformações específicas da estrutura foram do tipo unidirecional simples (Figura 3.17).

Conforme mencionado anteriormente, foram instrumentadas cinco estacas e um ponto sob a laje. Em cada estaca foram utilizados quatro extensômetros, um em cada face, de modo a identificar eventual flexão nas mesmas. No ponto sob a laje do cais, foram utilizados dois extensômetros, um no sentido longitudinal e outro no sentido transversal do cais, para controlar as deformações de tração decorrentes da deformação da laje durante o carregamento. 


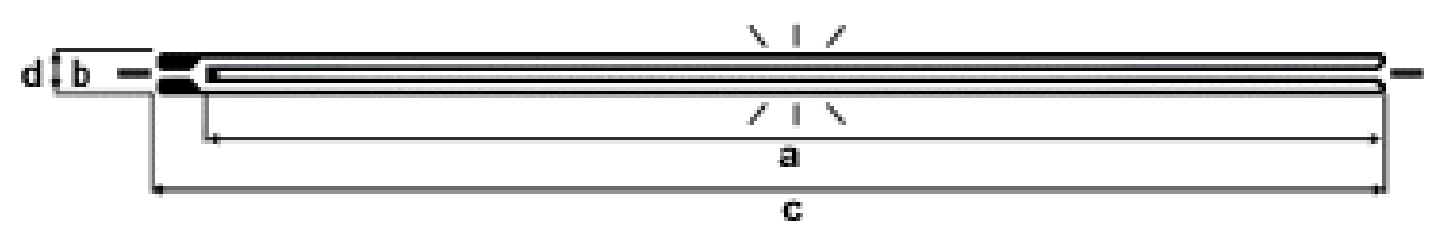

Figura 3.17 - Extensômetro Elétrico unidirecional simples (www.excelsensor.com.br).

\subsubsection{1.}

\section{Princípio de funcionamento}

Os extensômetros elétricos são resistências elétricas utilizadas para medir deformação específica associada à variação da resistência. A relação entre a variação da resistência e a deformação está descrita na Equação 3.10, onde o valor de $k$, conhecido como gage factor, é fornecido pelo fabricante.

$$
\frac{\Delta R}{R_{0}}=k \times \varepsilon
$$

O circuito formado por cada extensômetro elétrico forma um quarto de ponte de Wheatstone (Figura 3.18), e o restante da ponte é completa por três resistências conhecidas.

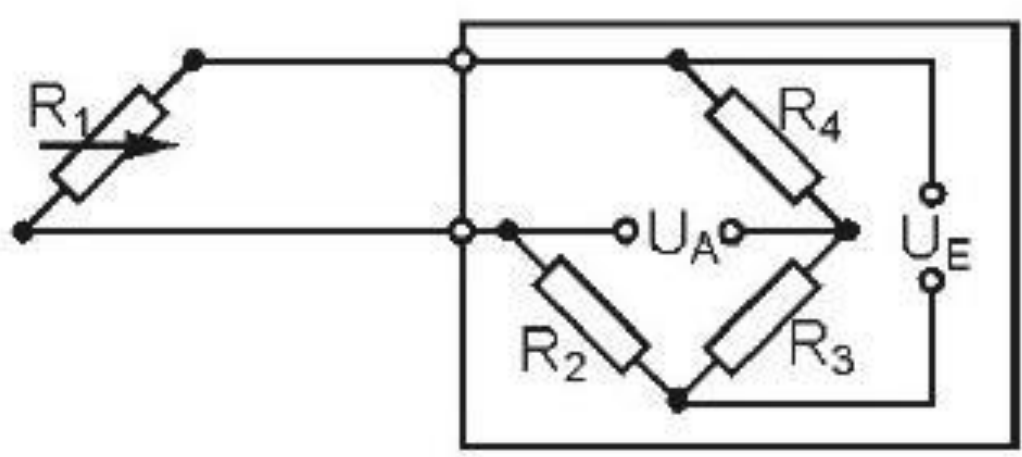

Figura 3.18 - Circuito elétrico dos extensômetros elétricos.

\subsubsection{2. Montagem}

Diferentemente dos eletroníveis, os extensômetros elétricos podem ser utilizados expostos sem proteção externa, uma vez que este modelo de extensômetro é feito para uma única utilização. 
A única preparação necessária para a utilização em campo foi a montagem de uma conexão serial para evitar deformações nos sensores devido ao peso próprio dos cabos, como está mostrado na Figura 3.19.

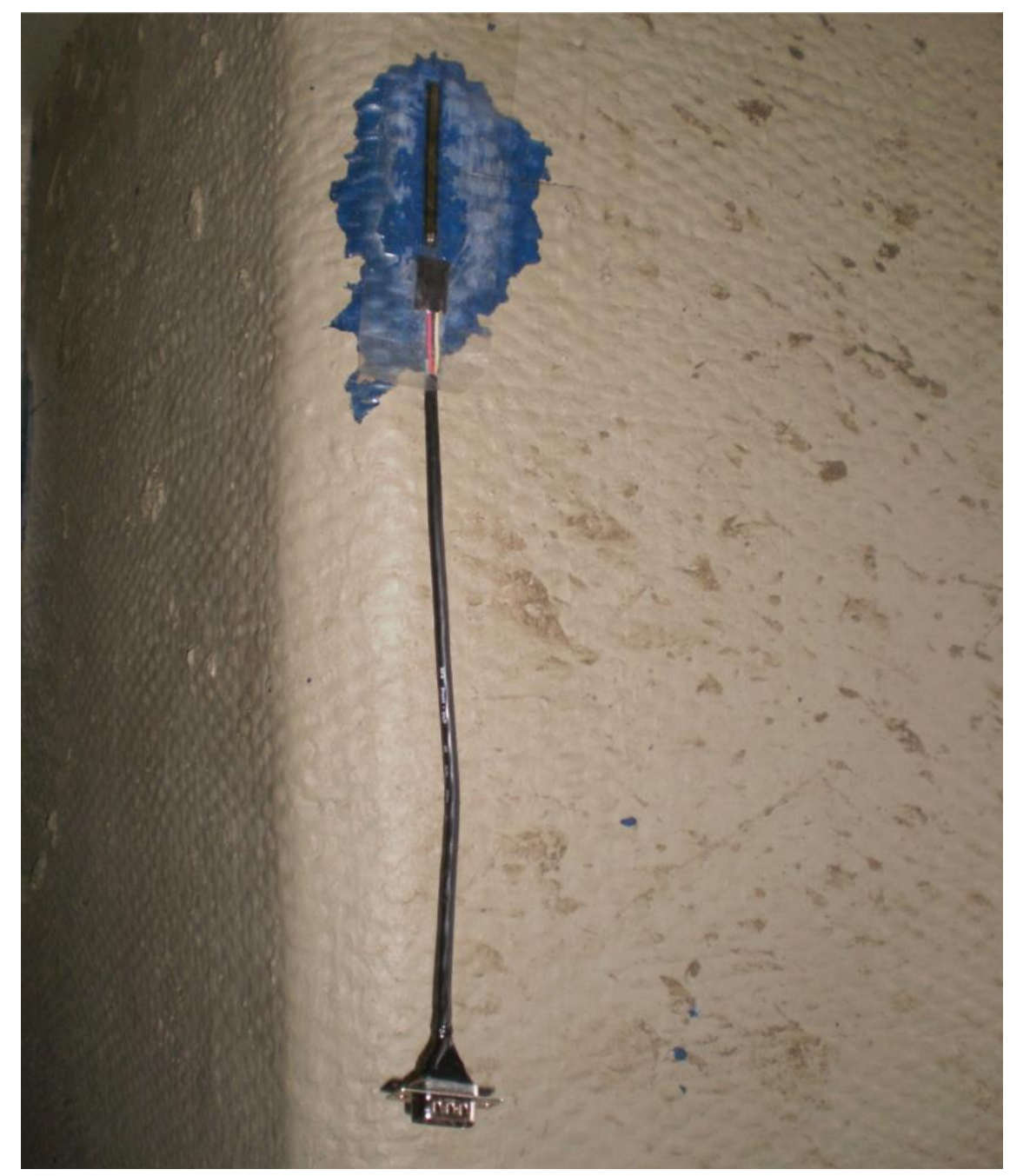

Figura 3.19 - Detalhe da conexão serial dos extensômetros elétricos.

\subsubsection{3.}

\section{Calibração}

A calibração dos extensômetros elétricos é fornecida pelo fabricante de acordo com o lote de fabricação, conforme mencionado anteriormente.

O valor do gage factor, $k$, do lote de extensômetros elétricos utilizados foi de 2,14. Portanto, a Equação 3.10 pode ser redefinida.

$$
\frac{\Delta R}{R_{0}}=2,1 \times \varepsilon
$$




\subsubsection{4.}

\section{Instalação}

Após a preparação dos extensômetros elétricos em laboratório, foi realizada sua instalação em campo.

Como mencionado anteriormente, as estacas e o fundo da laje do cais são reforçados com fibra de carbono, resultando em uma superfície irregular devido à rugosidade do material. Logo, foi necessário um tratamento da superfície para uma fixação adequada dos extensômetros elétricos.

Primeiramente a superfície foi lixada de modo a promover a remoção total da massa de revestimento da fibra de carbono (Figura 3.20). Quando a superfície remanescente apresentou regularidade, a fixação foi feita utilizando resina epóxi, e quando esta se apresentou irregular devido à rugosidade da fibra de carbono, foi utilizada massa epóxi.

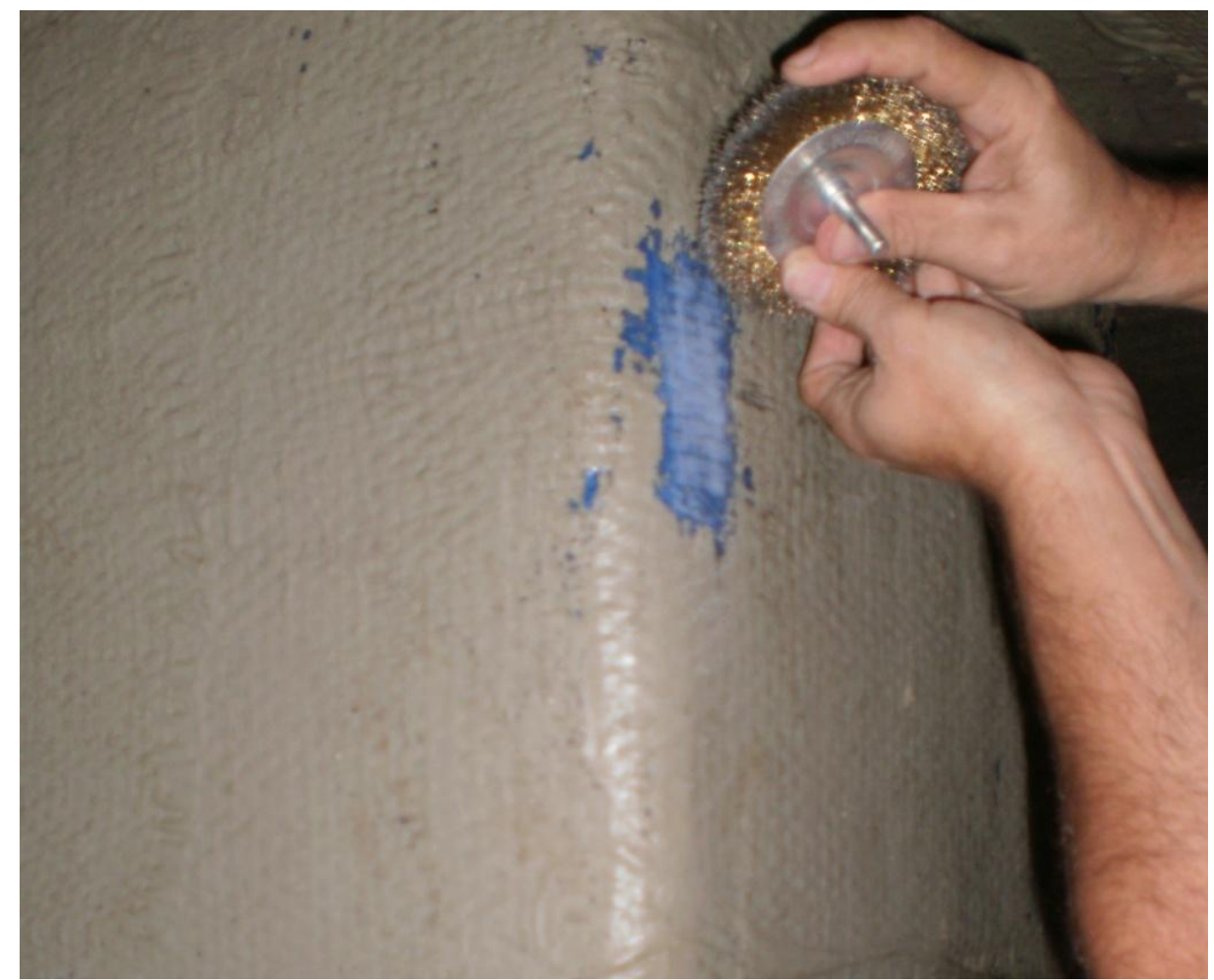

Figura 3.20 - Tratamento da superfície de instalação dos extensômetros elétricos.

Após a instalação, foram conectados cabos de 50 metros de comprimento até a posição do sistema de aquisição de dados. 
Para as estacas E47 e E48, os cabos foram fixados a uma guia de aço (Figura 3.21) de modo a evitar o contato com a água do mar.

\subsection{4.}

\section{Nivelamento topográfico}

O deslocamento vertical foi medido utilizando um nível digital Leica NA3003, com precisão de $0,01 \mathrm{~mm}$, nos três pontos identificados na planta de locação da instrumentação (Figura 3.3).

Somente foram realizadas leituras em uma linha da laje do cais, uma vez que a carga em sua posição final se torna um obstáculo para a visada topográfica para os demais pontos.

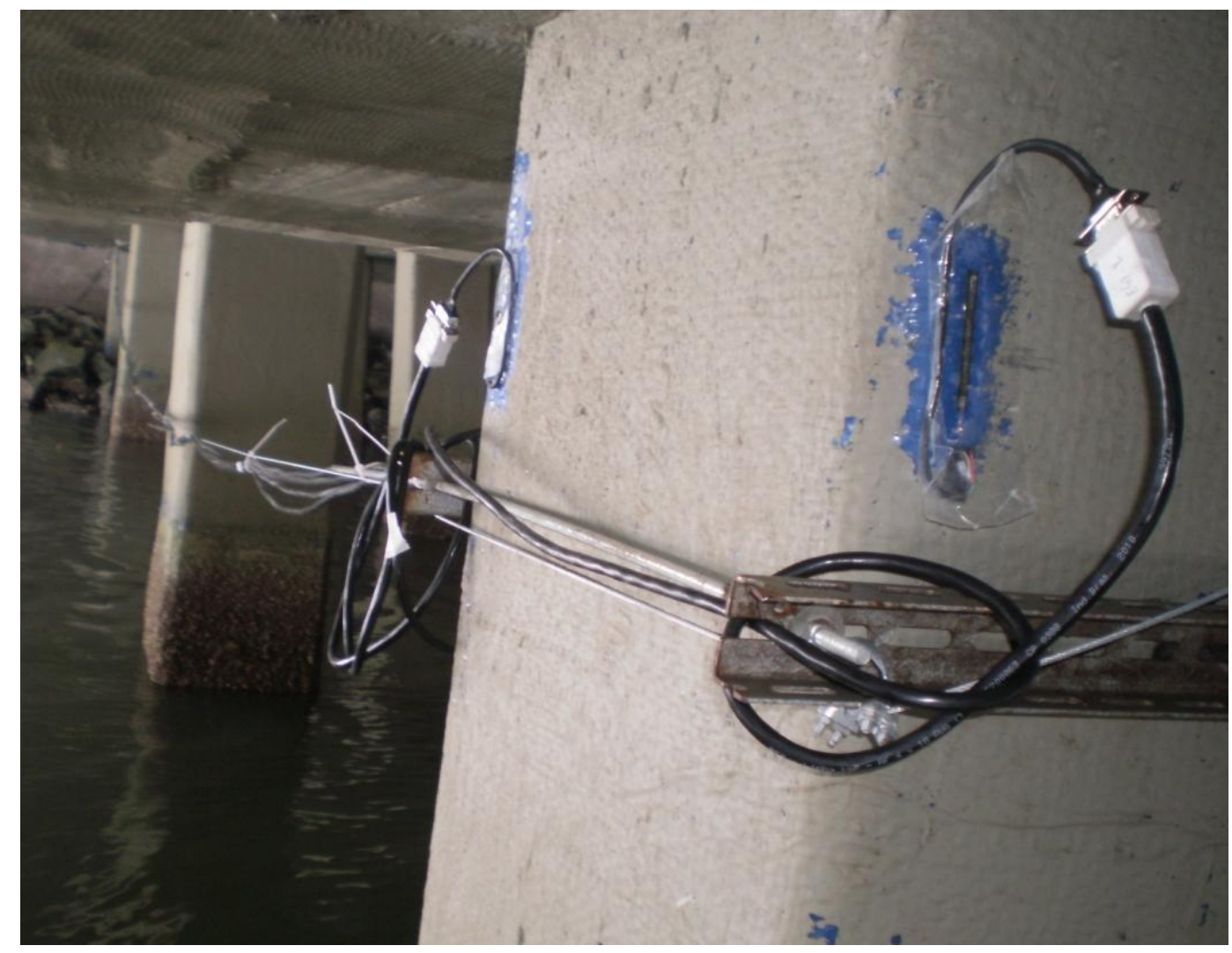

Figura 3.21 - Detalhe da fixação dos cabos. 


\section{Resultados}

Conforme mencionado no Capítulo 1, o objetivo do teste de carga foi de averiguar a capacidade do cais em suportar a passagem de um módulo de compressão de gás de 927 tf, transportado por dois trailers que, juntos, pesam $126 \mathrm{tf}$, totalizando $1053 \mathrm{tf}$.

O carregamento foi realizado de modo a simular a situação real da maneira mais próxima possível. Logo, foram utilizados os mesmos trailers a serem utilizados no transporte do módulo, porém carregados com placas de aço e tanques de água (Figura 4.1).

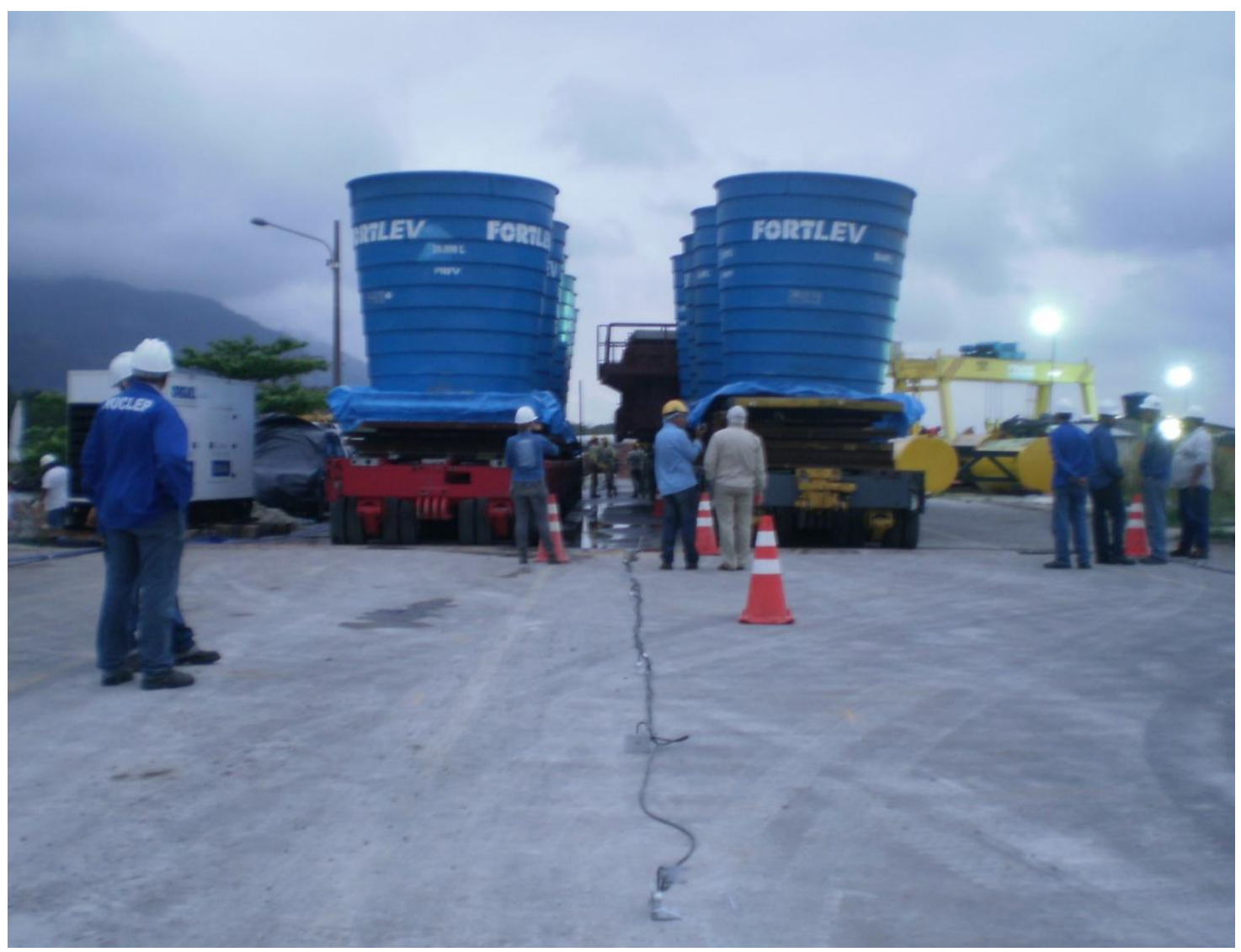

Figura 4.1 - Trailers carregados com placas de aço e tanques de água.

O valor total da carga dos trailers carregados com chapas de aço e com os tanques cheios de água foi de 1207 tf, medido pelo conjunto de manômetros dos 
trailers com precisão de $\pm 10 \%$, correspondendo a 1.15 vezes a carga do módulo de compressão de gás mais os trailers.

\section{1.}

\section{Procedimento do teste}

Após a montagem de todo o sistema de aquisição de dados descrito no capítulo 3, foi feito um plano de carregamento dividido em sete estágios, onde cada estágio corresponde a uma posição dos trailers sobre o cais (Figura 4.2).

O estágio 0 corresponde ao cais descarregado. Os estágios de 1 a 6 correspondem aos trailers posicionados conforme mostrado na Figura 4.2, sendo que entre os estágios 1 a 5 os trailers estavam carregados somente com as placas de aço, e o estágio 6 corresponde ao final do enchimento dos tanques com água. $\mathrm{O}$ estágio 7 corresponde à situação após a retirada dos trailers (cais descarregado).

As cargas correspondentes a cada estágio mostradas na Tabela 4.1 foram calculadas dividindo a carga total dos trailers antes do enchimento dos tanques pelo número total de eixos multiplicado pelo número de eixos sobre o cais, conforme indicado na Figura 4.2. No estágio 6, por exemplo, a carga por eixo pode ser calculada pela Equação 4.1.

$$
\begin{gathered}
Q_{6}=\frac{Q_{\text {total }}}{n^{\circ} \text { total de eixos }} \times n^{\circ} \text { de eixos sobre o pier (Eq. 4.1) } \\
Q_{6}=\frac{1207}{18} \times 15=1006 \mathrm{tf}
\end{gathered}
$$

\begin{tabular}{clcc}
\hline Estágio & \multicolumn{1}{c}{ Carga total aplicada no cais $(\mathbf{t f )}$} & $\begin{array}{c}\text { Tempo } \\
\text { (hh:mm:ss) }\end{array}$ & $\begin{array}{c}\text { Tempo } \\
\text { decorrido } \\
\text { (hh:mm:ss) }\end{array}$ \\
\hline 0 & $\mathbf{0}$ & $18: 05: 35$ & $00: 00: 00$ \\
1 & Chapas de aço + trailers $=138+22=\mathbf{1 6 0}$ & $18: 06: 13$ & $00: 00: 38$ \\
2 & Chapas de aço + trailers $=276+43=\mathbf{3 1 9}$ & $18: 06: 30$ & $00: 00: 55$ \\
3 & Chapas de aço + trailers $=414+64=\mathbf{4 7 8}$ & $18: 08: 20$ & $00: 02: 45$ \\
4 & Chapas de aço + trailers $=552+85=\mathbf{6 3 7}$ & $18: 09: 07$ & $00: 03: 32$ \\
5 & Chapas de aço + trailers $=690+106=\mathbf{7 9 6}$ & $18: 11: 26$ & $00: 05: 51$ \\
6 & Chapas de aço + trailers + tanques $=690+$ & $22: 10: 15$ & $04: 04: 40$ \\
7 & $\mathbf{0}$ & $22: 34: 30$ & $04: 29: 20$ \\
\hline
\end{tabular}

Tabela 4.1 - Estágios de aplicação de carga. 


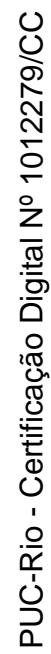
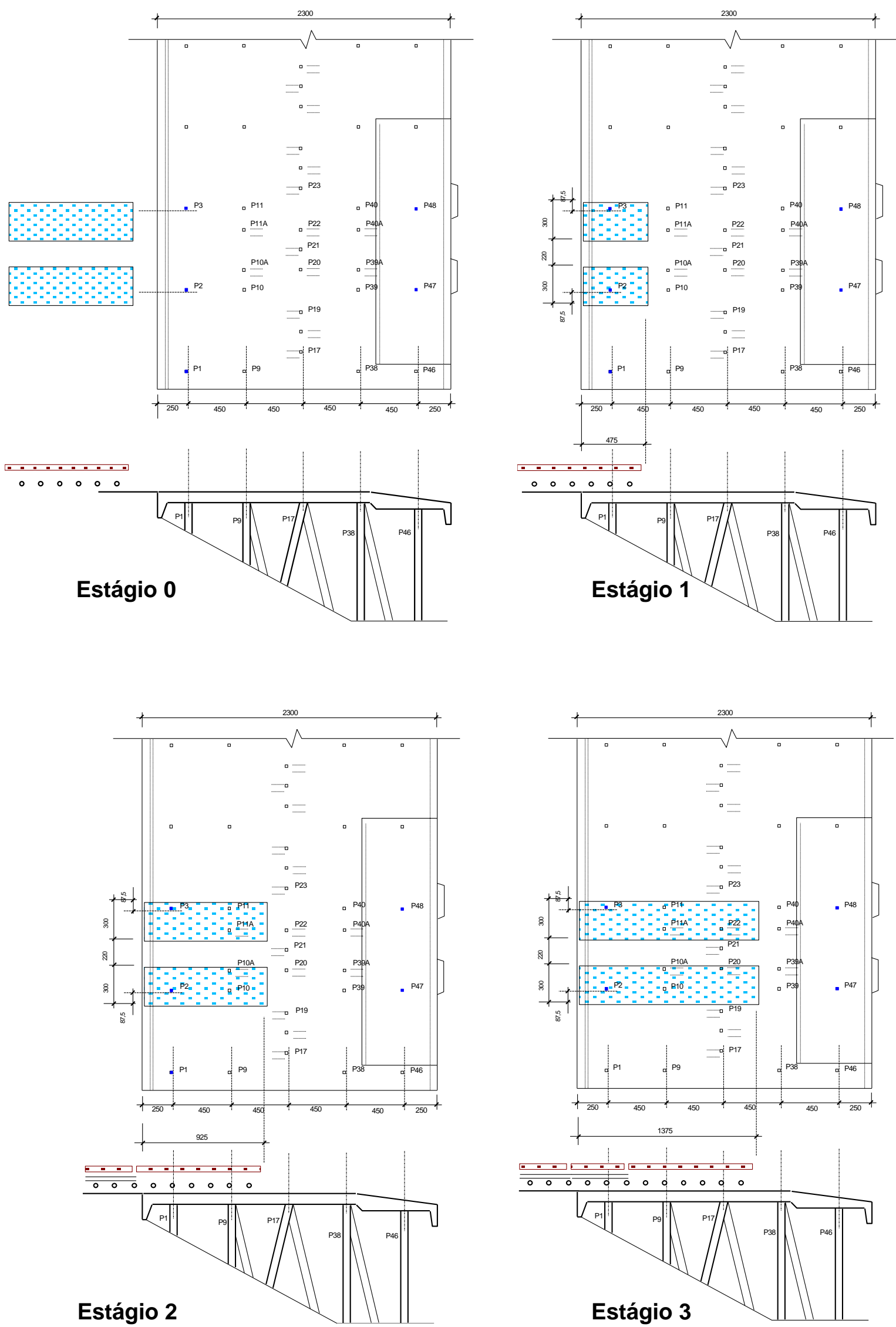

Figura 4.2 - Estágios de aplicação da carga. 


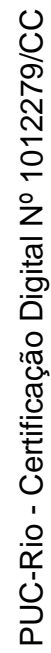
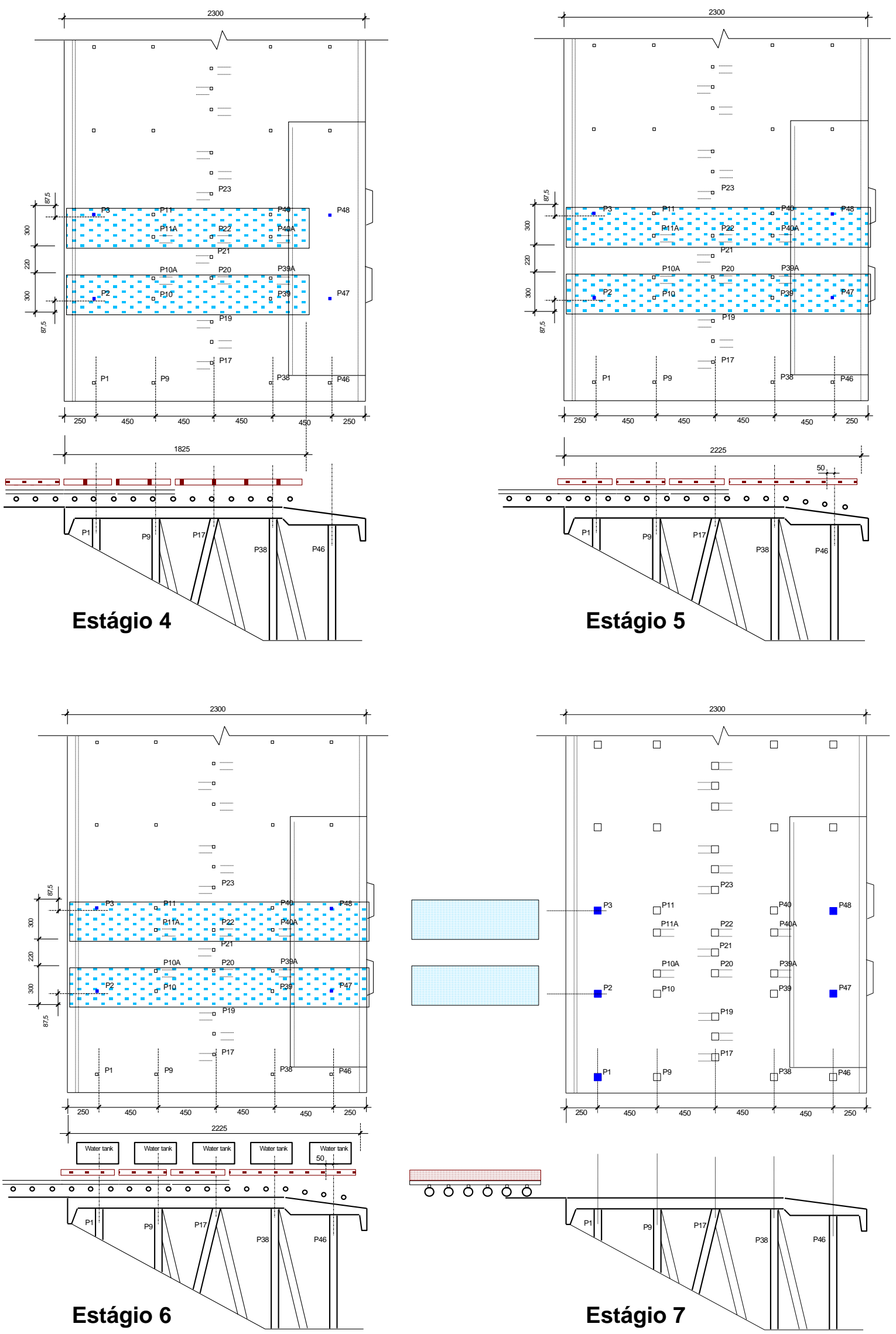

Figura 4.2 - Estágios de aplicação de carga (continuação). 
Todo o procedimento durou 4 horas, 29 minutos e 20 segundos, sendo que somente para o enchimento dos tanques com água foram necessárias 3 horas, 58 minutos e 49 segundos.

\section{2.}

\section{Rotações}

As rotações da laje do cais foram medidas por um conjunto de dezesseis eletroníveis, conforme descrito anteriormente no Capítulo 3, com registro de leituras a cada dez segundos.

A Figura 4.3 mostra os ângulos de rotação em graus da laje do cais medidos pelos eletroníveis para cada estágio de carga. Há um aumento aparente nas rotações entre os estágios 5 e 6 , porque foram necessárias quatro horas no processo de enchimento dos tanques com água, enquanto que a entrada dos trailers sobre o cais (estágios 1 a 5 ) levou apenas cinco minutos. As leituras podem ser visualizadas em função do tempo na Figura 4.4.

Analisando a Figura 4.4 é possível notar que a evolução das leituras em geral não sofre nenhum aumento súbito que possa caracterizar alguma anomalia do comportamento da estrutura ou do sistema de aquisição de dados.

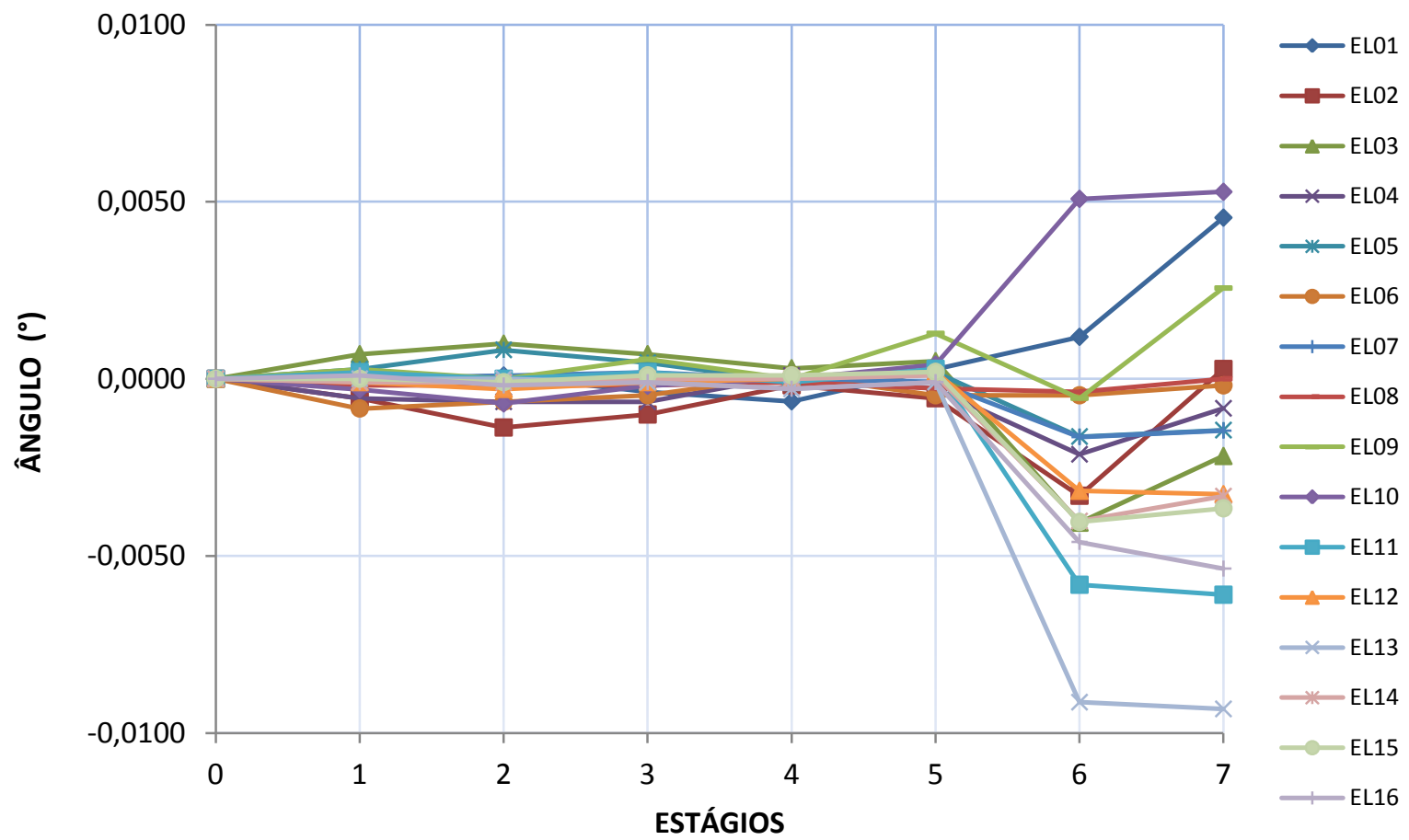

Figura 4.3 - Ângulo de rotação da laje do cais em cada estágio. 


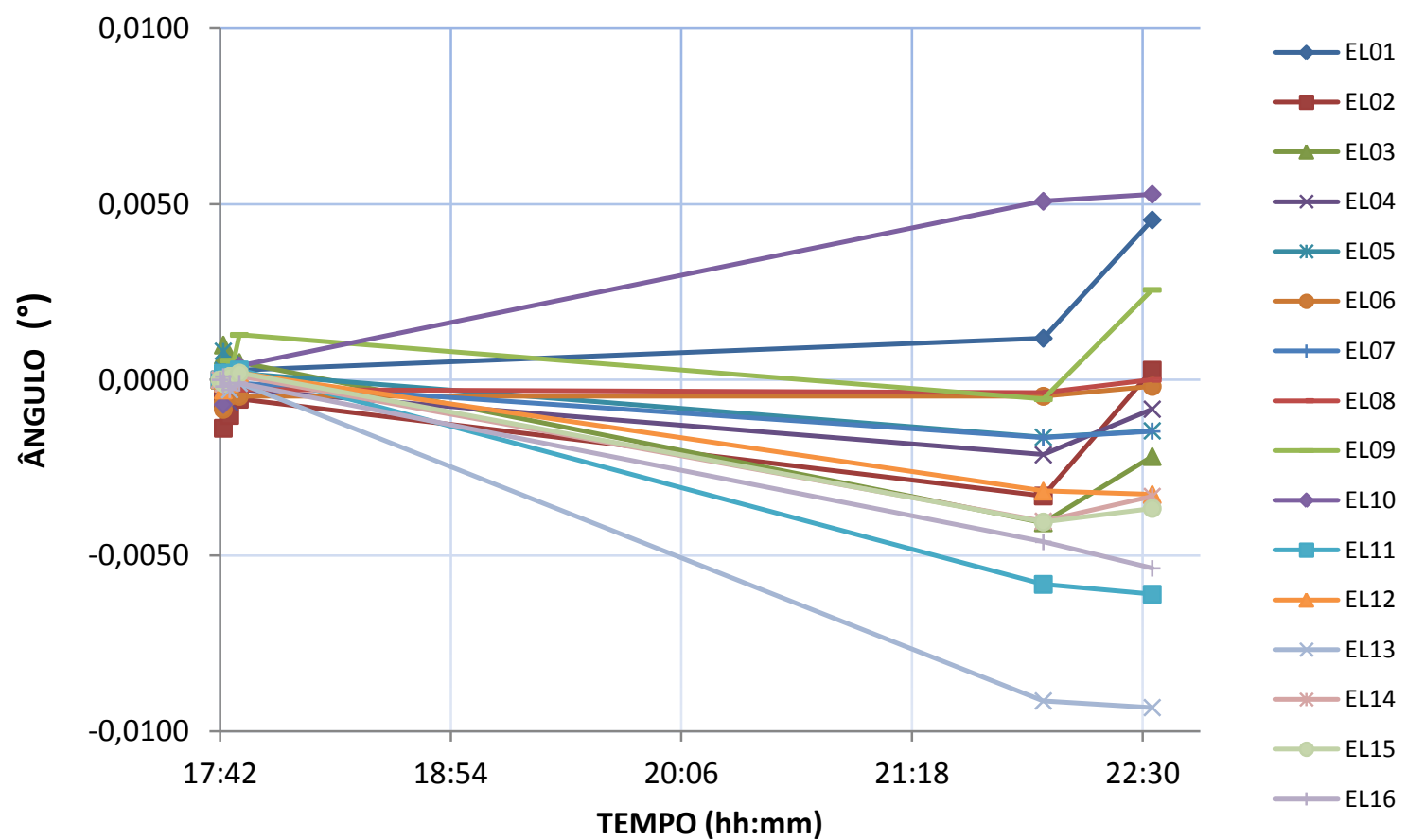

Figura 4.4 - Ângulo de rotação da laje do cais ao longo do tempo.

Vale ressaltar que nesta figura estão apresentadas apenas as leituras correspondentes aos estágios definidos (Figura 4.2). A variação completa das leituras dos eletroníveis, com intervalos de dez segundos, está apresentada em anexo neste trabalho, e pode-se visualizar grande variação durante o processo de enchimento dos tanques (período entre 18:00 e 21:59). Esta variação foi conseqüência da seqüência de enchimento dos tanques em localizações distintas, resultando em acréscimo de carregamento localizado de forma aleatória, uma vez que os tanques não foram cheios simultanteamente.

Os valores máximos dos ângulos medidos e distorção angular correspondente para cada eletronível estão descritos na Tabela 4.2. A máxima distorção angular medida foi da ordem de 1:6000, correspondente ao eletronível EL 13.

\section{3.}

\section{Deformações}

A deformação total das estacas é composta pela deformação causada pelo carregamento realizado durante o teste mais a deformação devido ao peso próprio da estrutura. A deformação causada pelo carregamento foi medida pela instrumentação descrita no capítulo 3, e a deformação devido ao peso próprio foi 
estimada a partir de uma análise estrutural previamente realizada. Os resultados de cada uma destas componentes são mostrados a seguir.

\begin{tabular}{|c|c|c|}
\hline Eletronível & $\begin{array}{c}\text { Ângulo } \\
\text { Máx. }\left(^{\circ}\right.\end{array}$ & $\begin{array}{c}\text { Distorção } \\
\text { Angular }\end{array}$ \\
\hline EL01 & 0,0046 & $1: 12455$ \\
\hline EL02 & $-0,0033$ & $1: 17362$ \\
\hline EL03 & $-0,0041$ & $1: 13974$ \\
\hline EL04 & $-0,0021$ & $1: 27283$ \\
\hline EL05 & $-0,0016$ & $1: 35809$ \\
\hline EL06 & $-0,0005$ & $1: 114591$ \\
\hline EL07 & $-0,0016$ & $1: 35809$ \\
\hline EL08 & $-0,0004$ & $1: 143239$ \\
\hline EL09 & 0,0026 & $1: 22036$ \\
\hline EL10 & 0,0053 & $1: 10810$ \\
\hline EL11 & $-0,0061$ & $1: 9392$ \\
\hline EL12 & $-0,0033$ & $1: 17362$ \\
\hline EL13 & $-0,0093$ & $1: 6160$ \\
\hline EL14 & $-0,0040$ & $1: 14323$ \\
\hline EL15 & $-0,0040$ & $1: 14323$ \\
\hline EL16 & $-0,0054$ & $1: 10610$ \\
\hline
\end{tabular}

Tabela 4.2 - Ângulo máximo e distorção angular medida pelos eletroníveis.

\subsection{1. \\ Deformações devido ao carregamento}

As deformações específicas nas estacas E2, E3, E47 e E48 resultantes do carregamento aplicado medidas durante o teste estão mostradas nas Figuras 4.5 a 4.8, onde as séries sg1 a sg4 correspondem aos quatro extensômetros elétricos instalados em cada face da estaca conforme descrito no capítulo 3 . Os maiores valores foram da ordem de $0,10 \mathrm{~mm} / \mathrm{m}$ correspondentes às estacas E2 e E3. 


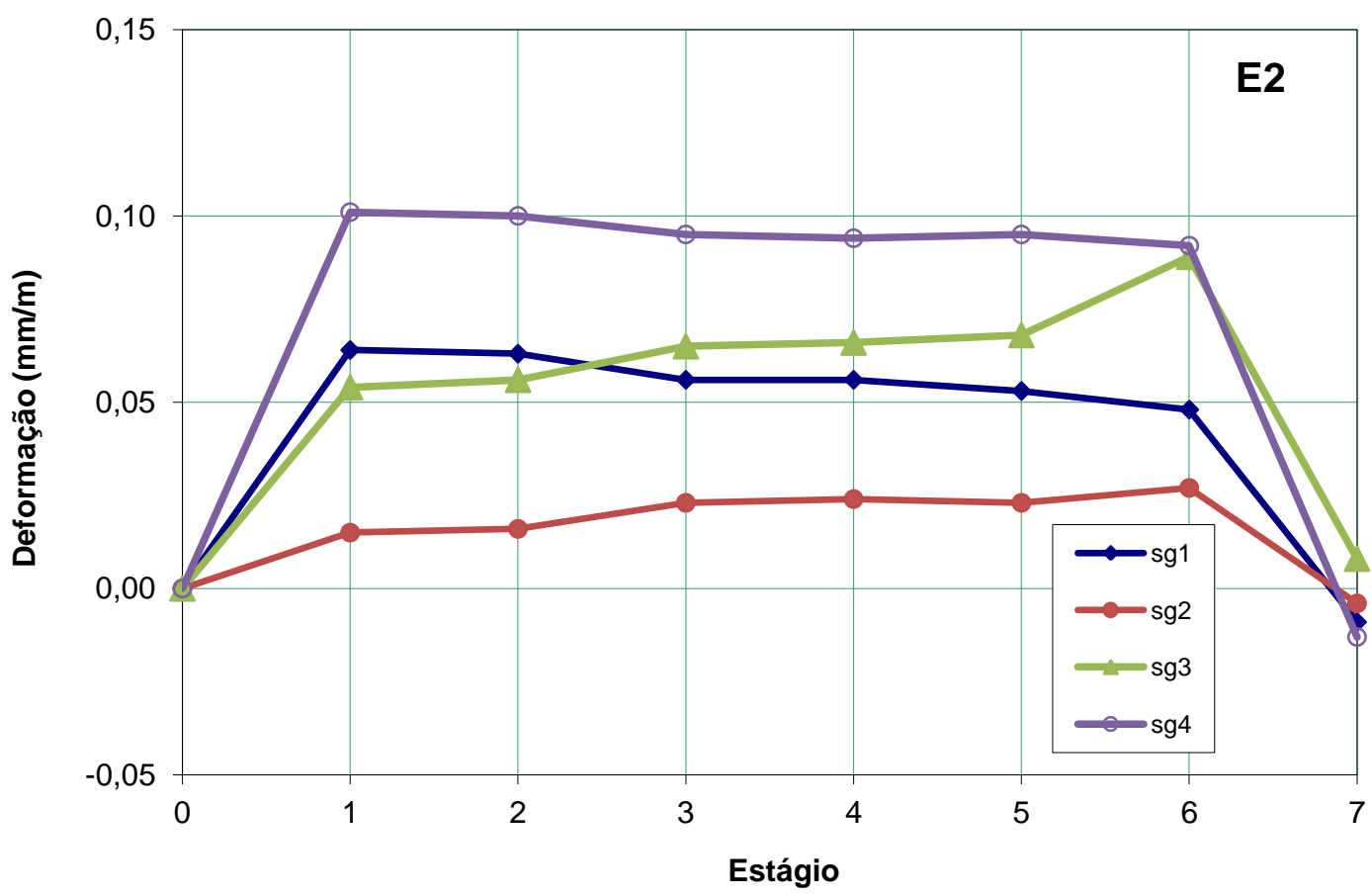

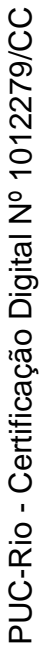

Figura 4.5 - Estaca E2: deformação específica em cada estágio.

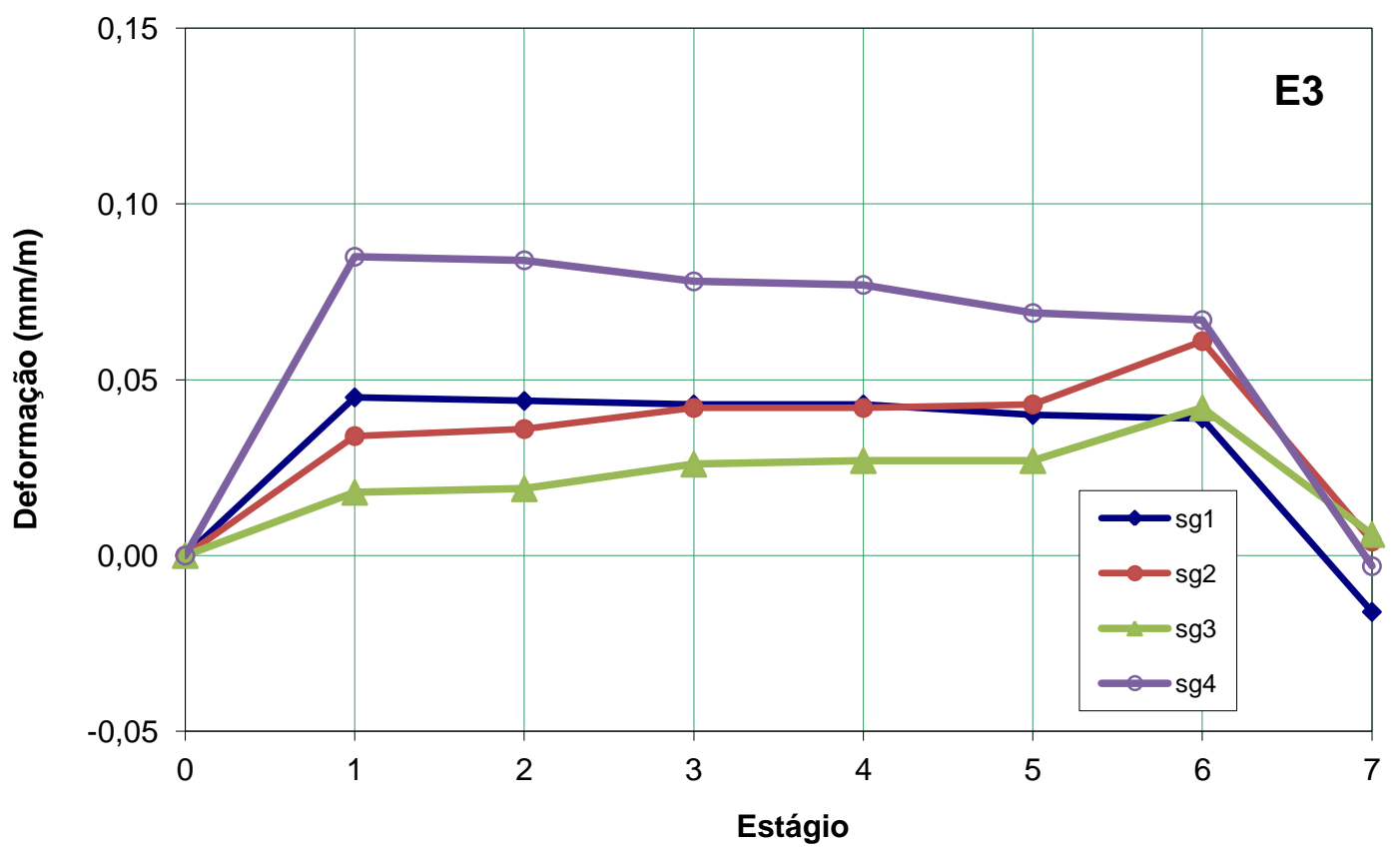

Figura 4.6 - Estaca E3: deformação específica em cada estágio. 


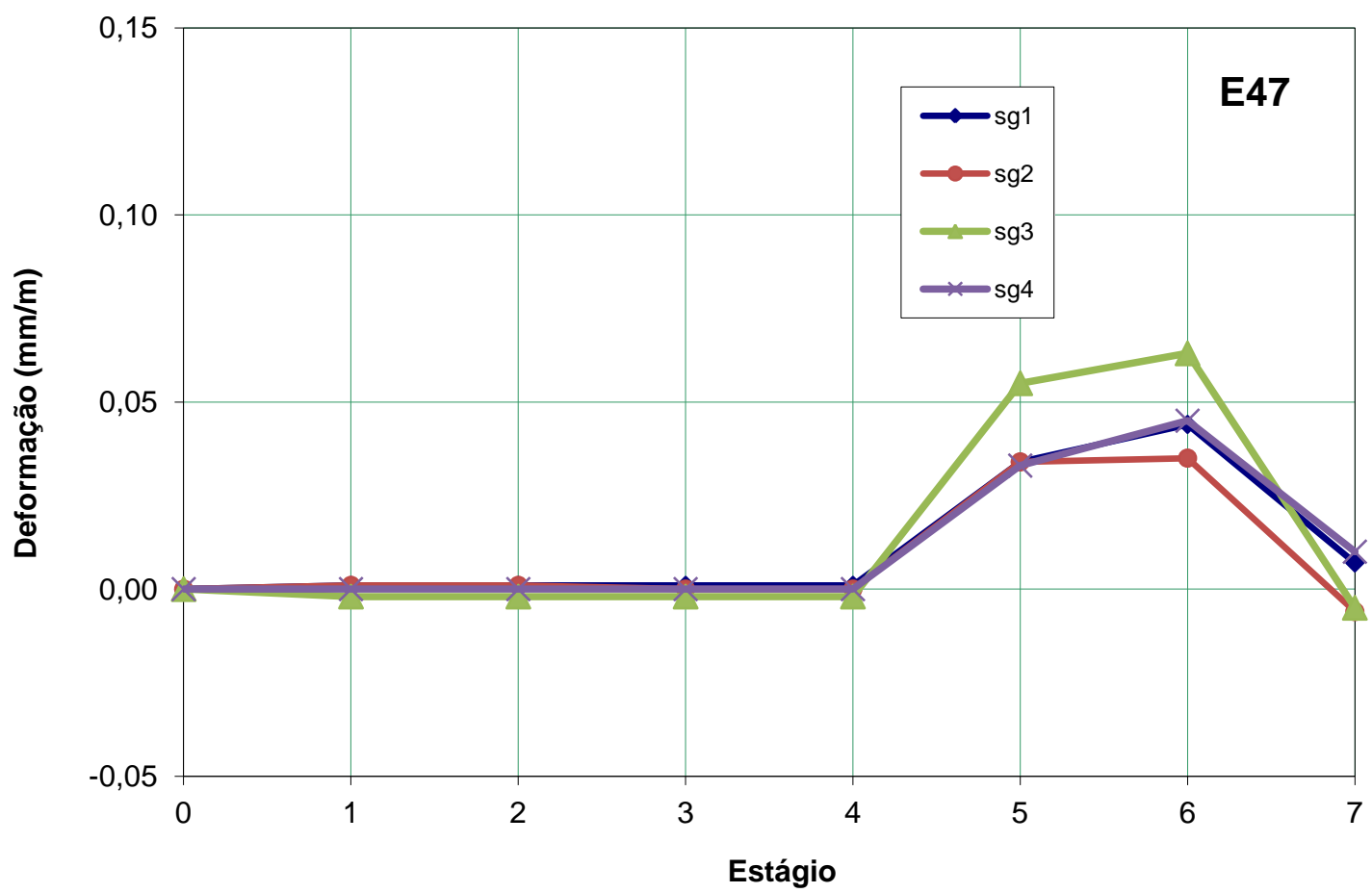

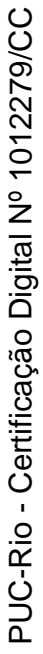

Figura 4.7 - Estaca E47: deformação específica em cada estágio.

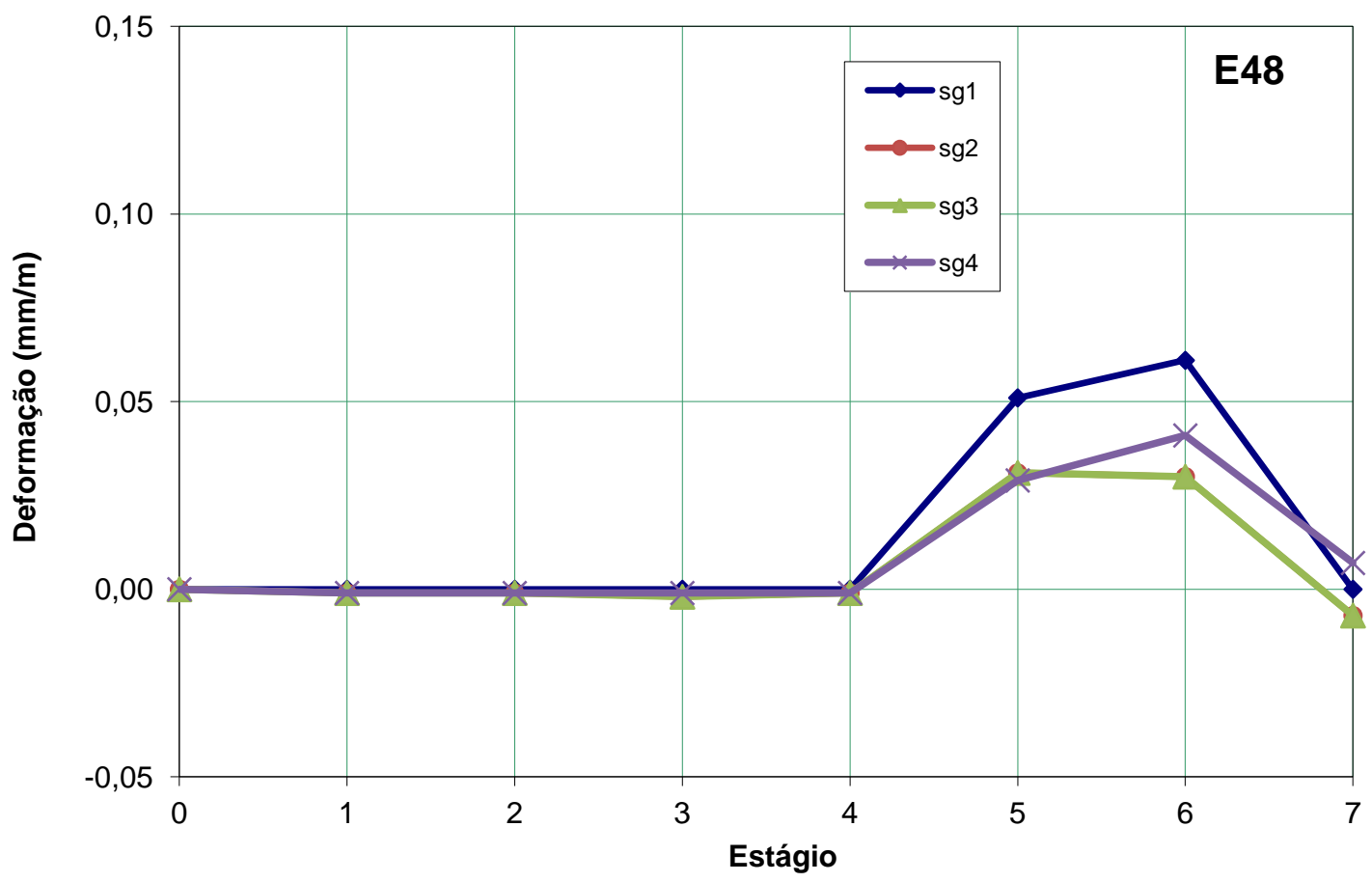

Figura 4.8 - Estaca E48: deformação específica em cada estágio. 
Pode-se observar que em todas as quatro estacas a deformação foi totalmente recuperada após a retirada do carregamento, representando comportamento elástico das estacas

\subsection{2.}

\section{Deformações devido ao peso próprio da estrutura}

Conforme mencionado anteriormente, foi realizada uma análise estrutural prévia ao teste, onde foi estimada a carga atuante em cada estaca devido ao peso próprio $\left(\mathrm{P}_{\mathrm{P}}\right)$.

Uma vez conhecida a carga e a seção transversal da estaca, temos a tensão aplicada nas estacas devido ao peso próprio da estrutura $\left(\sigma_{\mathrm{p}}\right)$. Os valores da carga e tensão aplicada nas estacas E2, E3, E47 e E48 estão na Tabela 4.3.

A deformação nas estacas devido ao peso próprio da estrutura pode ser obtida pela Lei de Hooke.

$$
\varepsilon=\frac{\sigma}{E}
$$

De modo a estimar as deformações devido ao peso próprio da estrutura, as propriedades mecânicas do concreto foram devidamente atualizadas.

De acordo com o projeto original do cais, a resistência característica $\left(f_{c k}\right)$ do concreto das estacas era de 25,0 MPa. Uma vez que o cais foi construído na década de 1980, as propriedades mecânicas do concreto foram atualizadas considerando um tempo decorrido de 20 (vinte) anos.

Como o resultado do teste foi destinado a uma empresa inglesa, as propriedades do concreto foram atualizadas de acordo com o Eurocode 2 Design of concrete structures.

Segundo o Eurocode 2, as propriedades mecânicas do concreto podem ser atualizadas como mostrado a seguir.

A resistência à compressão média com 28 dias $\left(\mathrm{f}_{\mathrm{cm}}\right)$ é dada pela Equação 4.3.

$$
f_{c m}=f_{c k}+8(M P a)=25+8=33 M P a
$$

A resistência à compressão média com uma idade de $t$ dias é dada pela Equação 4.4, onde o parâmetro $\beta_{c c}$ é dado pela Equação 4.5. 


$$
\begin{aligned}
& f_{c m}(t)=\beta_{c c}(t) f_{c m} \\
& \beta_{c c}(t)=\exp \left\{s\left[1-\left(\frac{28}{t}\right)^{0,5}\right]\right\}
\end{aligned}
$$

A constante $s$ é função do tipo de cimento, e para o concreto com cimento de endurecimento normal seu valor é igual a 0,25 . O tempo $t$ corresponde ao tempo decorrido, no caso 20 anos, que equivale a 7300 dias. Substituindo estes valores na Equação 4.5, temos:

$$
\beta_{c c}=\exp \left\{0,25\left[1-\left(\frac{28}{7300}\right)^{0,5}\right]\right\}=1,26
$$

Logo, temos a resistência à compressão média correspondente a uma idade de 7300 dias, a partir da Equação 4.4.

$$
f_{c m}(7300)=1,26 \times 33=41,6 M P a
$$

Assim como feito para a resistência à compressão, foi necessária a atualização do módulo de elasticidade para o tempo decorrido de 7300 dias.

$\mathrm{O}$ módulo de elasticidade médio $\left(\mathrm{E}_{\mathrm{cm}}\right)$ relativo à construção do cais pode ser estimado empiricamente pela Equação 4.6.

$$
\begin{gathered}
E_{c m}=22\left(\frac{f_{c m}}{10}\right)^{0,3} \\
E_{c m}=22\left(\frac{33}{10}\right)^{0,3}=31,5 \mathrm{GPa}=31500 \mathrm{MPa}
\end{gathered}
$$

O módulo de elasticidade médio a uma idade de $t$ dias é dado pela Equação 4.7.

$$
\begin{gathered}
E_{c m}(t)=\beta_{c c}(t)^{0,3} E_{c m} \\
E_{c m}(t)=1,26^{0,3} \times 31,5=33,8 \mathrm{GPa}=33800 \mathrm{MPa}
\end{gathered}
$$


A partir das propriedades do concreto devidamente atualizadas, as deformações causadas pelo peso próprio da estrutura podem ser estimadas, aplicando a Equação 4.2. Os resultados estão apresentados na tabela abaixo.

\begin{tabular}{|c|c|c|c|}
\hline Estaca & $\mathbf{P}_{\mathbf{p}}(\mathbf{t f})$ & $\begin{array}{c}\boldsymbol{\sigma}_{\mathbf{p}} \\
(\mathbf{M p a})\end{array}$ & $\boldsymbol{\varepsilon}_{\mathbf{p}}(\mathbf{m m} \backslash \mathbf{m})$ \\
\hline E2 & 111,0 & 3,8 & 0,112 \\
\hline E3 & 100,0 & 3,4 & 0,101 \\
\hline E47 & 108,0 & 3,7 & 0,109 \\
\hline E48 & 104,0 & 3,6 & 0,107 \\
\hline
\end{tabular}

Tabela 4.3 - Deformação nas estacas devido ao peso próprio da estrutura.

Estes valores, somados à deformação causada pelo carregamento do teste, resultam na deformação total das estacas.

\section{4. \\ Deslocamento vertical}

O deslocamento vertical da laje do cais foi medido em três pontos conforme descrito no capítulo 3. Somente foram realizadas leituras para os estágios 0, 5, 6 e 7. Entre os estágios 0 e 5 não houve tempo hábil para a realização das leituras, devido à velocidade de entrada das carretas sobre a laje do cais.

Vale ressaltar que os valores do deslocamento vertical são a soma do encurtamento elástico das estacas e o recalque das estacas. Uma vez que a deformação específica das estacas foi totalmente recuperada, como mostrado no item 4.3.1., o valor residual do deslocamento vertical após a retirada dos trailers (estágio 7) corresponde ao recalque das estacas.

A Figura 4.9 mostra o deslocamento vertical para cada estágio de carregamento para os três pontos, e a Figura 4.10 mostra o deslocamento vertical em função da carga total aplicada no cais.

O deslocamento vertical máximo foi de $1,10 \mathrm{~mm}$ no ponto PT2 durante o estágio 6 , e o deslocamento vertical residual máximo foi de $0,38 \mathrm{~mm}$ no ponto PT3. 


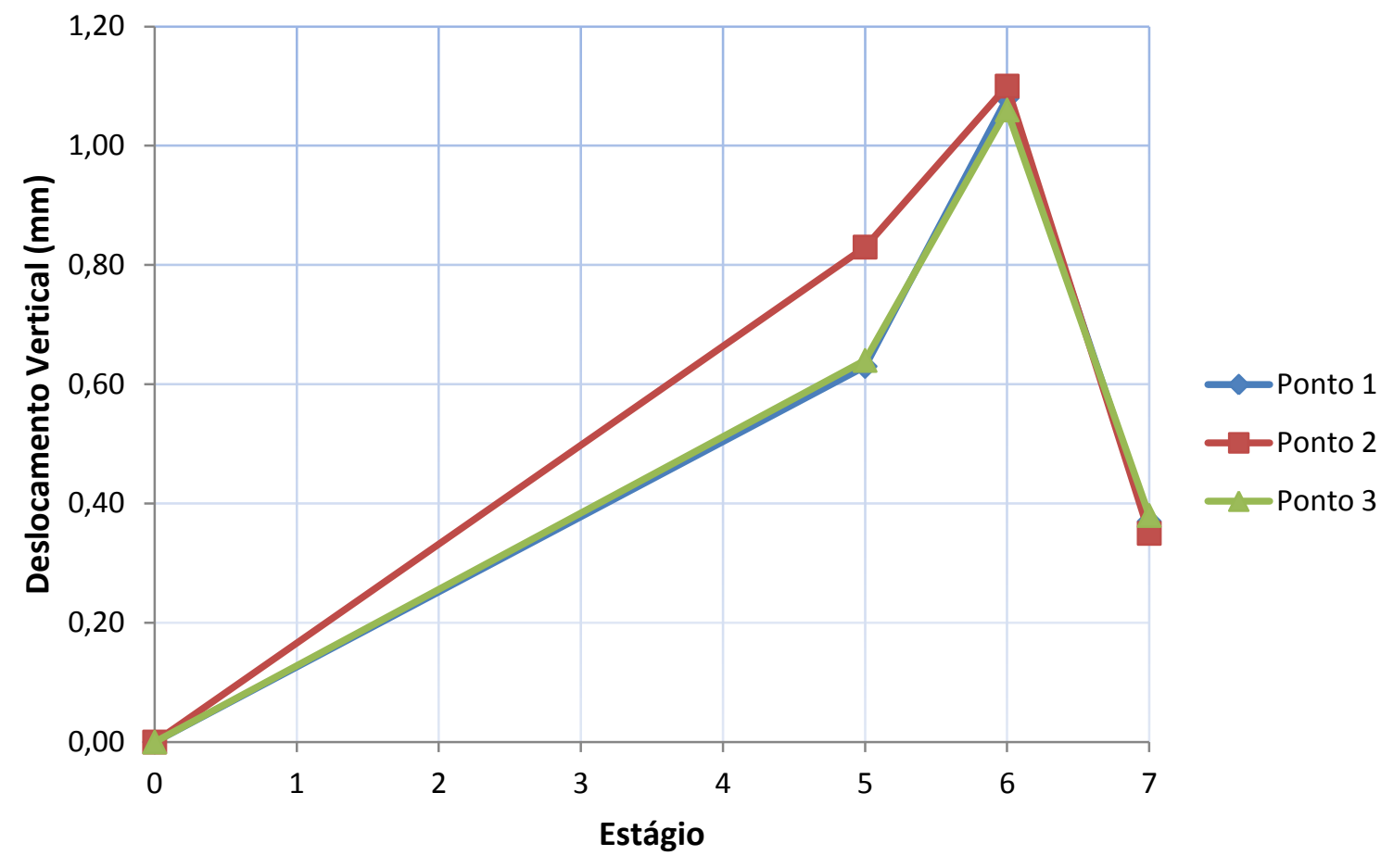

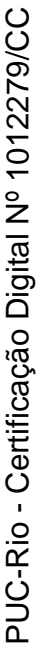

Figura 4.9 - Deslocamento vertical para cada estágio de carregamento.

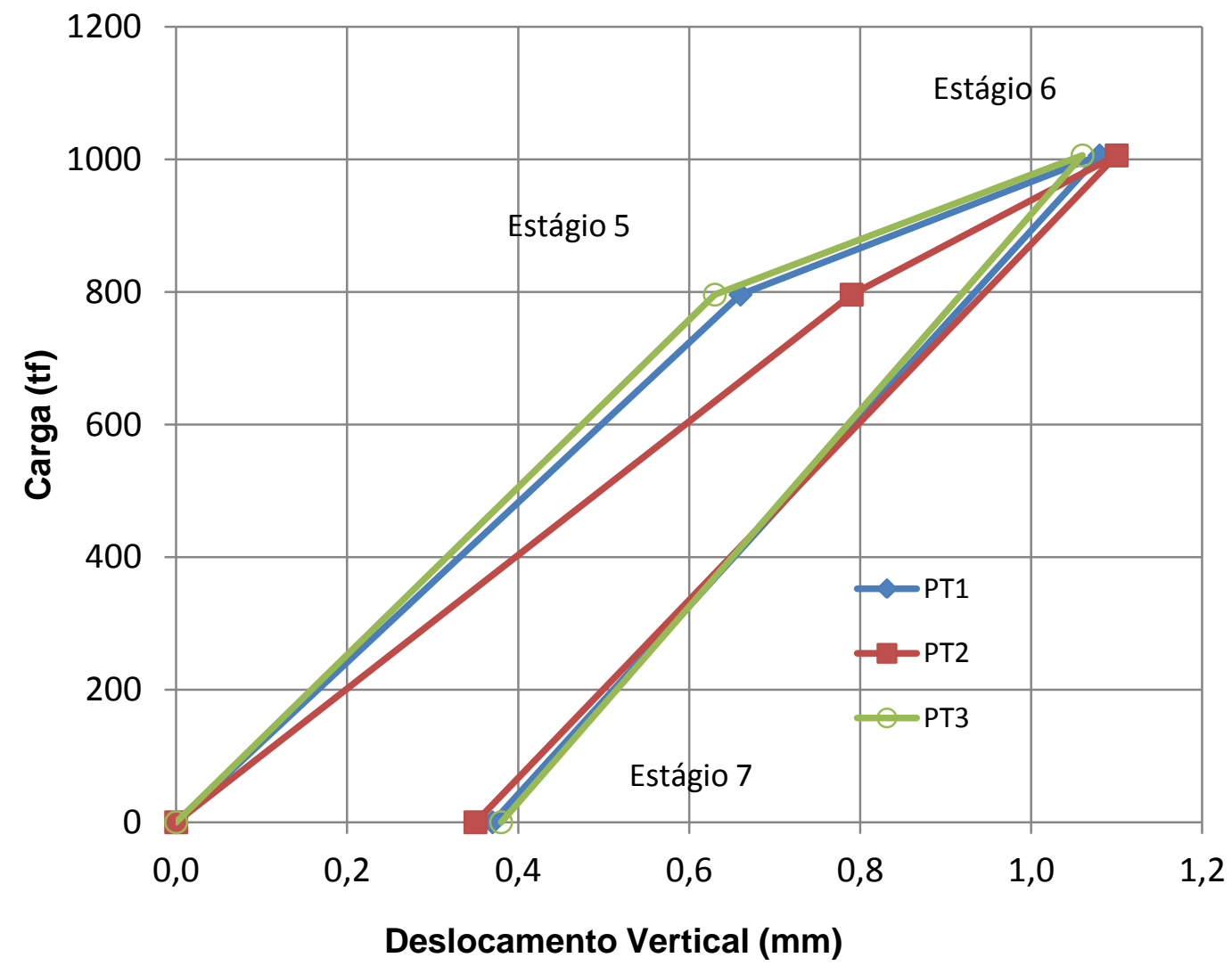

Figura 4.10 - Curva carga $\mathrm{x}$ recalque. 


\section{5.}

\section{Carga nas estacas}

A partir das deformações medidas durante o teste e das propriedades mecânicas do concreto devidamente estimadas, as cargas aplicadas em cada estaca podem ser obtidas e, se somadas às cargas devido ao peso próprio mostradas anteriormente, temos a carga total que atua nas estacas.

A Tabela 4.4 mostra as cargas máximas aplicadas durante o carregamento em cada estaca $\left(P_{q}\right)$, calculadas pela Equação 4.2, e a carga total máxima $\left(P_{t}\right)$ obtida somando a carga devido ao peso próprio $\left(P_{p}\right)$ é mostrada na Tabela 4.5.

\begin{tabular}{|c|c|c|c|}
\hline Estaca & $\boldsymbol{\varepsilon}_{\mathbf{q}}(\mathbf{m m} \backslash \mathbf{m})$ & $\boldsymbol{\sigma}_{\mathbf{q}}(\mathbf{M p a})$ & $\mathbf{P}_{\mathbf{q}} \mathbf{( t f )}$ \\
\hline E2 & 0,101 & 3,4 & 99,5 \\
\hline E3 & 0,085 & 2,9 & 83,8 \\
\hline E47 & 0,063 & 2,1 & 62,1 \\
\hline E48 & 0,068 & 2,3 & 67,0 \\
\hline
\end{tabular}

Tabela 4.4 - Carga atuando nas estacas devido ao carregamento.

\begin{tabular}{|c|c|c|c|}
\hline Estaca & zt $\mathbf{( m m \backslash \mathbf { m } )}$ & ot (Mpa) & $\mathbf{P t}(\mathbf{t f})$ \\
\hline E2 & 0,213 & 7,2 & 210,5 \\
\hline E3 & 0,186 & 6,3 & 183,8 \\
\hline E47 & 0,172 & 5,8 & 170,1 \\
\hline E48 & 0,175 & 5,9 & 171,0 \\
\hline
\end{tabular}

Tabela 4.5 - Carga total atuando nas estacas. 


\section{5 Conclusões e sugestões para trabalhos futuros}

5.1. Conclusões

O objetivo principal deste trabalho foi atingido com sucesso, onde foi verificada a capacidade do cais testado em suportar com segurança um carregamento $10 \%$ superior ao qual será submetido no futuro.

O sistema de aquisição de dados montado se mostrou uma ferramenta importante para descrever o comportamento da estrutura durante o carregamento.

O monitoramento das deformações nas estacas mostrou que o nível de carregamento está abaixo de sua capacidade estrutural, uma vez que a deformação máxima obtida durante o teste foi de $0,213 \mathrm{~mm} / \mathrm{m}$. Um elemento de concreto armado submetido à compressão, assim como as estacas do cais, alcança sua capacidade de carga ao atingir deformação da ordem de $2,0 \mathrm{~mm} / \mathrm{m}$.

As rotações medidas pelos eletroníveis foram de pequena magnitude, com distorção angular máxima da ordem de 1:6000 (EL13) na direção transversal ao carregamento (longitudinal do cais) e de 1:10000 (EL10) na direção longitudinal ao carregamento (transvelsal do cais). A partir destes valores, conclui-se que a laje de $80 \mathrm{~cm}$ do cais se comportou como um bloco rígido, onde a distribuição de cargas entre estacas é maior nas extremidades do que no centro, o que valida a escolha das estacas instrumentadas.

Assim como deformação e rotação, o recalque dos três pontos medidos topograficamente foram de pequena magnitude, onde o valor máximo obtido foi de 1,10 mm no ponto PT2. Analisando a seção formada pelos pontos PT1 a PT3, o recalque diferencial máximo, obtido entre os pontos PT2 e PT3, é de 0,19 mm correspondente ao estágio 5 .

Associando os espaçamentos entre estacas mostrados no Capítulo 3 às rotações obtidas pelos eletroníveis, os recalques diferenciais máximos nas direções transversal e longitudinal ao carregamento são da ordem de 1,0 mm e $0,4 \mathrm{~mm}$, respectivamente. 
Os recalques diferenciais obtidos diretamente a partir da seção monitorada topograficamente, e indiretamente adotando a simplificação de rotação de corpo rígido, apresentaram valores de baixa magnitude, e indicam baixa interação entre estacas para espaçamentos relativos (s/d) de 7,5 e 10,0 nos sentidos transversal e longitudinal do cais, respectivamente.

\section{2.}

\section{Sugestões para trabalhos futuros}

- Instrumentar mais estacas, incluindo uma estaca central para ilustrar a distribuição de carga entre estacas do grupo. Caso o bloco seja uniformemente carregado, instrumentar uma estaca de quina, borda e centro para comparar a distribuição de carregamento;

- Otimizar o posicionamento dos eletroníveis em pontos chave da estrutura onde é esperado maior rotação, como proximidade dos apoios;

- Aperfeiçoar o sistema monitoração dos eletroníveis (SME) para leituras diretas de ângulo, considerando o fator de calibração de cada eletronível. 


\section{Referências Bibliográficas}

ASSOCIAÇÃO BRASILEIRA DE NORMAS TÉCNICAS. NBR 6122: Projeto e Execução de Fundações. Rio de Janeiro, 2010. 91p.

BACELAR, C.J.R. Análises de Recalque em Radiers Estaqueados. 2003. 193p. Tese (Doutorado em Engenharia Civil) - Pontifícia Universidade Católica do Rio de Janeiro - RJ.

COOKE, R.W.; PRICE, G. Strains and Displacements around Friction Piles. Proceedings, $8^{\text {th }}$ International Conference on Soil Mechanics and Foundation Engineering, Moscow, 1973. Vol. 2.1, pp. 53-60.

COOKE, R.W. The Settlement of Friction Pile Foundations. Proceedings of the Conference on Tall Buildings, Kuala Lumpur, 1974. No. 3, pp. 7-19.

COOKE, R.W.; PRICE, G.; TARR, K. Jacked Piles in London Clay: A Study of Load Transfer and Settlement under Working Conditions. Geotechnique, Vol. 29, No. 2, 1979, pp. $113-147$.

COOKE, R.W.; PRICE, G.; TARR, K. Jacked Piles in London Clay: Interaction and Group Behaviour under Working Conditions. Geotechnique, Vol. 30, No. 2, 1980, pp. $97-136$.

\section{EUROCODE 2: Design of Concrete Structures.}

GOOSSENS, D.; VAN IMPE, W.F. Long Term Settlements of a Pile Group Foundation in Sand, Overlaying in Clayey Layer. Proceedings, $10^{\text {th }}$ European Conference on Soil Mechanics and Foundation Engineering, Firenze, 1991.

HOFFMANN, K. Applying the Wheatstone Bridge Circuit. HBM.

MANDOLINI, A.; VIGGIANI, C. Settlement of piled foundations. Geotechnique, Vol. 47, No. 4, 1997, pp. 791-816 (apud POULOS, 2005).

MARINHO, F.A.M. Características de deformabilidade do solo residual do campo experimental II da PUC/RJ obtidas a partir de ensaios triaxiais axissimétricos. 1986. Dissertação (Mestrado em Engenharia Civil) - Pontifícia Universidade Católica do Rio de Janeiro - RJ.

POULOS, H.G.; DAVIS, E.H. Pile Foundation Analysis and Design. John Wiley \& Sons, 1980.

POULOS, H.G. Modified Calculation of Pile-Group Settlement Interaction. Journal of Geotechnical Engineering, Vol. 114, No. 6, 1988, p.p. 697 - 706.

POULOS, H.G. Common Procedures for Foundation Settlement Analysis Are They Adequate?. Proceedings, $8^{\text {th }}$ Australia New Zeland Conference on Geomechanics, Hobart, 1999, p. 3- 25. 
POULOS, H.G. Pile Group Settlement Estimation - Research to Practice. Proceedings of Sessions of GeoShanghai, Shanghai, 2005, pp. $1-22$.

PRICE, G.; WARDLE, I.F.; ROCHA FILHO, P. Development of an improved load cell for construction work. Field Measurements in Geomechanics, Oslo, 2003, p. $605-612$.

RAMOS, D.T. Aplicação de Eletroníveis para Obtenção das Deflexões e dos Momentos Fletores da Face de Concreto de Barragens de Enrocamento. 2009. 148p. Dissertação (Mestrado em Engenharia Civil) - Pontifícia Universidade Católica do Rio da Janeiro - RJ.

RANDOLPH, M.F. Design methods for pile groups and piled rafts. Proceedings, 13th International Conference on Soil Mechanics and Foundation Engineering, Nova Deli, 1994. No. 5, pp. 61-82 (apud POULOS, 2005).

ROCHA FILHO, P.; ROMANEL, C. Análise do Recalque de Fundações Profundas. GEOSUL, Porto Alegre, 1998, p. $45-78$.

ROCHA FILHO, P. Slab deflection of a concrete faced rockfill dam. Dam Engineering - Journal of the British Dam Society, Vol. VI Issue 3, setembro, 1995. pp. $185-197$.

ROCHA FILHO, P; PRICE, G. Curso: Instrumentação em Engenharia Geotécnica - Aplicação da Técnica de Eletroníveis. Sociedade Portuguesa de Geotecnia, 2000. 45p.

ROCHA FILHO, P. Behaviour of a large diameter pile in a sandstone. Field Measurements in Geomechanics, Oslo, 2003, p. $299-306$.

TECNOSOLO S.A. Relatório de sondagens ER-1504. 1980.

VESIC, A.B. Beams on Elastic Subgrade and the Winkler's Hypothesis. Proceedings, $5^{\text {th }}$ International Conference of Soil Mechanics, 1963, pp. $845-850$ (apud POULOS, 1998).

ZHEMCHUZHNIKOV, A. Análise Comparativa dos Diversos Métodos da Previsão do Recalque de Grupo de Estacas no Meio Homogêneo. 2011. 130p. Dissertação (Mestrado em Engenharia Civil) - Pontifícia Universidade Católica do Rio de Janeiro - RJ. 
Apêndice 1

Curvas de calibração dos eletroníveis EL01 a EL16 
72

Apêndice 1

Curvas de calibração dos eletroníveis EL01 a EL16

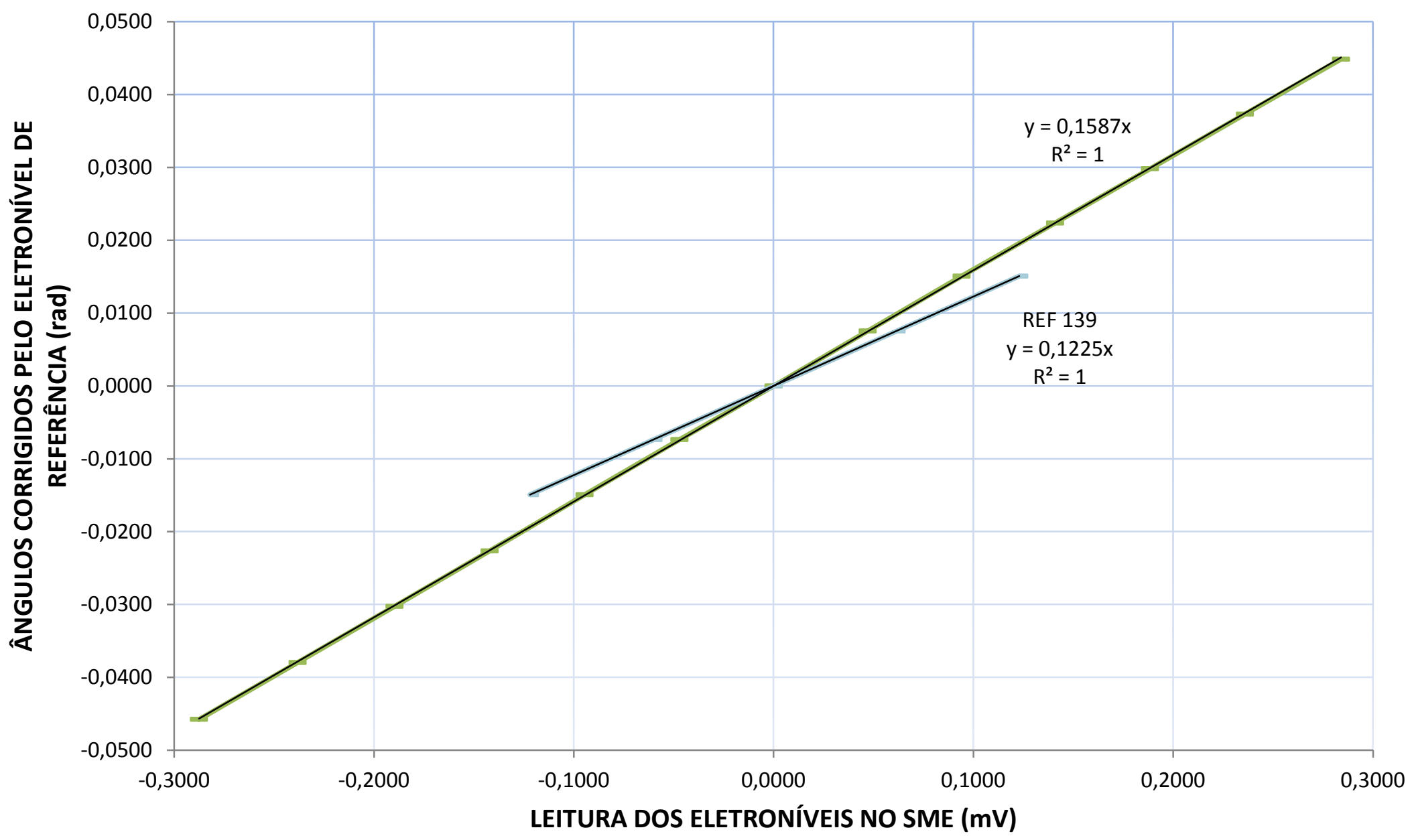

Figura A1.1 - Curva de calibração do eletronível EL01. 
73

Apêndice 1

Curvas de calibração dos eletroníveis EL01 a EL16

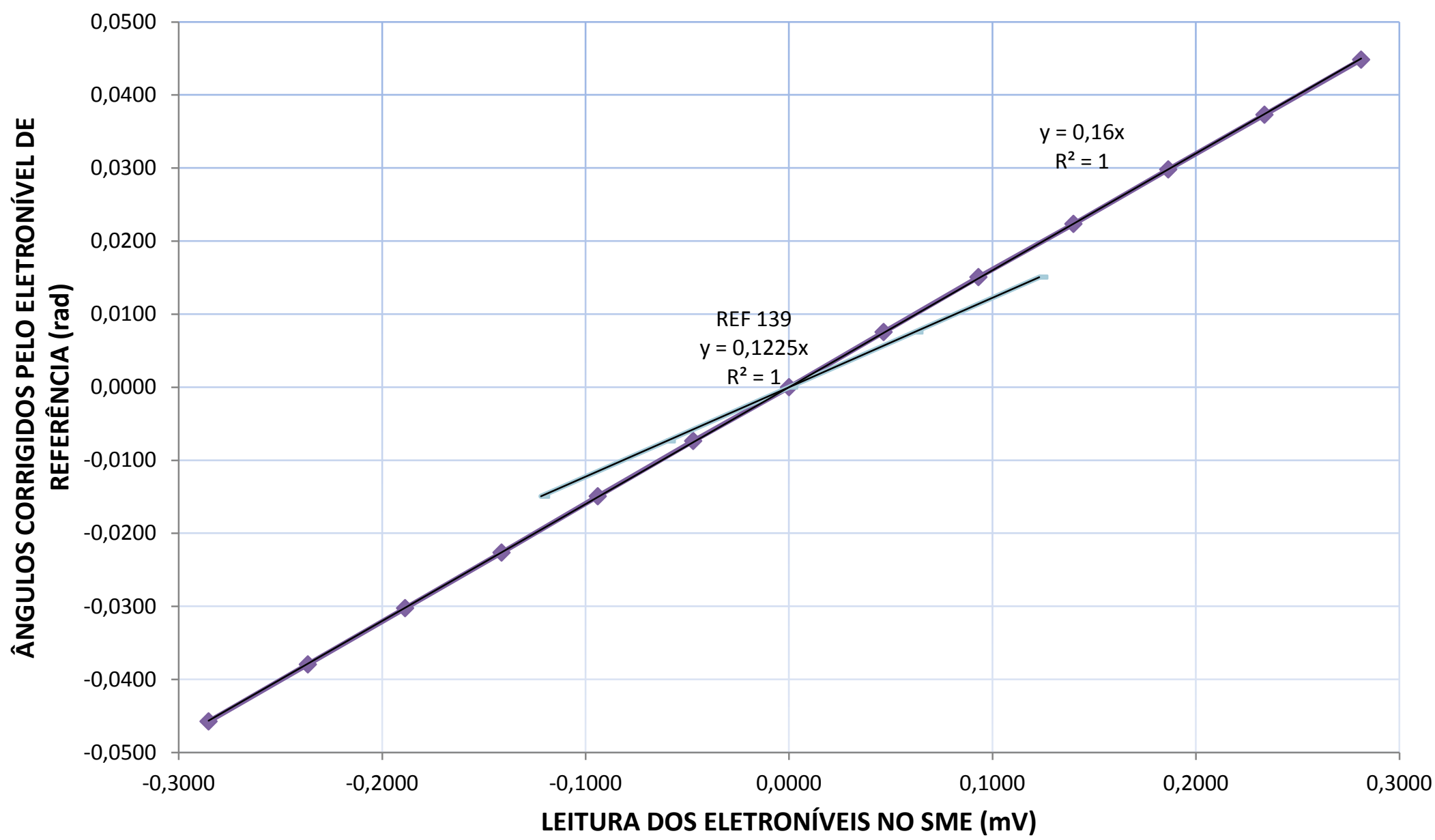

Figura A1.2 - Curva de calibração do eletronível EL02. 
Apêndice 1

Curvas de calibração dos eletroníveis EL01 a EL16

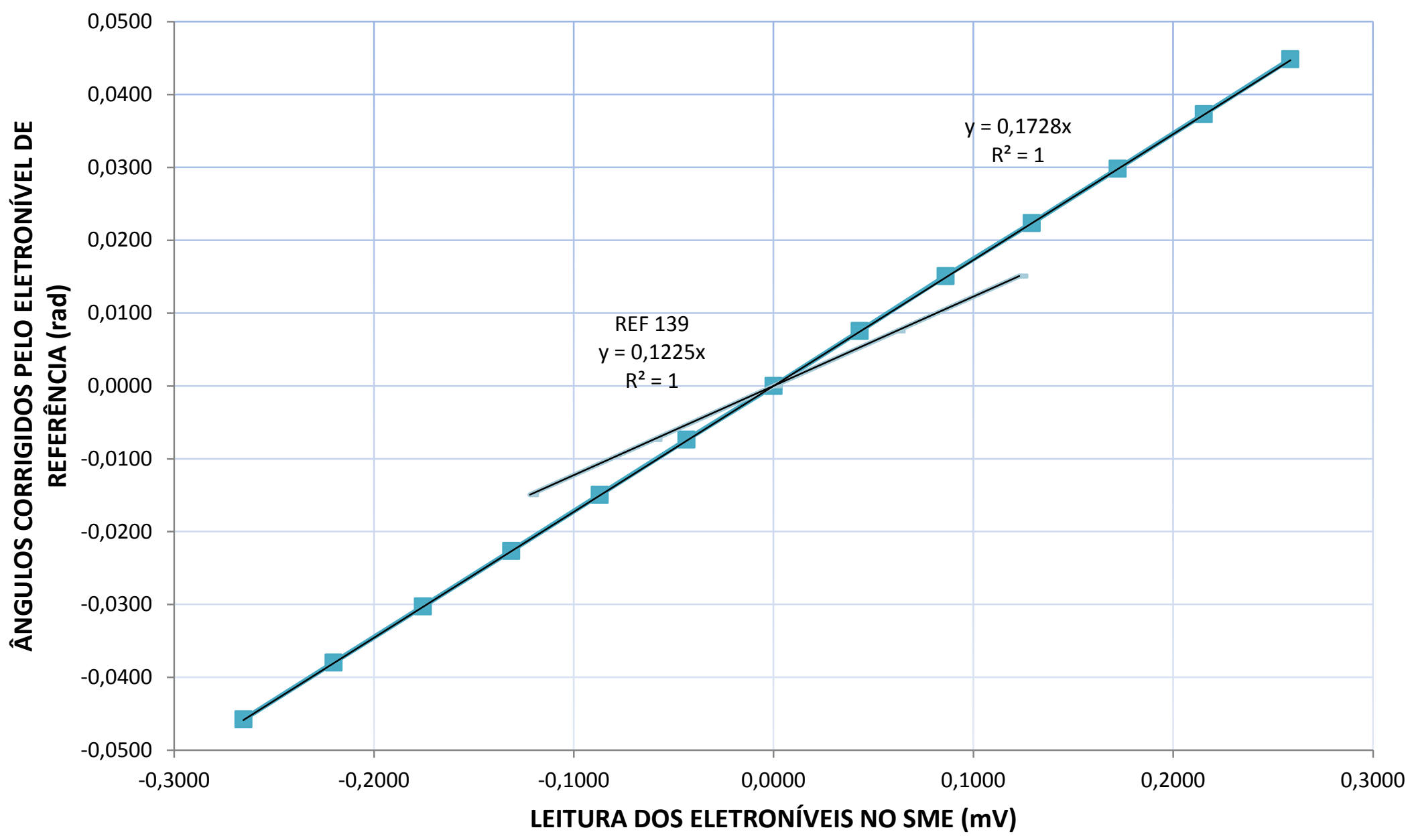

Figura A1.3 - Curva de calibração do eletronível EL03. 
75

Apêndice 1

Curvas de calibração dos eletroníveis EL01 a EL16

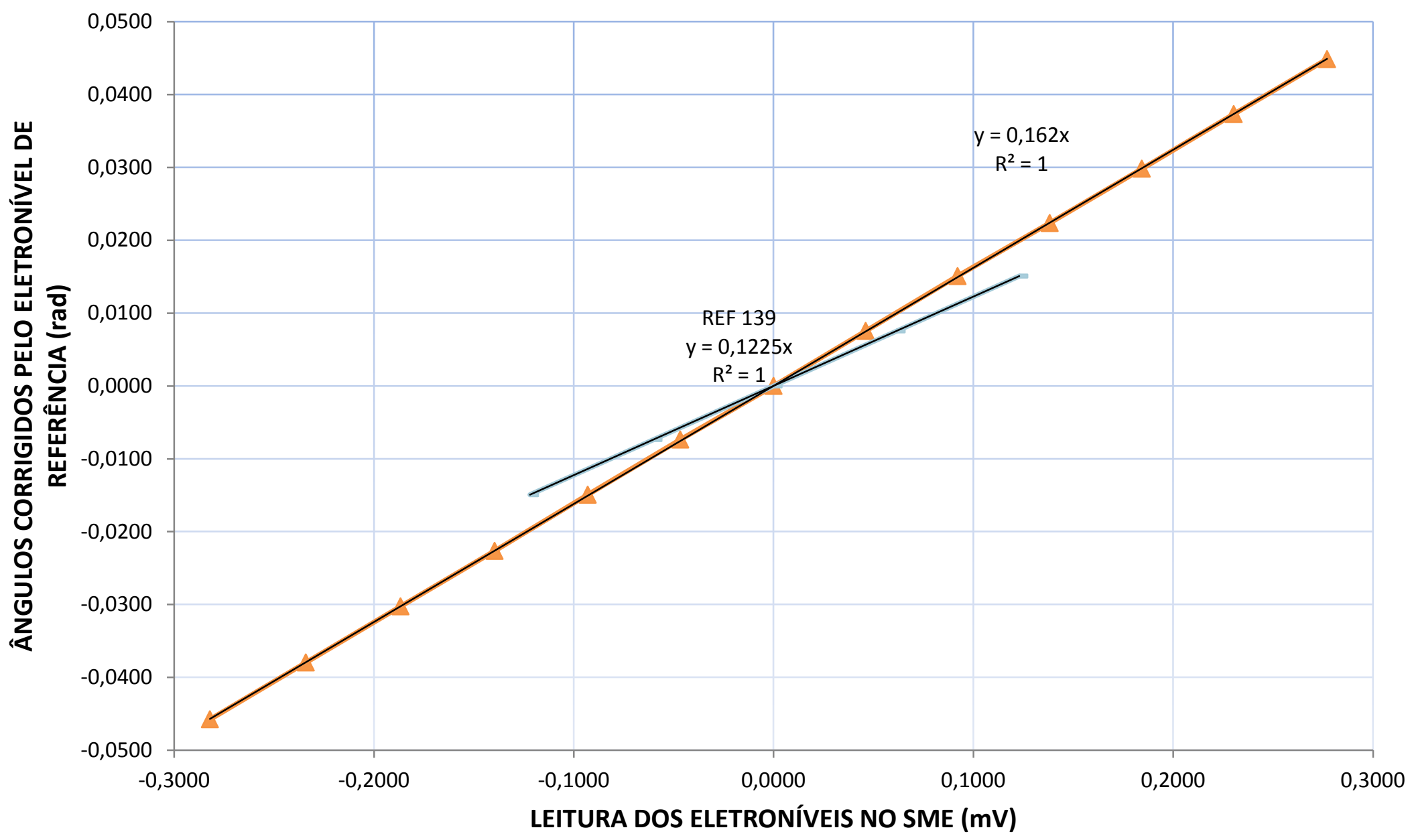

Figura A1.4 - Curva de calibração do eletronível EL04. 
76

Apêndice 1

Curvas de calibração dos eletroníveis EL01 a EL16

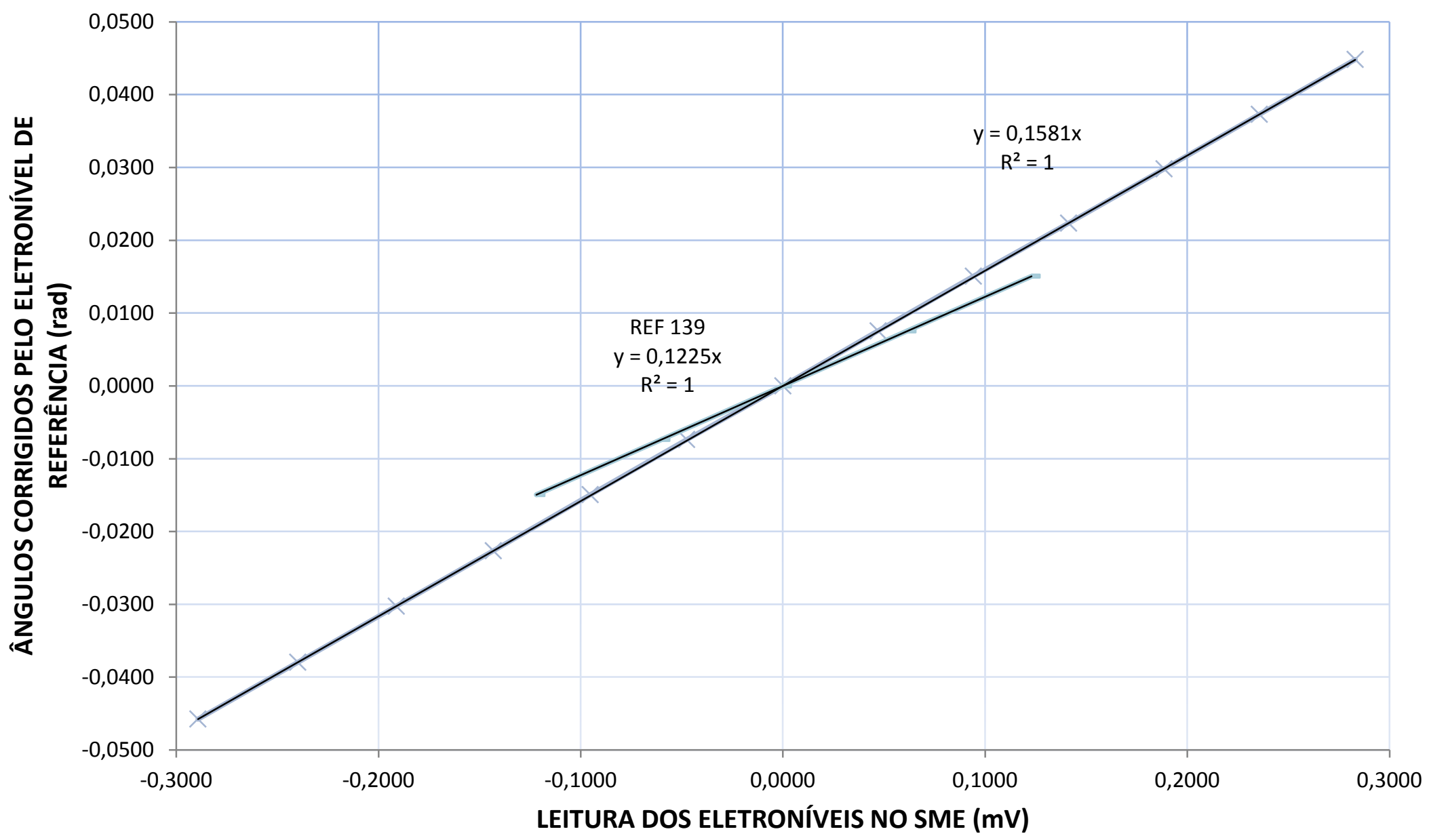

Figura A1.5 - Curva de calibração do eletronível EL05. 
77

Apêndice 1

Curvas de calibração dos eletroníveis EL01 a EL16

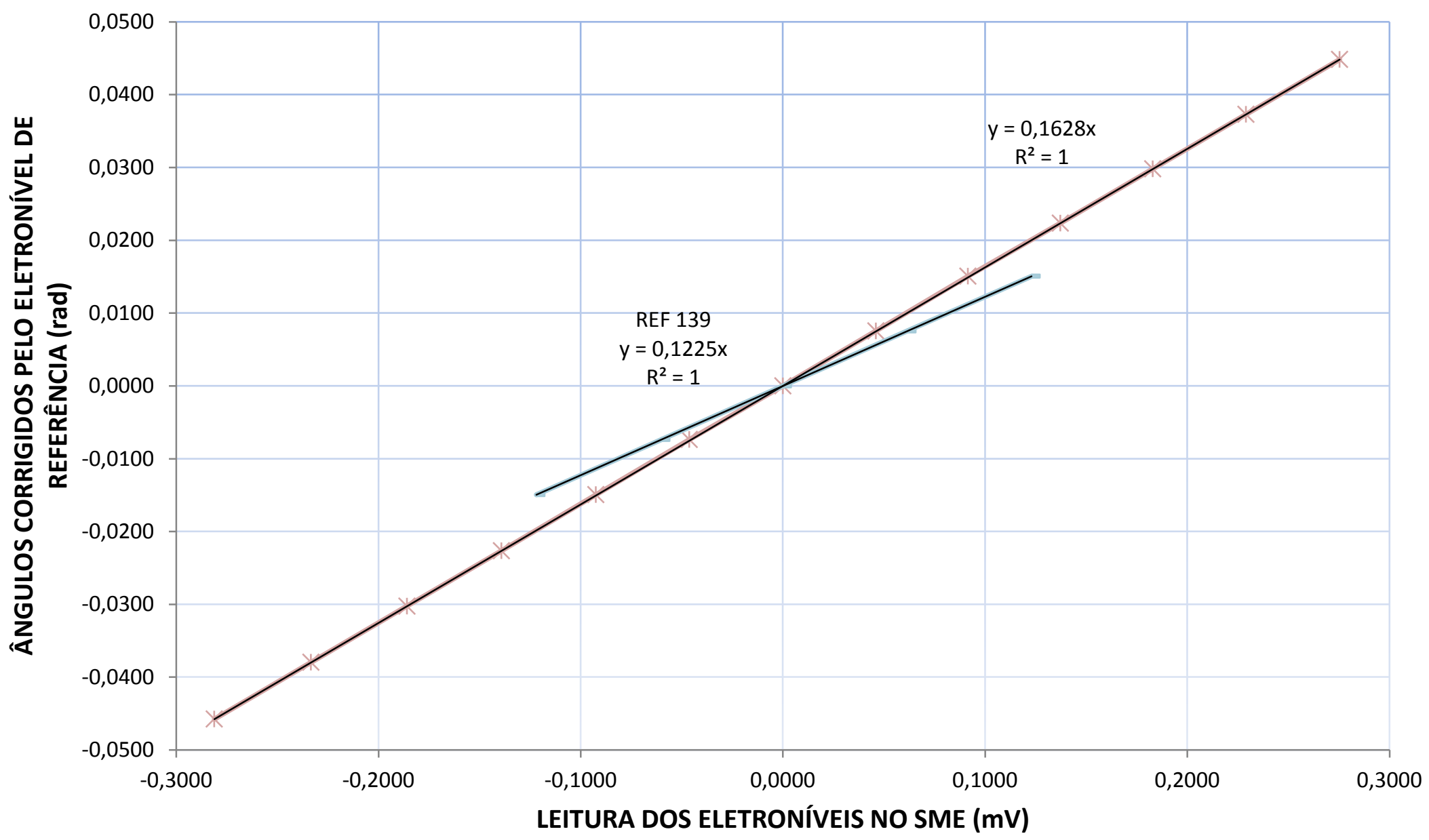

Figura A1.6 - Curva de calibração do eletronível EL06. 
Apêndice 1

Curvas de calibração dos eletroníveis EL01 a EL16

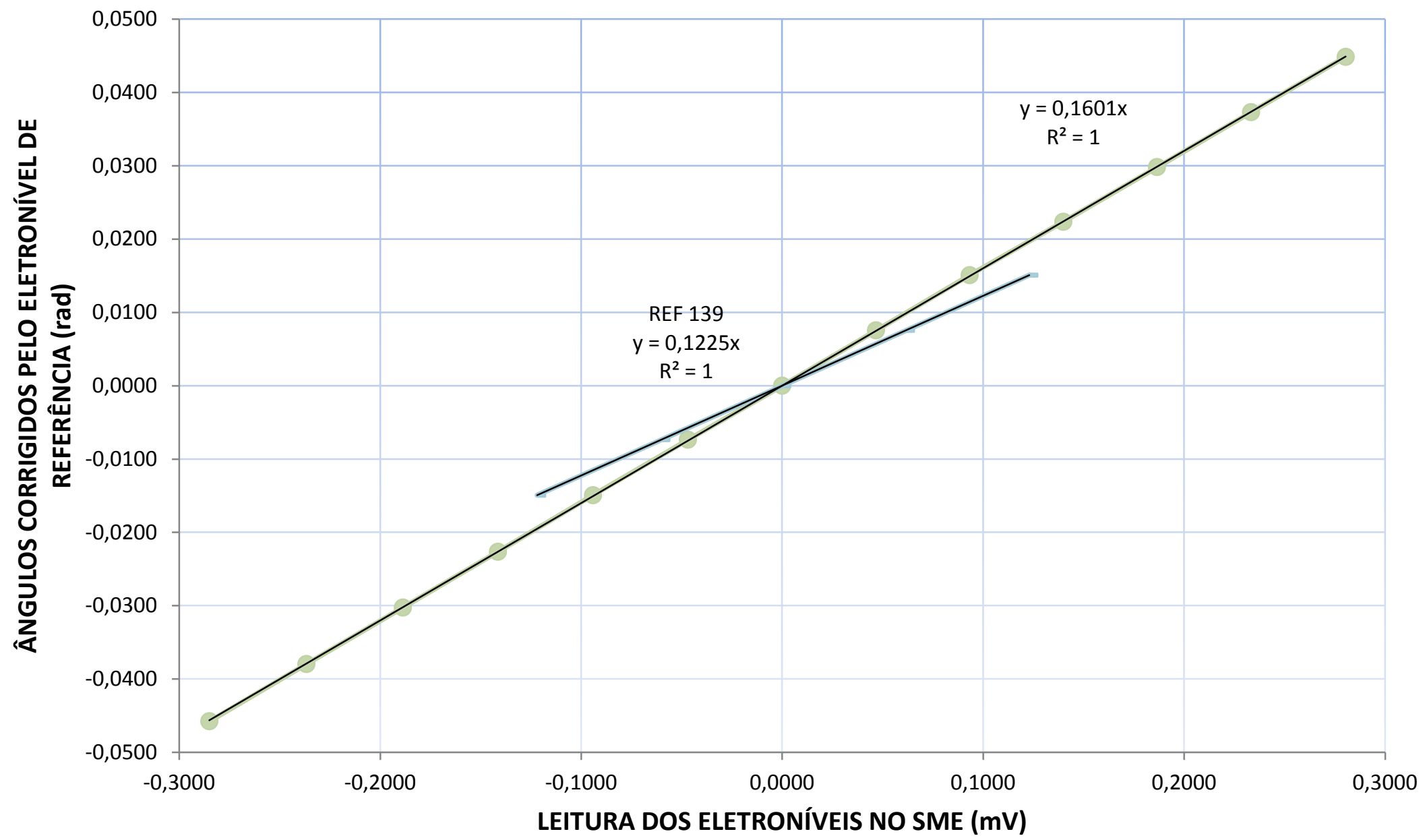

Figura A1.7 - Curva de calibração do eletronível EL07. 
79

Apêndice 1

Curvas de calibração dos eletroníveis EL01 a EL16

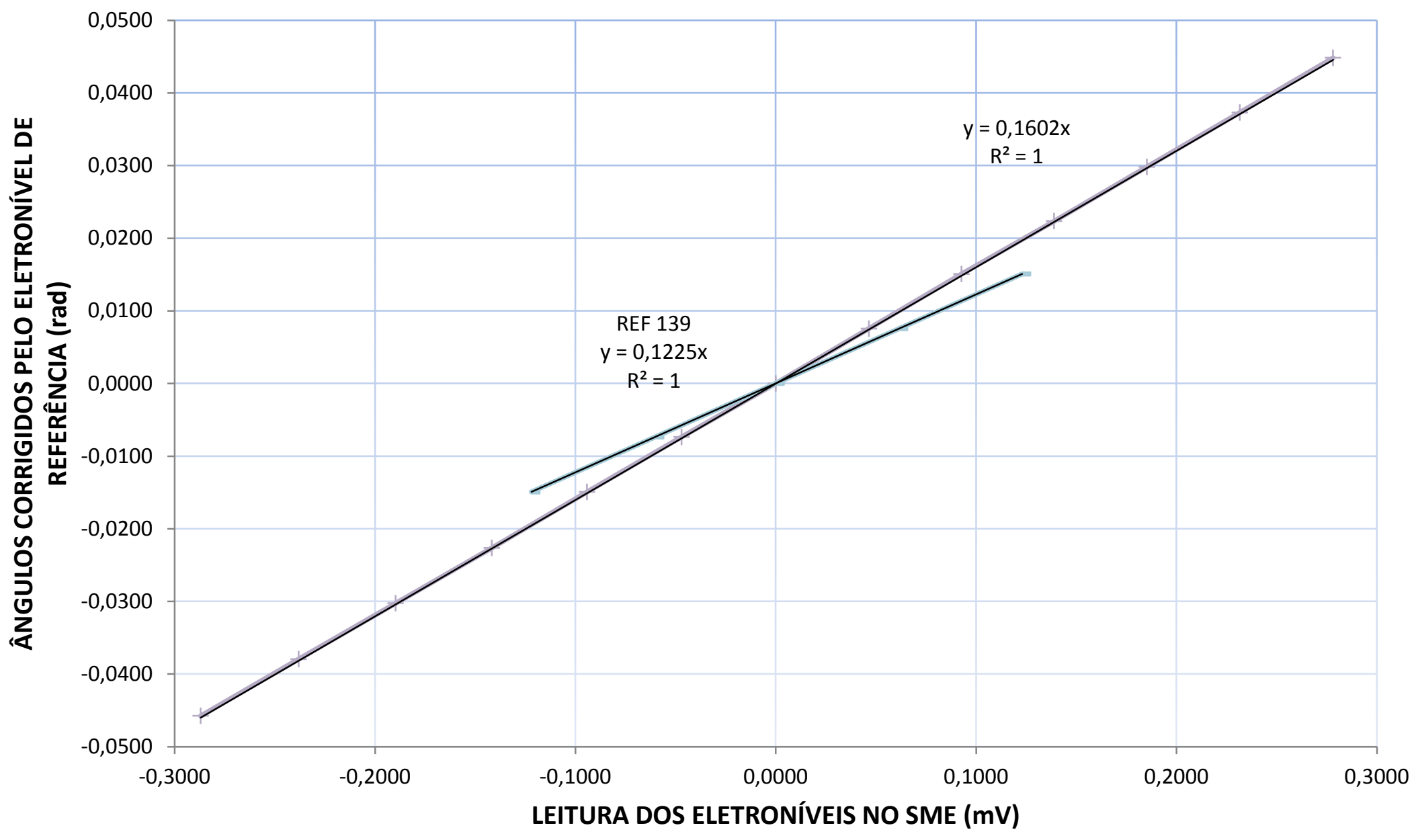

Figura A1.8 - Curva de calibração do eletronível EL08. 
Apêndice 1

Curvas de calibração dos eletroníveis EL01 a EL16

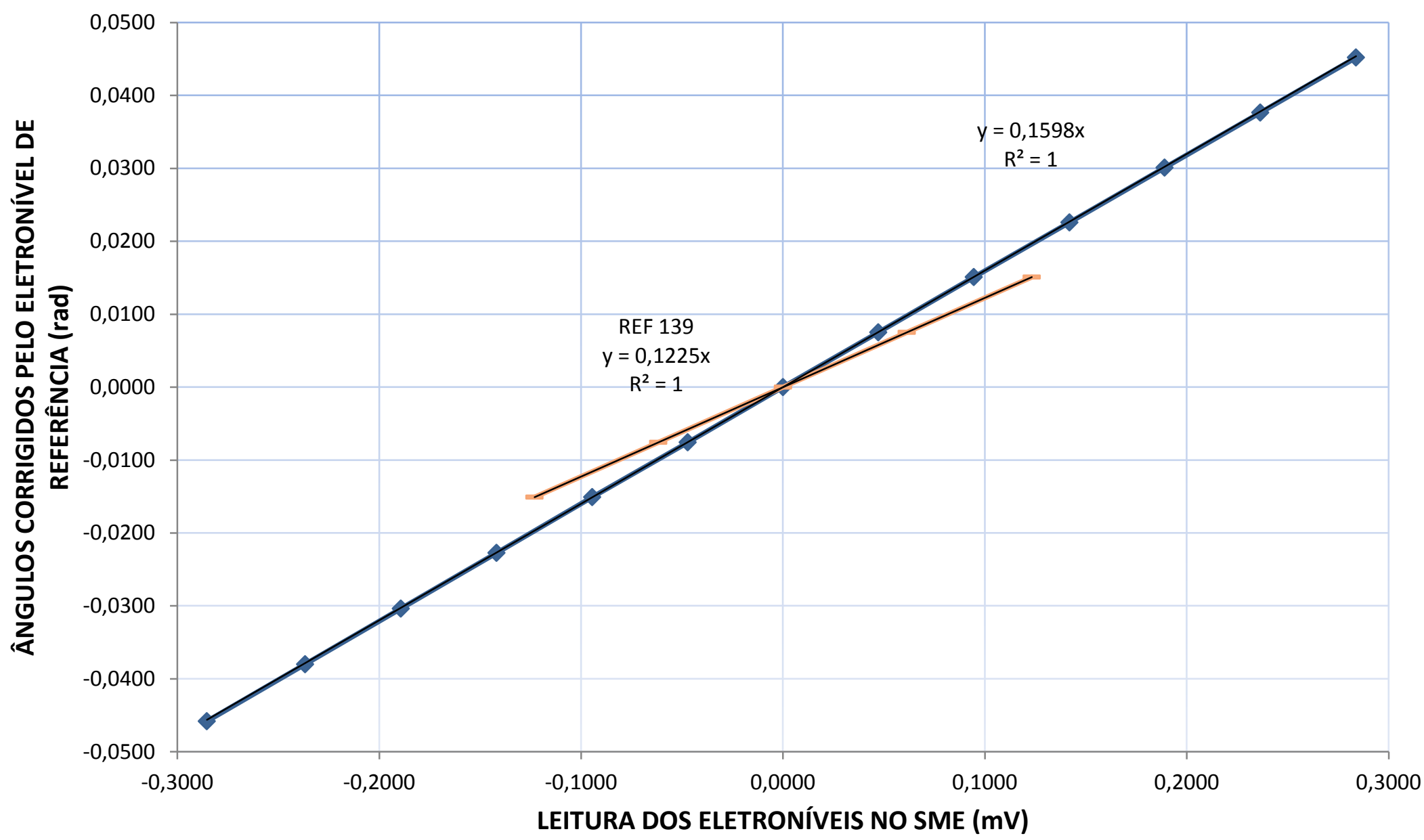

Figura A1.9 - Curva de calibração do eletronível EL09. 
81

Apêndice 1

Curvas de calibração dos eletroníveis EL01 a EL16

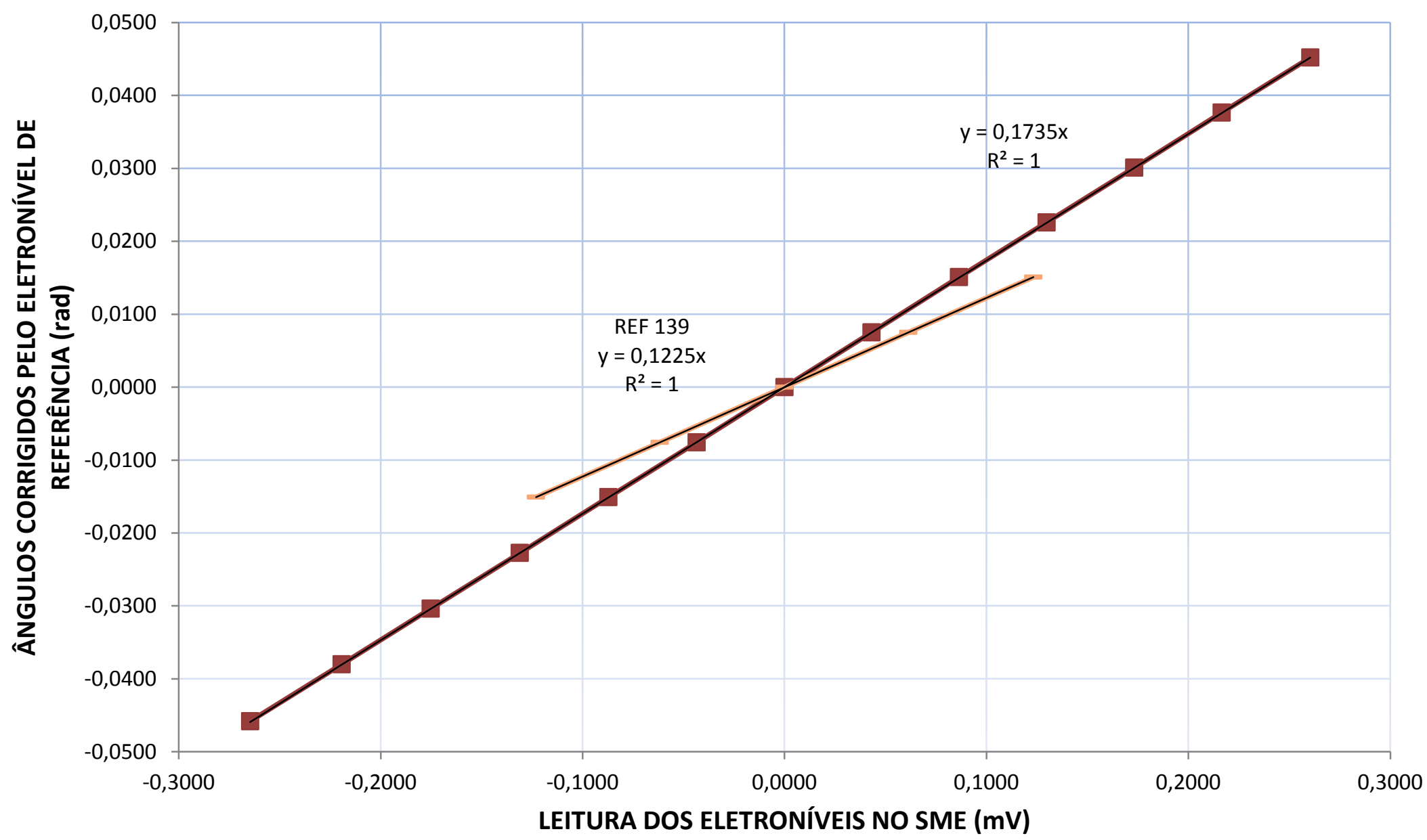

Figura A1.10 - Curva de calibração do eletronível EL10. 
82

Apêndice 1

Curvas de calibração dos eletroníveis EL01 a EL16

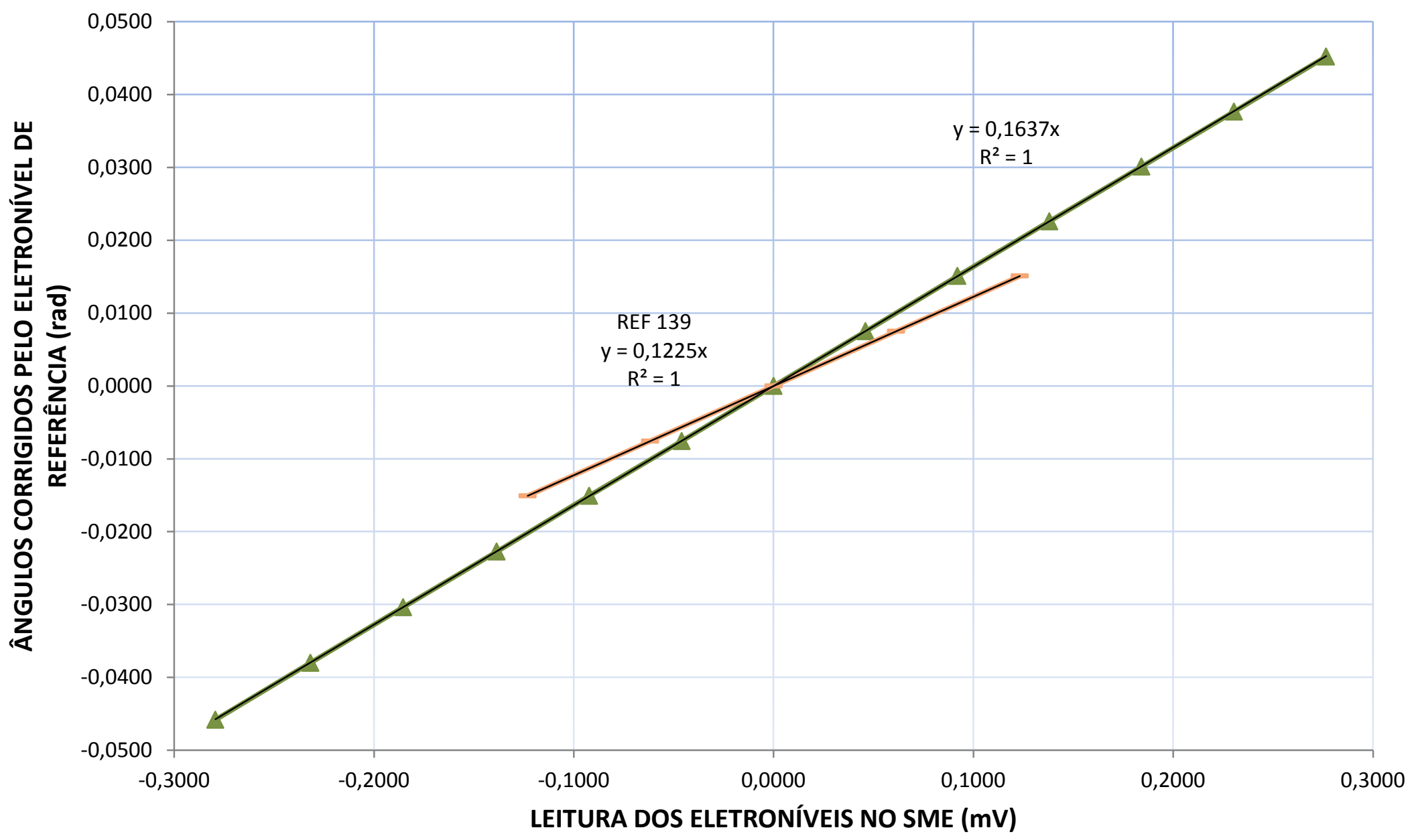

Figura A1.11 - Curva de calibração do eletronível EL11. 
Apêndice 1

Curvas de calibração dos eletroníveis EL01 a EL16

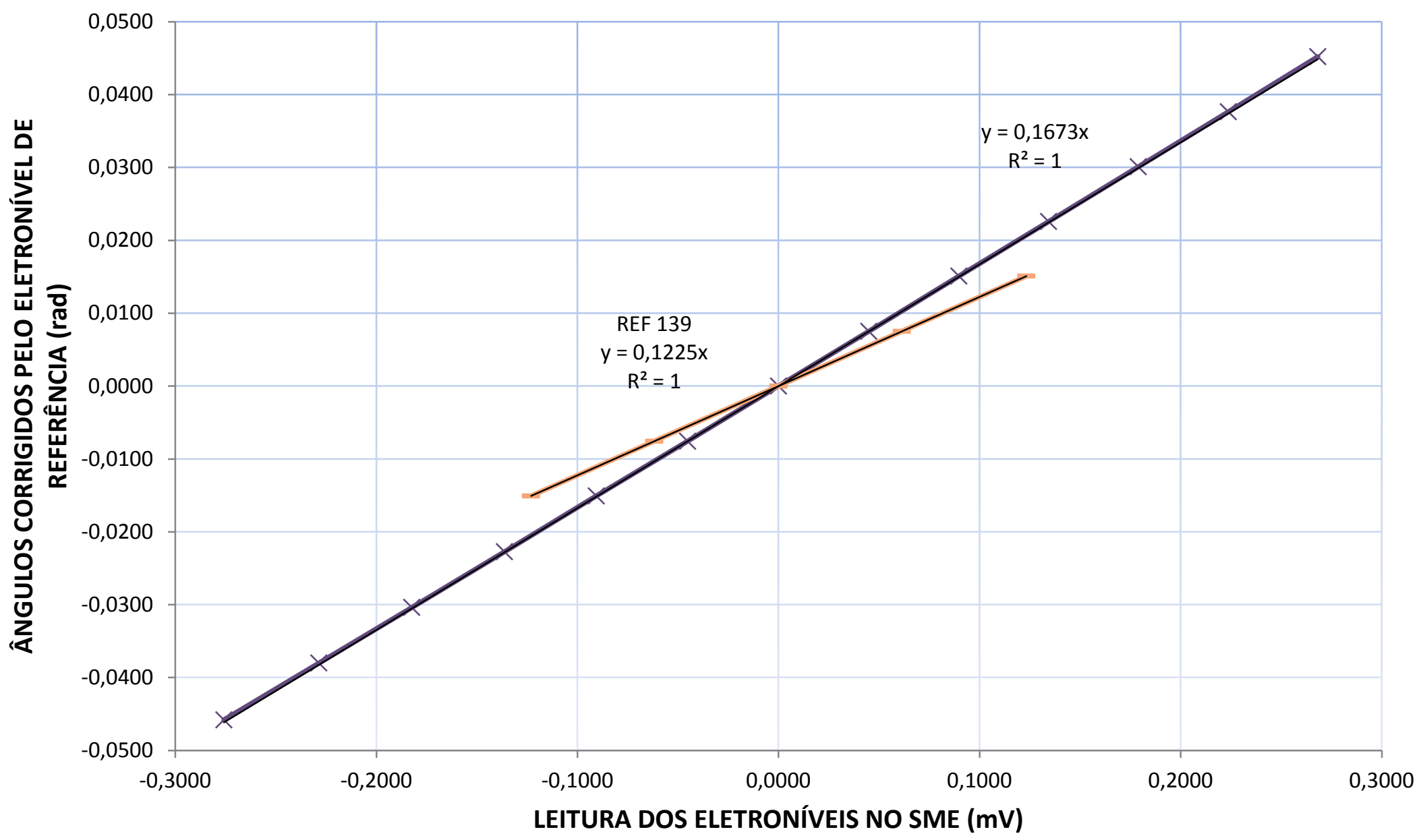

Figura A1.12 - Curva de calibração do eletronível EL12. 
Apêndice 1

Curvas de calibração dos eletroníveis EL01 a EL16

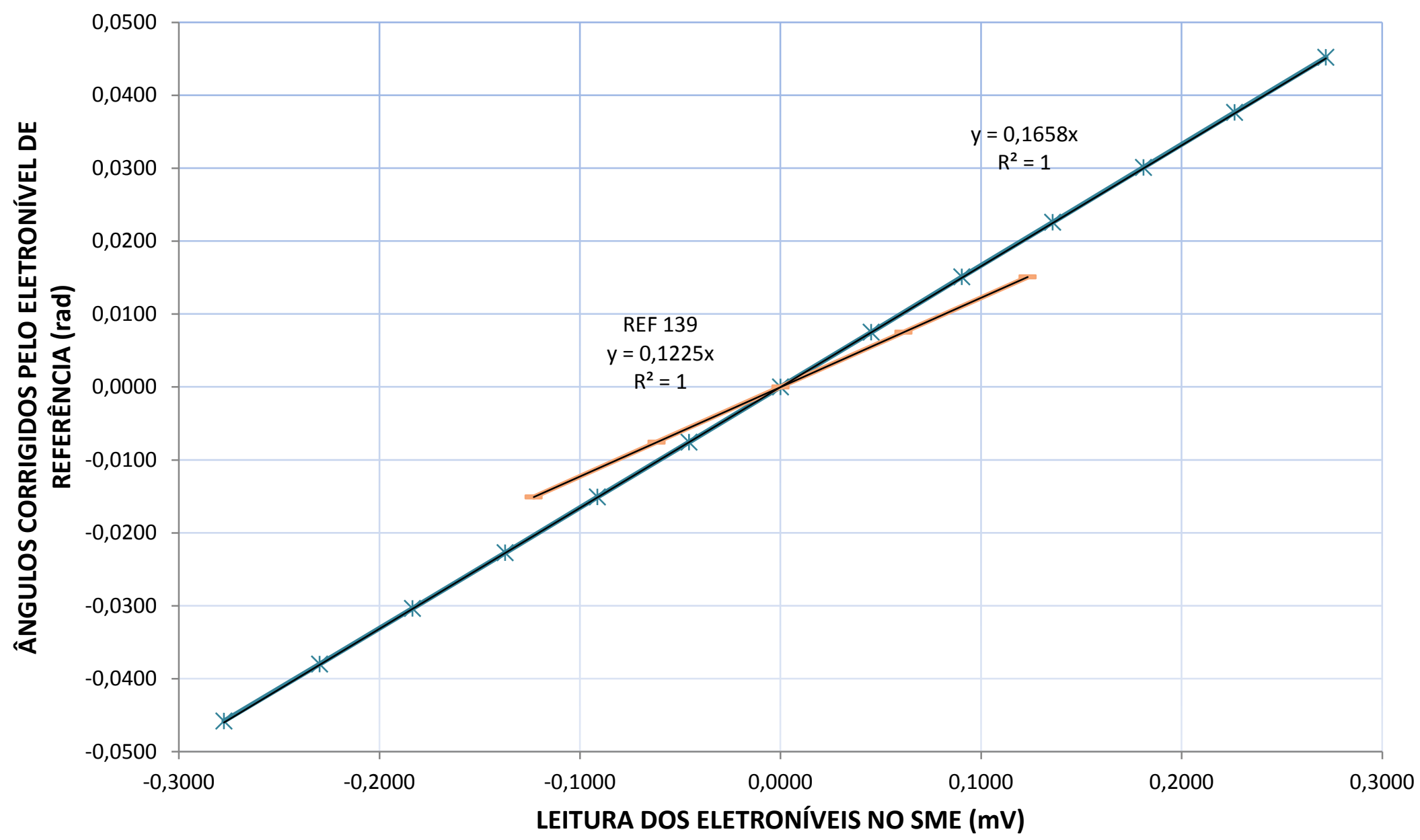

Figura A1.13 - Curva de calibração do eletronível EL13. 
85

Apêndice 1

Curvas de calibração dos eletroníveis EL01 a EL16

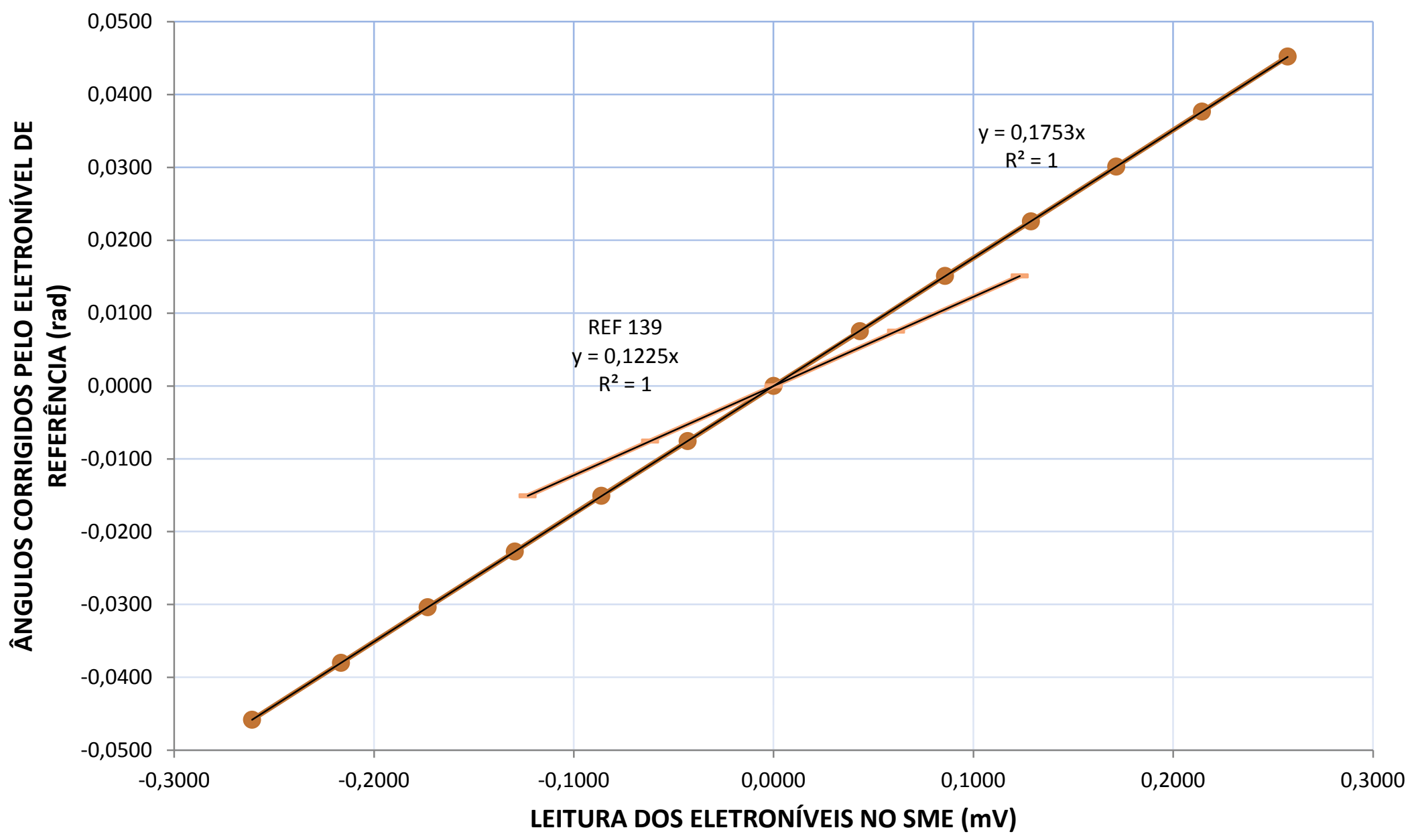

Figura A1.14 - Curva de calibração do eletronível EL14. 
Apêndice 1

Curvas de calibração dos eletroníveis EL01 a EL16

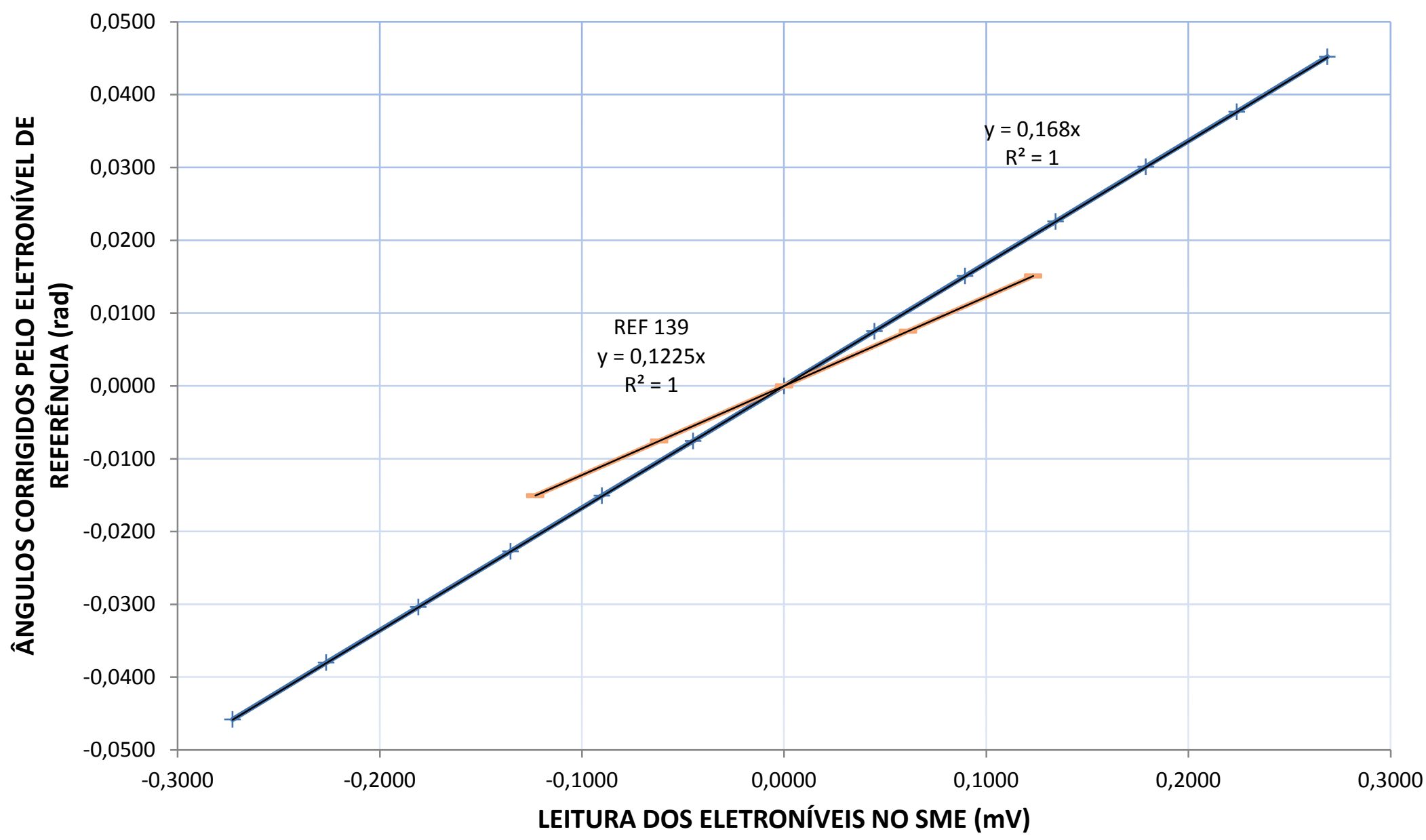

Figura A1.15 - Curva de calibração do eletronível EL15. 
Apêndice 1

Curvas de calibração dos eletroníveis EL01 a EL16

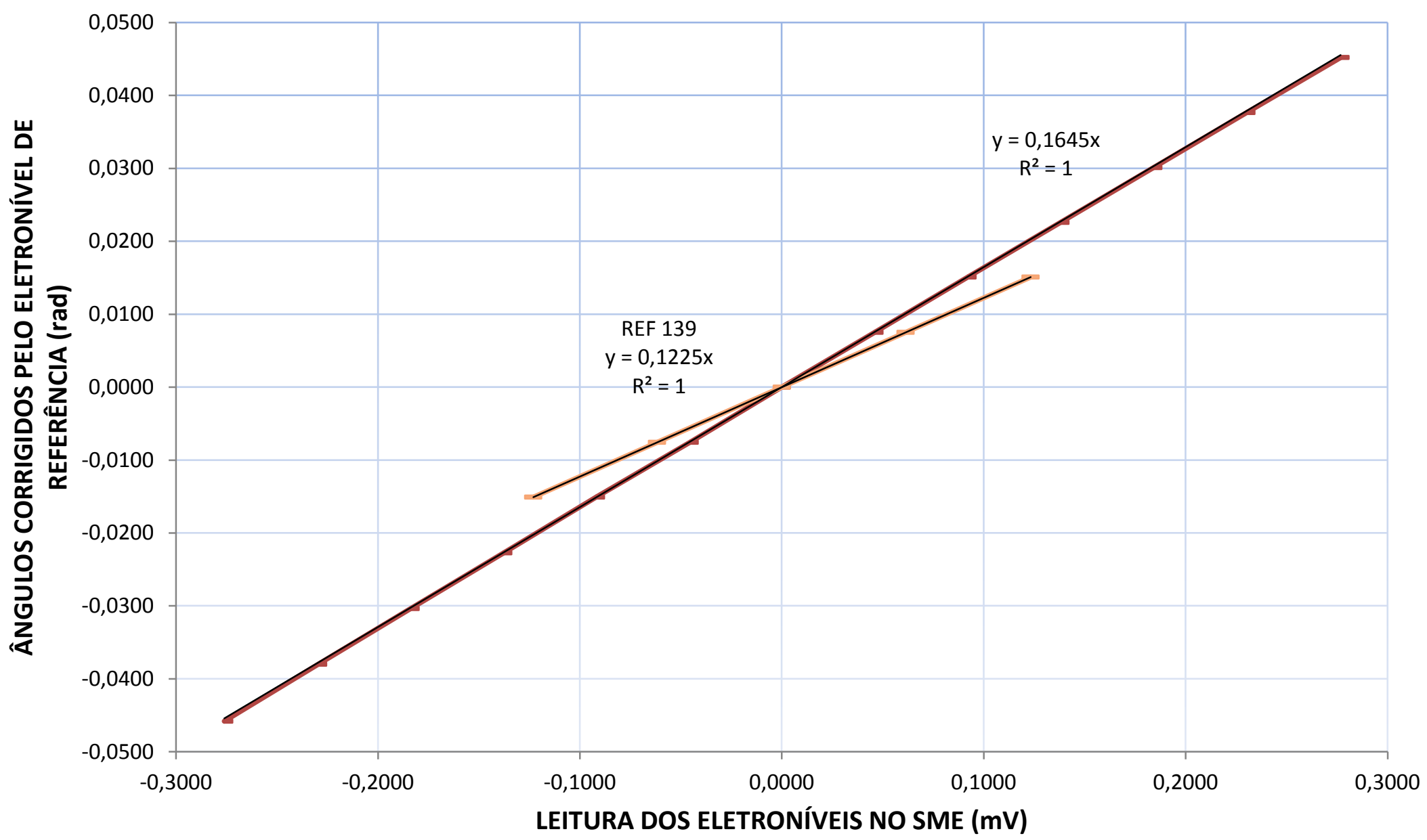

Figura A1.16 - Curva de calibração do eletronível EL16. 
Apêndice 2

Leituras dos eletroníveis EL01 a EL16 
Apêndice 2

Leituras dos eletroníveis EL01 a EL16

\section{EL01}

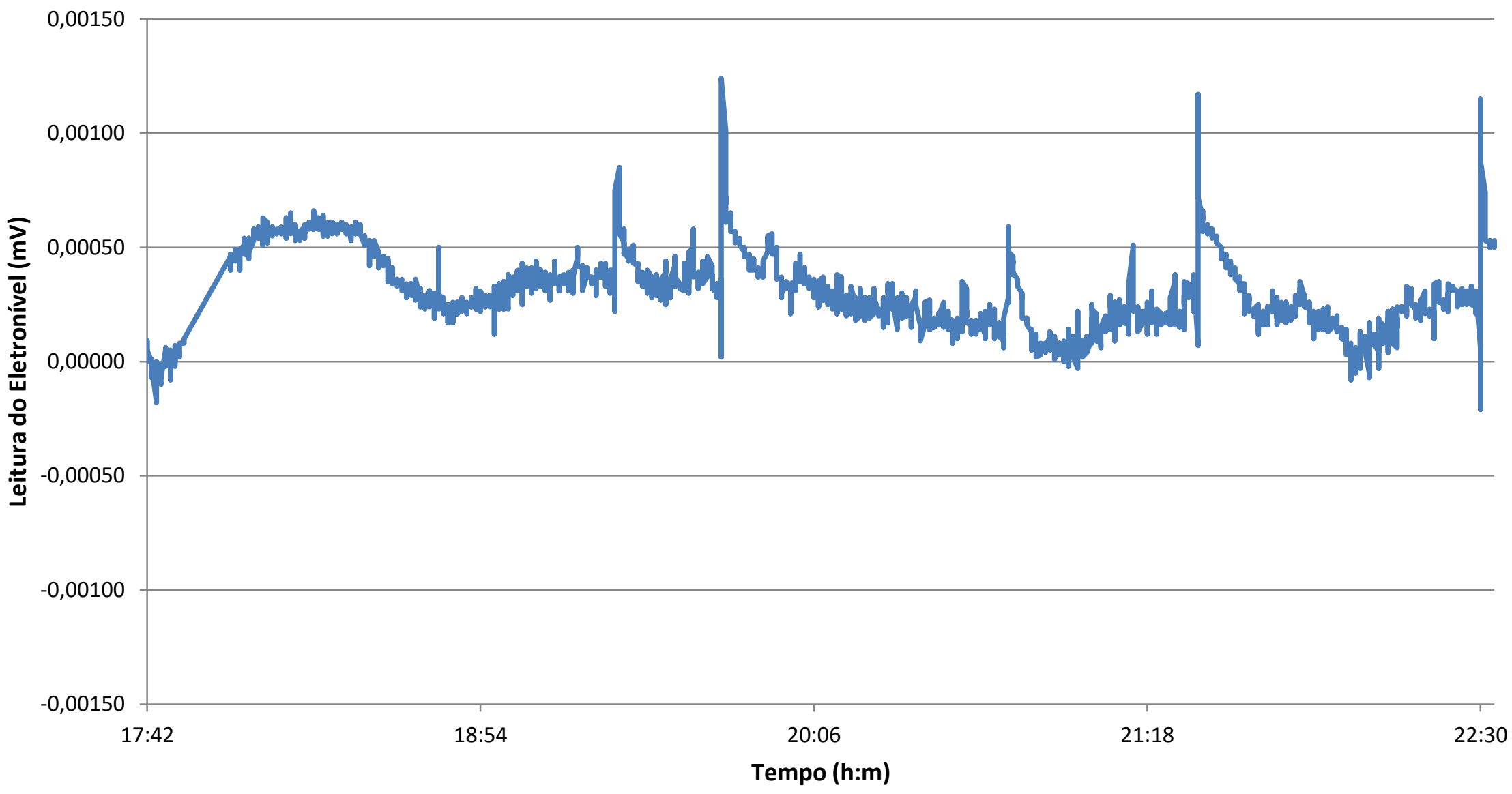

Figura A2.1 - Leituras do eletronível EL01. 
Apêndice 1

Curvas de calibração dos eletroníveis EL01 a EL16

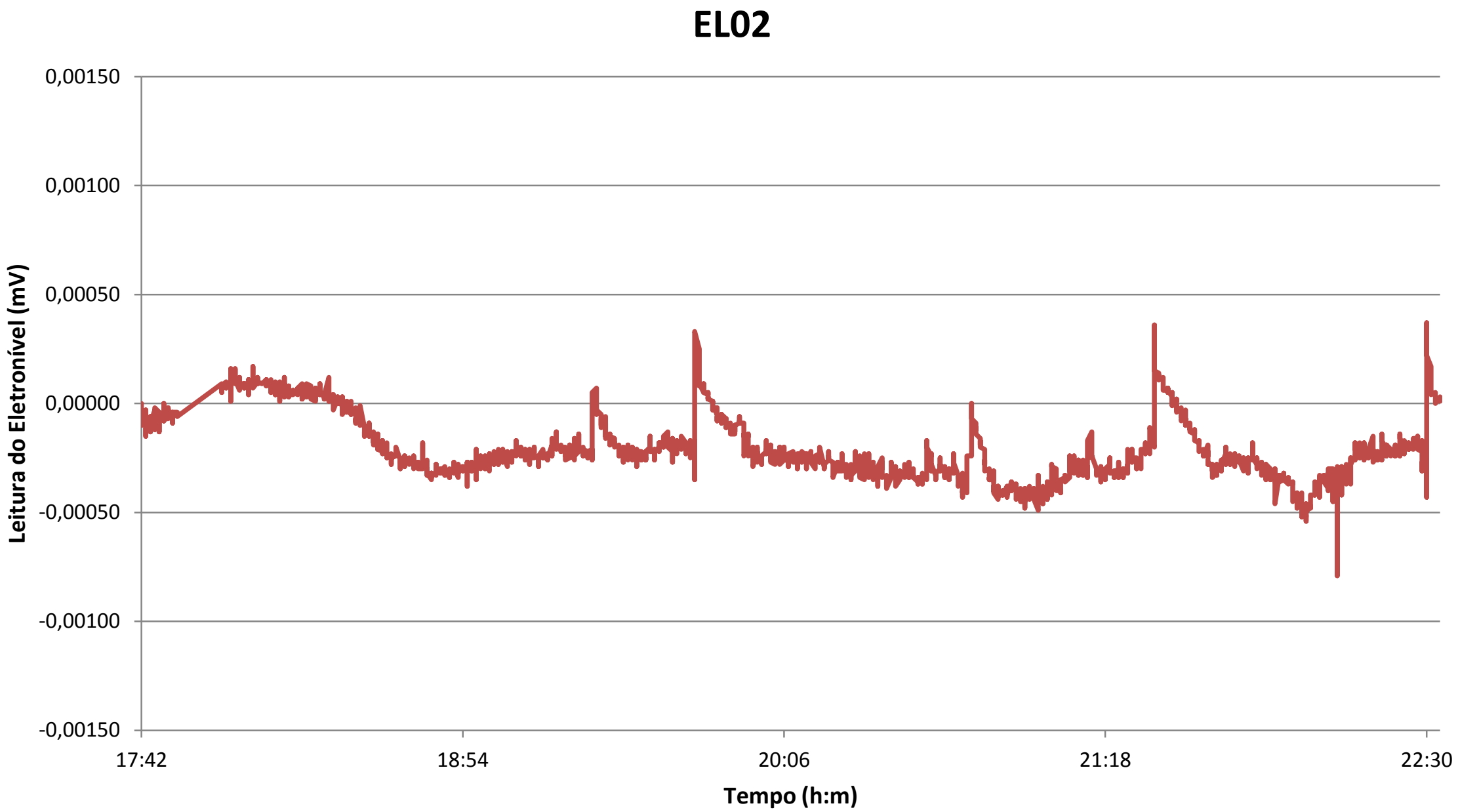

Figura A2.2 - Leituras do eletronível EL02. 
Apêndice 1

Curvas de calibração dos eletroníveis EL01 a EL16

\section{EL03}

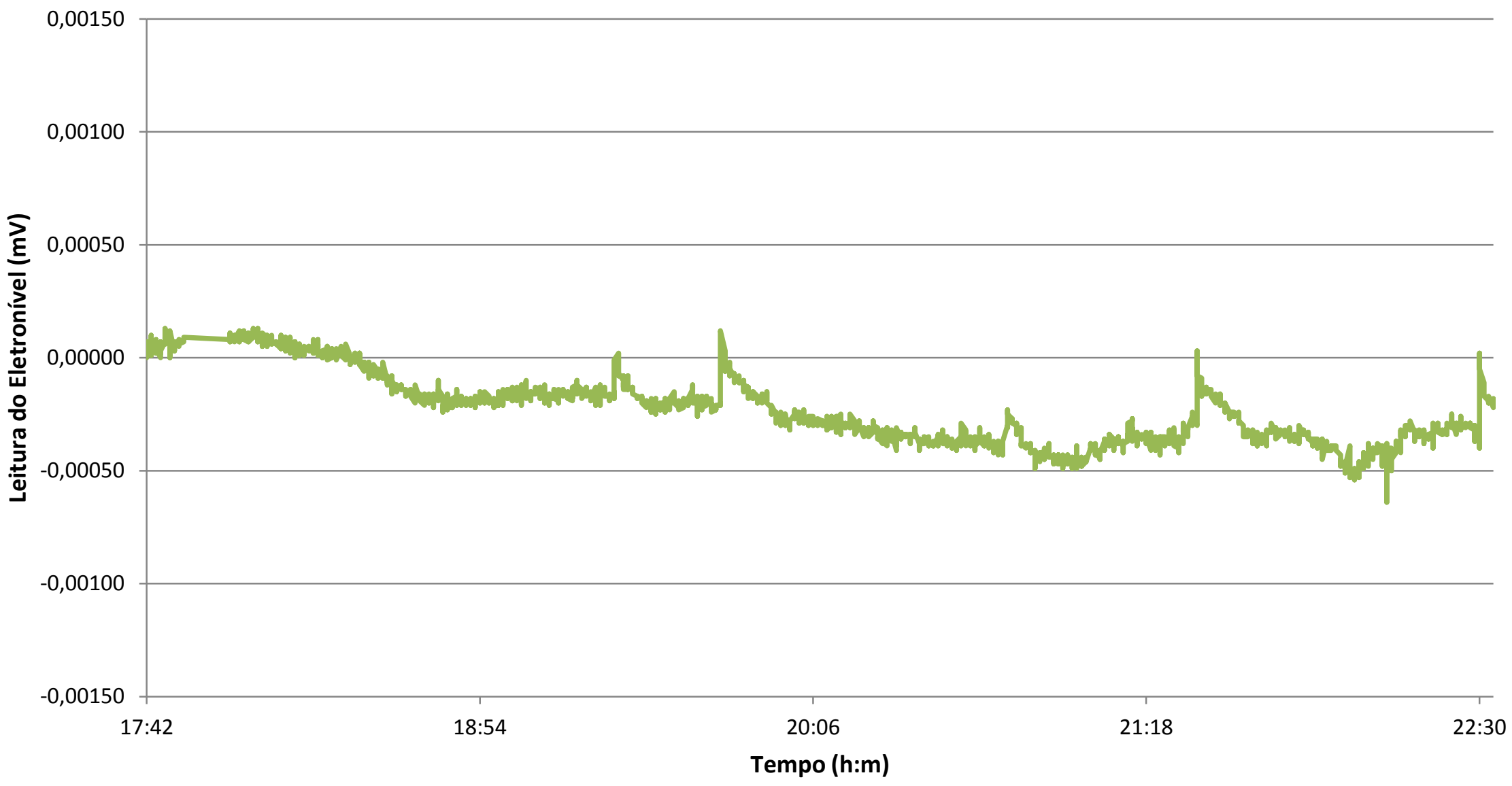

Figura A2.3 - Leituras do eletronível EL03. 
Apêndice 1

Curvas de calibração dos eletroníveis EL01 a EL16

EL04

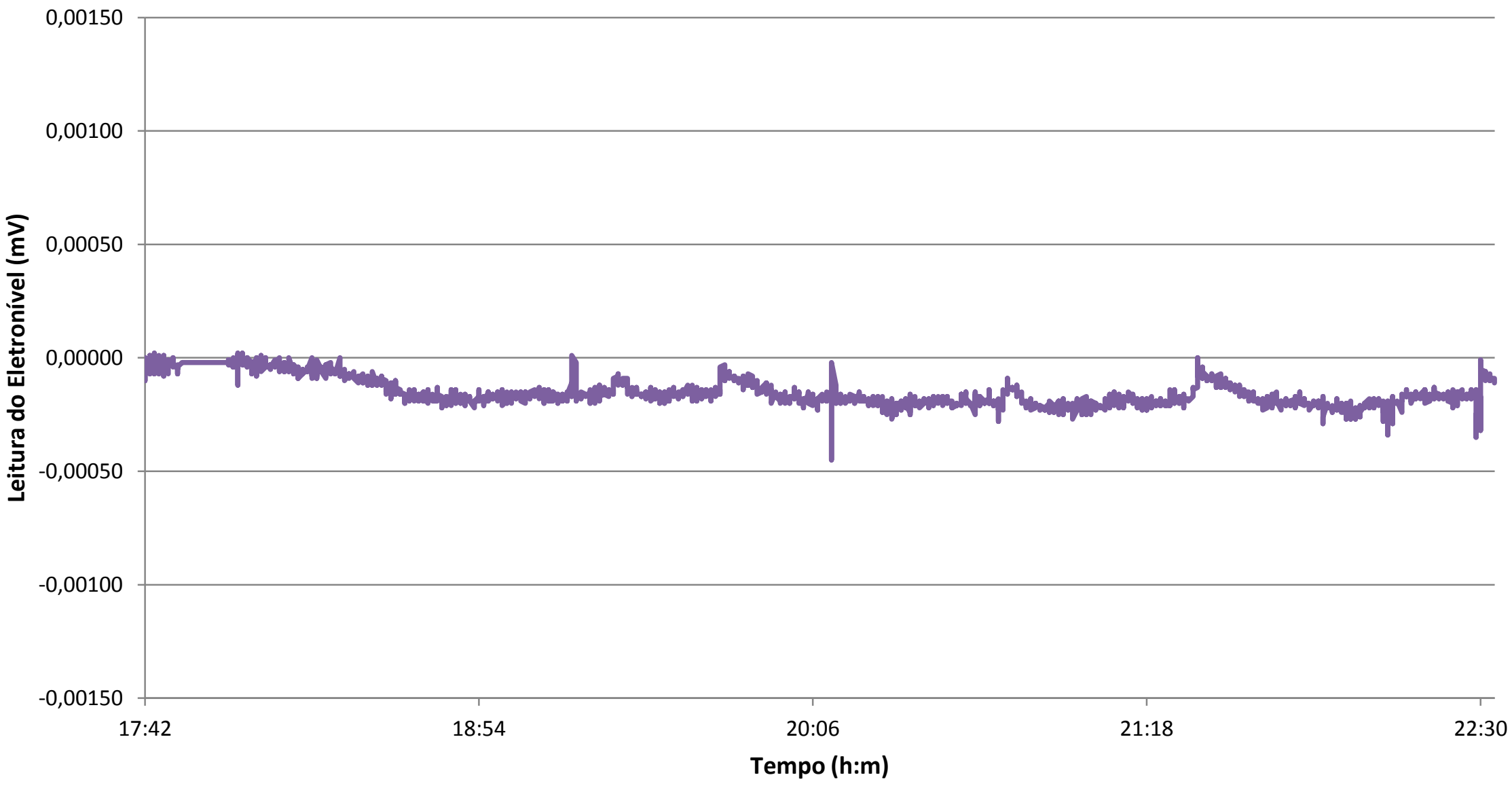

Figura A2.4 - Leituras do eletronível EL04. 
Apêndice 1

Curvas de calibração dos eletroníveis EL01 a EL16

EL05

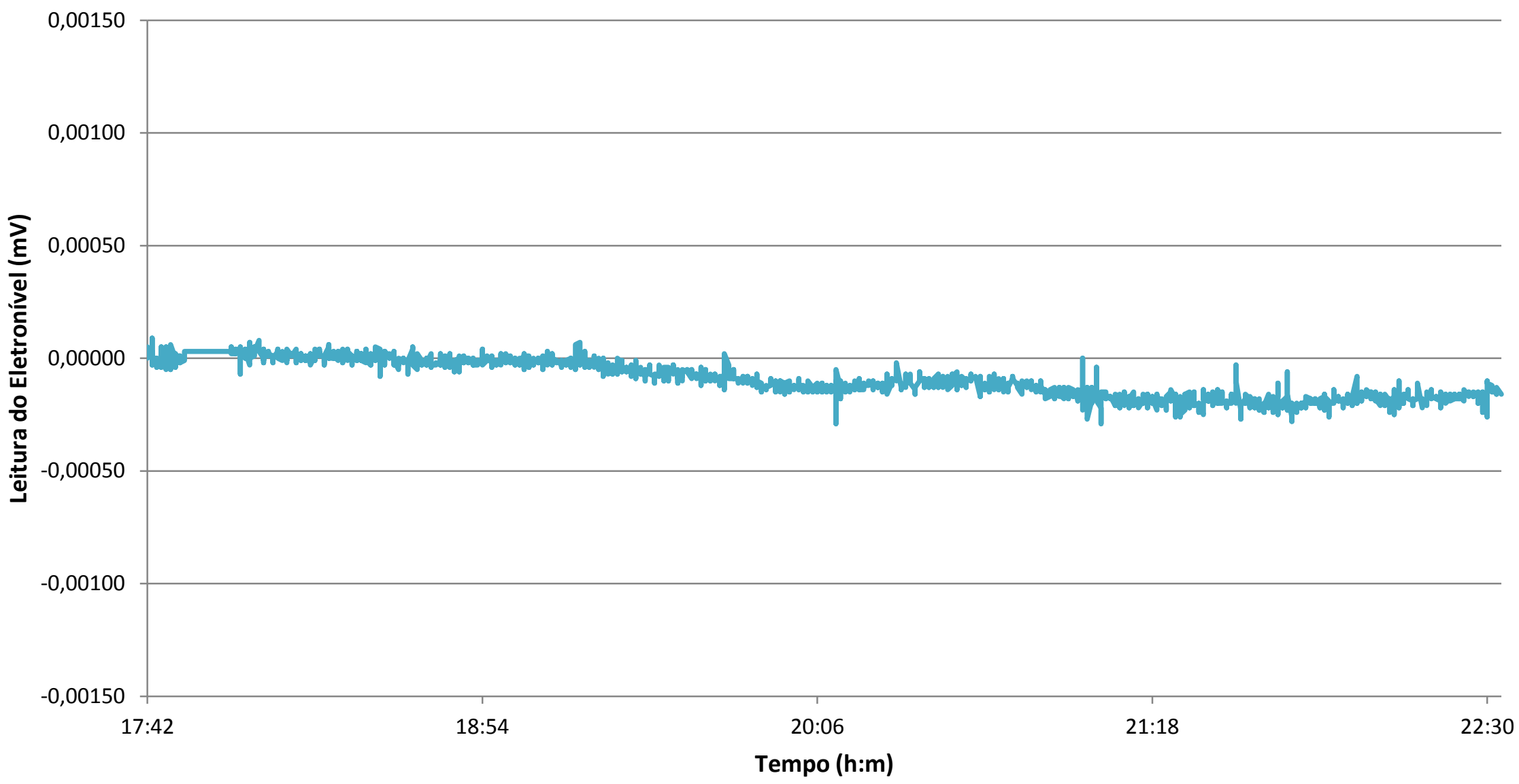

Figura A2.5 - Leituras do eletronível EL05. 
Apêndice 1

Curvas de calibração dos eletroníveis EL01 a EL16

\section{EL06}

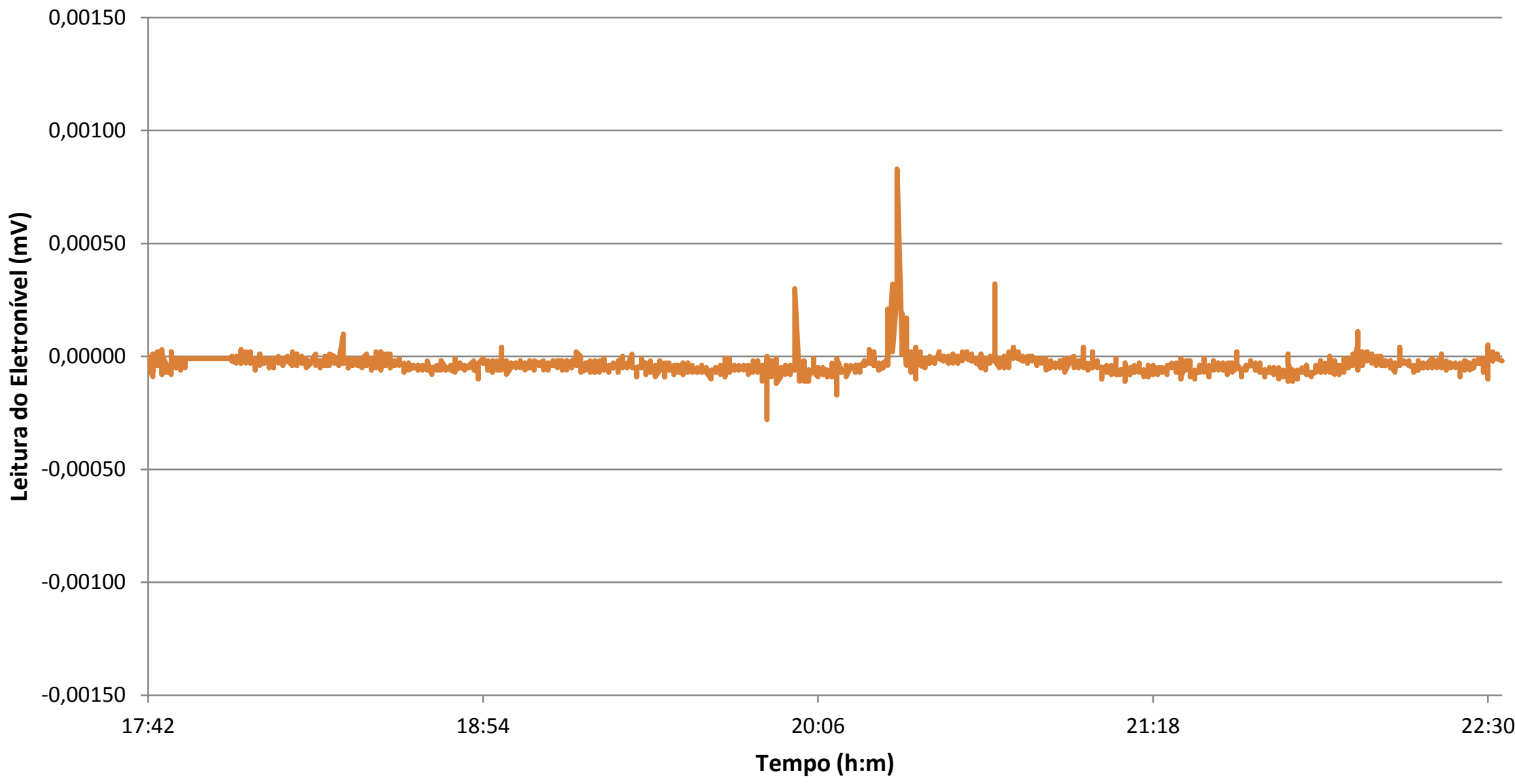

Figura A2.6 - Leituras do eletronível EL06. 
Apêndice 1

Curvas de calibração dos eletroníveis EL01 a EL16

\section{EL07}

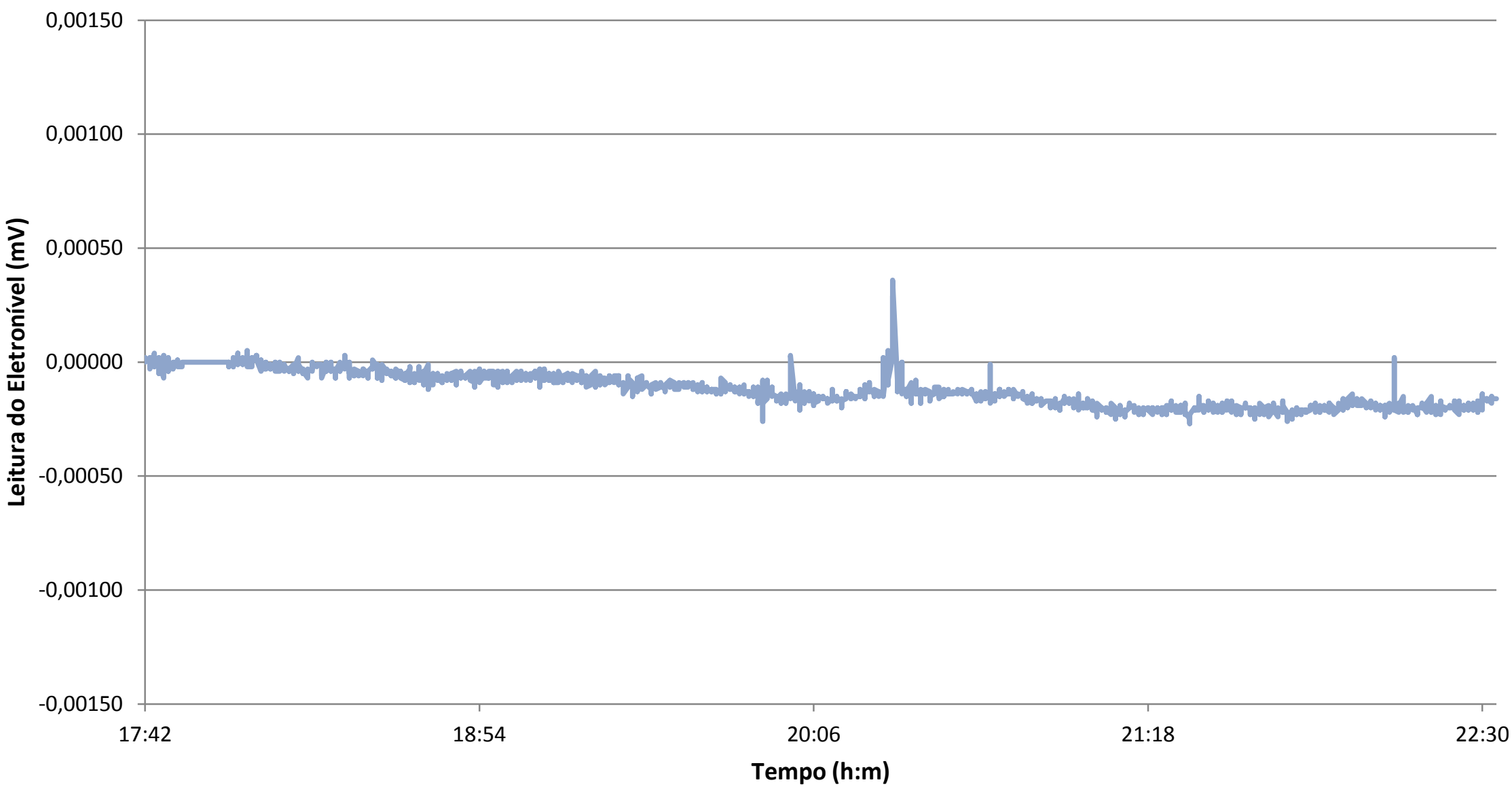

Figura A2.7 - Leituras do eletronível EL07. 
Apêndice 1

Curvas de calibração dos eletroníveis EL01 a EL16

\section{EL08}

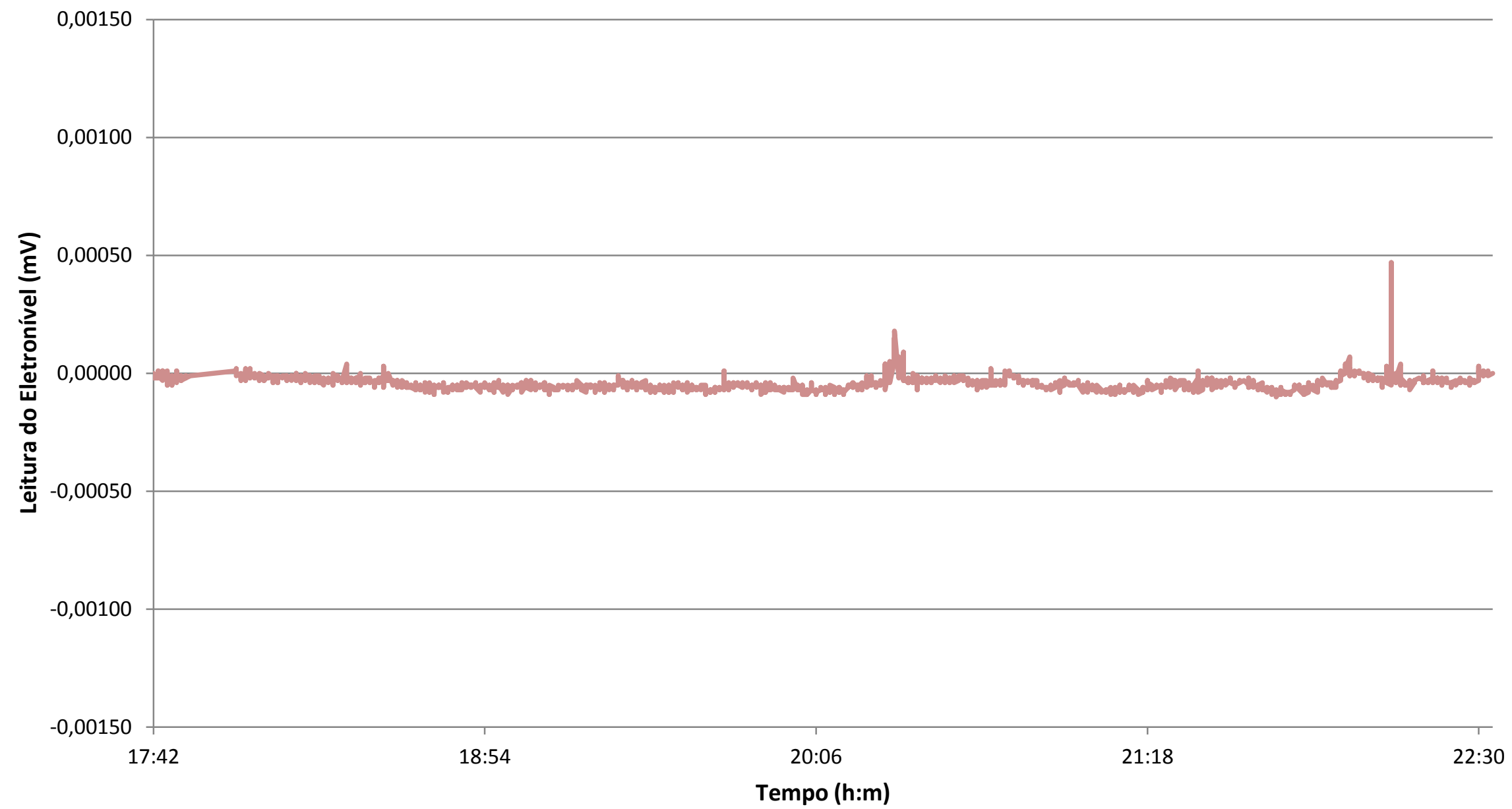

Figura A2.8 - Leituras do eletronível EL08. 
Apêndice 1

Curvas de calibração dos eletroníveis EL01 a EL16

\section{EL09}

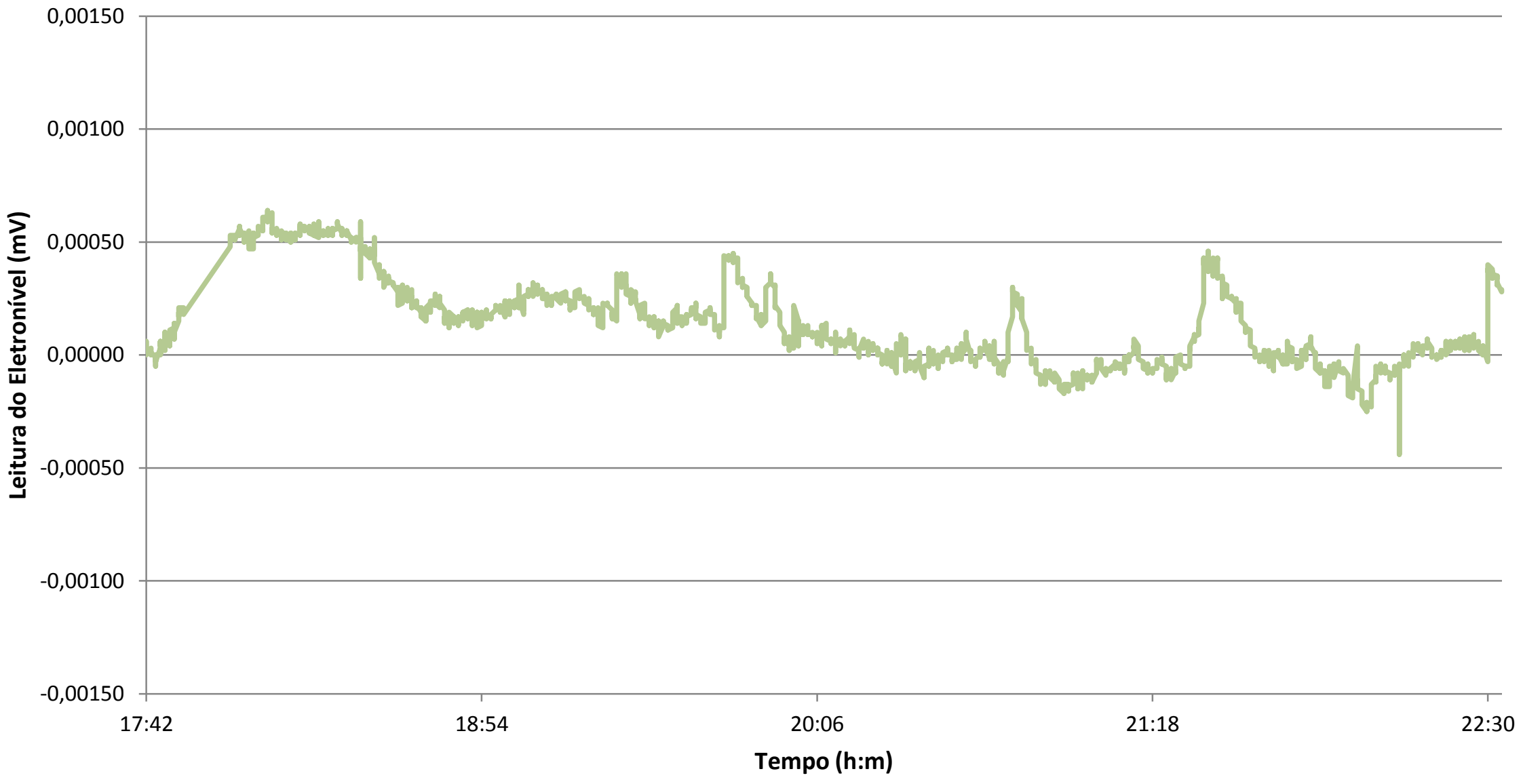

Figura A2.9 - Leituras do eletronível EL09. 
Apêndice 1

Curvas de calibração dos eletroníveis EL01 a EL16

\section{EL10}

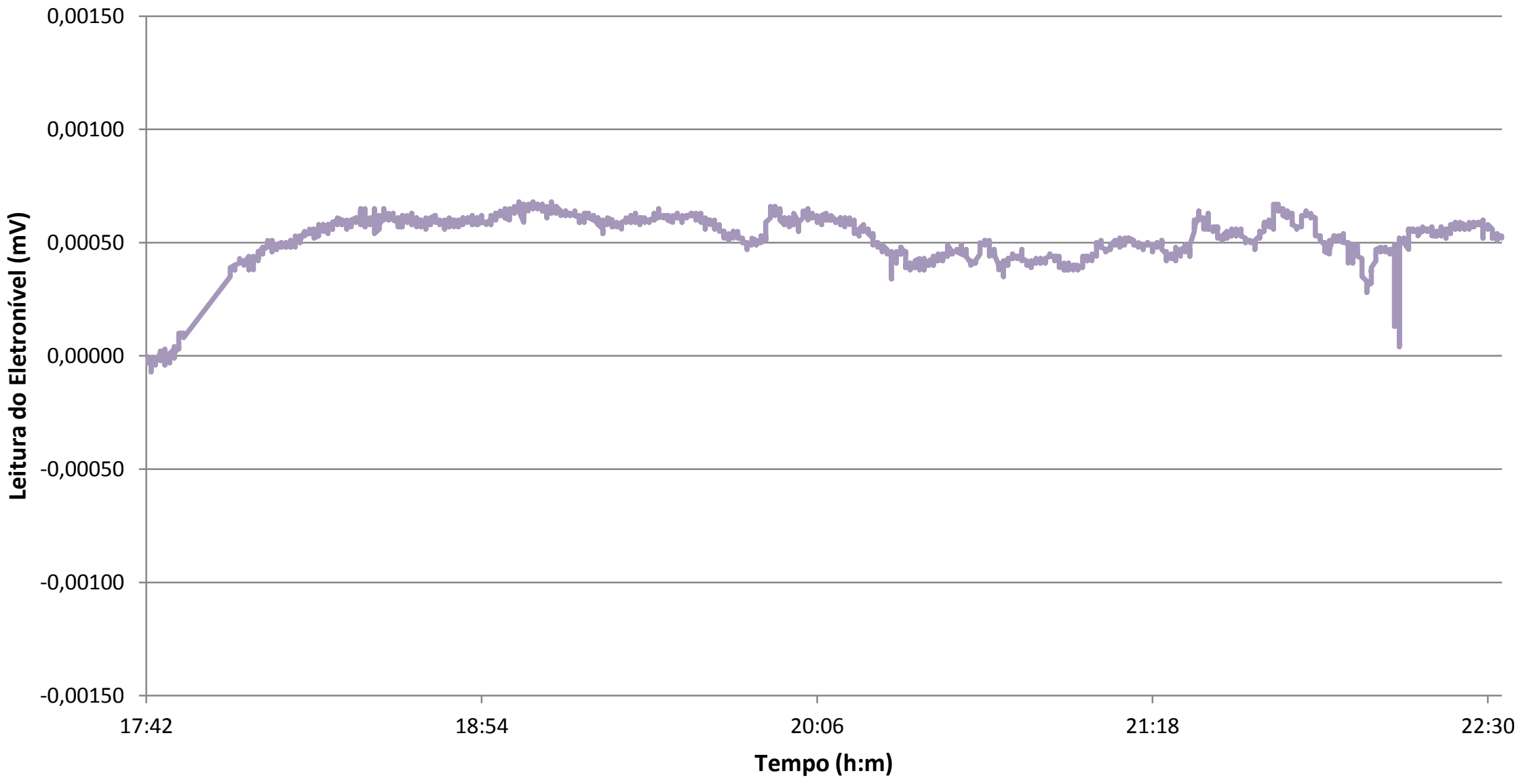

Figura A2.10 - Leituras do eletronível EL10. 
Apêndice 1

Curvas de calibração dos eletroníveis EL01 a EL16

EL11

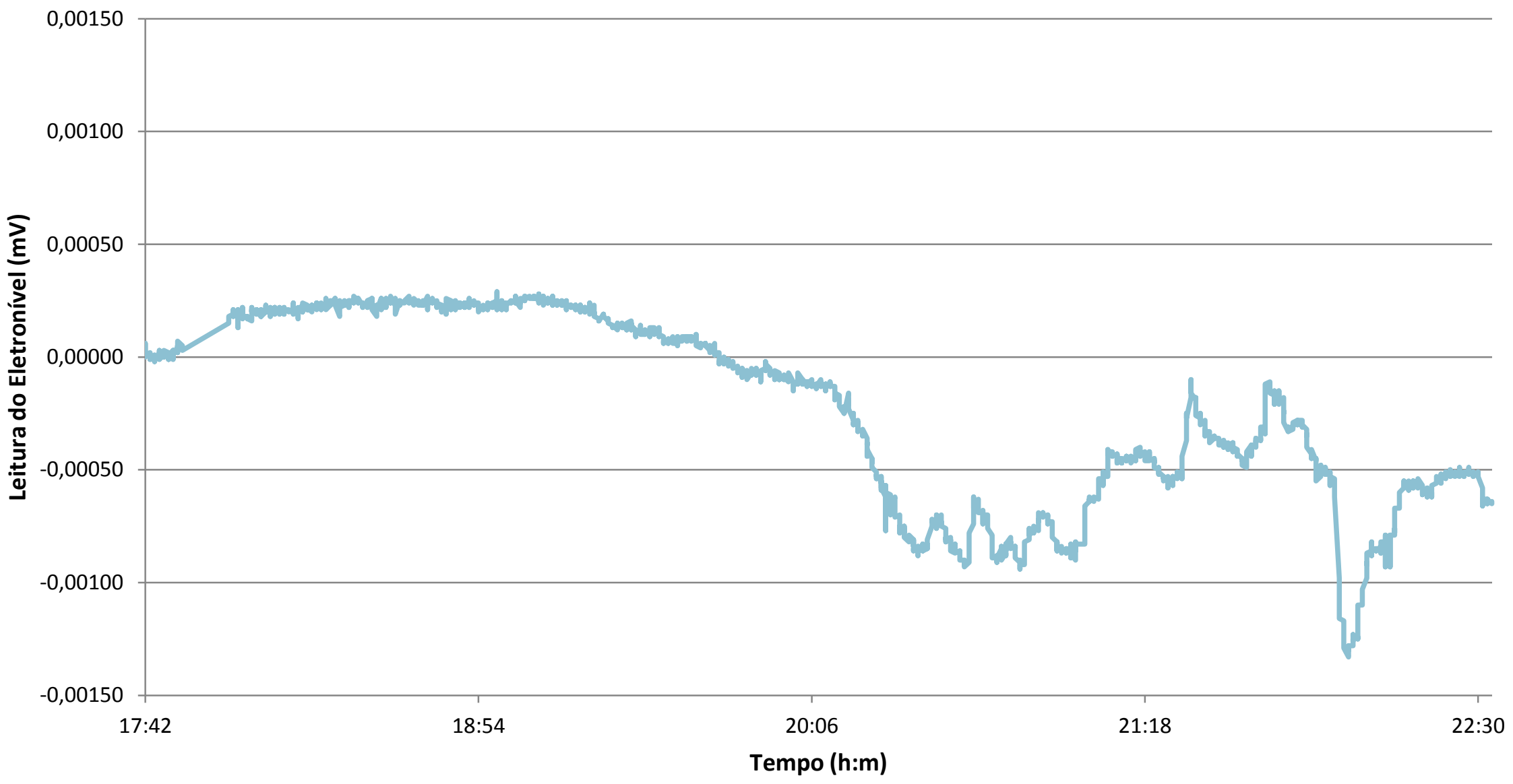

Figura A2.11 - Leituras do eletronível EL11. 
Apêndice 1

Curvas de calibração dos eletroníveis EL01 a EL16

\section{EL12}

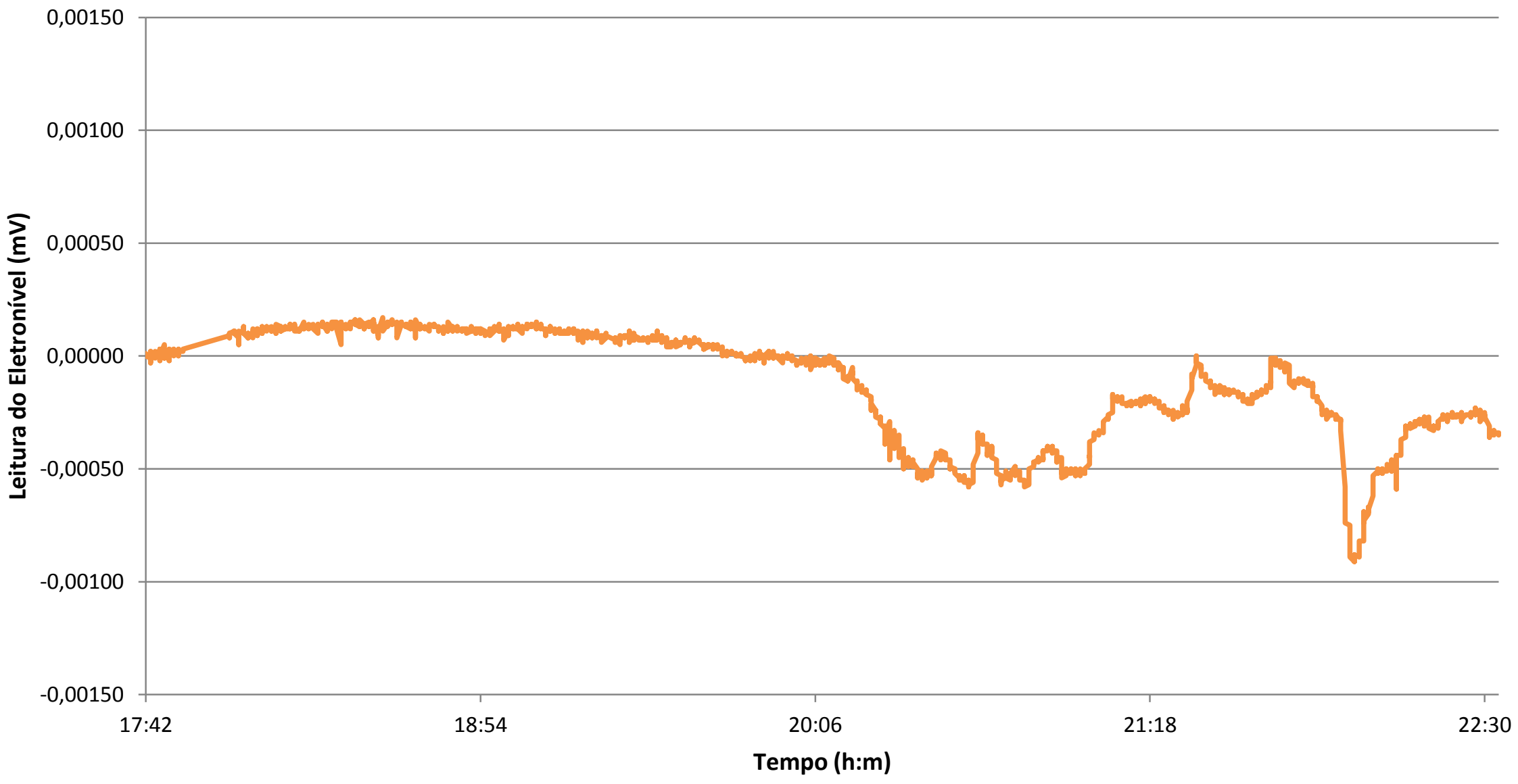

Figura A2.12 - Leituras do eletronível EL12. 
Apêndice 1

Curvas de calibração dos eletroníveis EL01 a EL16

\section{EL13}

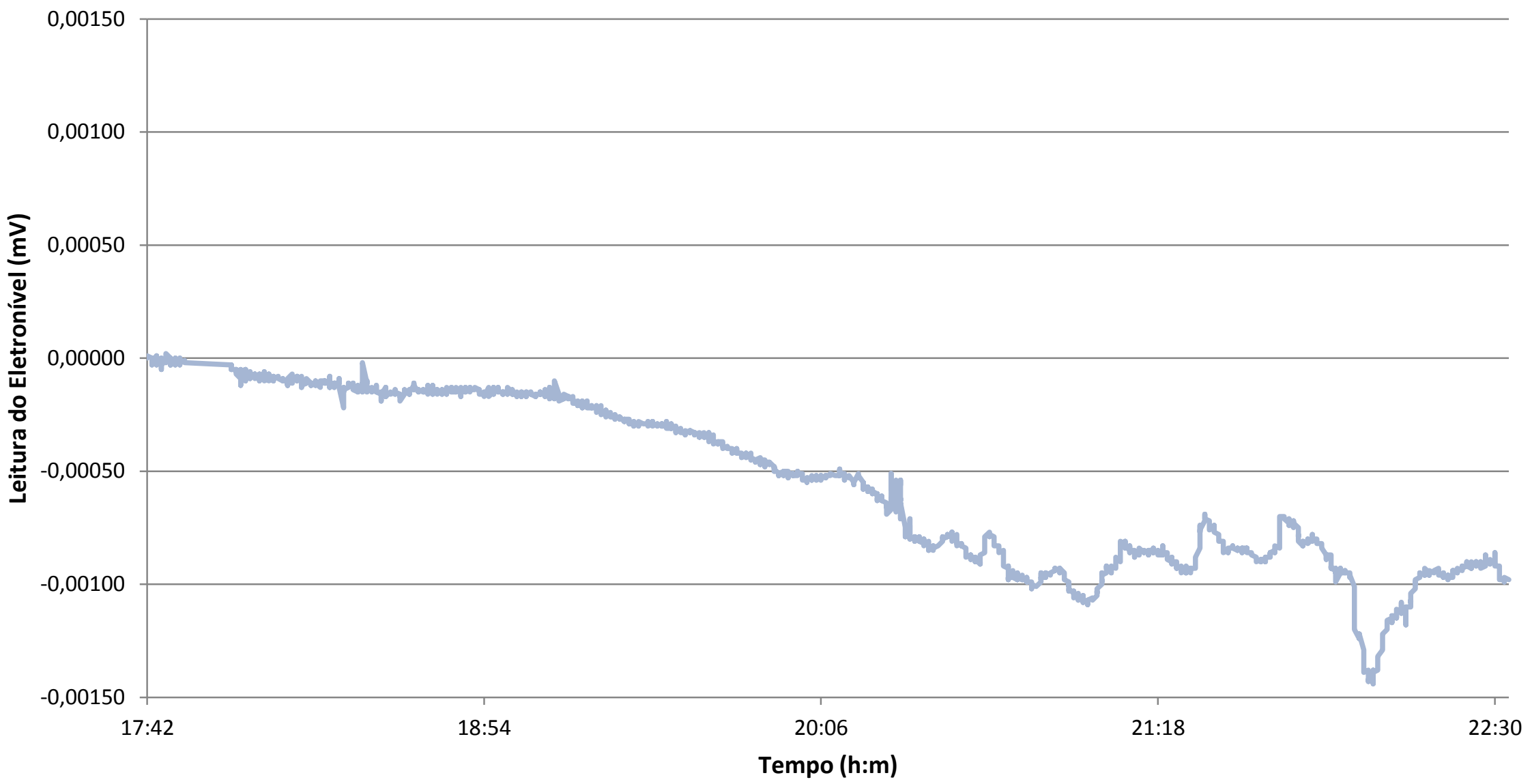

Figura A2.13 - Leituras do eletronível EL13. 
Apêndice 1

Curvas de calibração dos eletroníveis EL01 a EL16

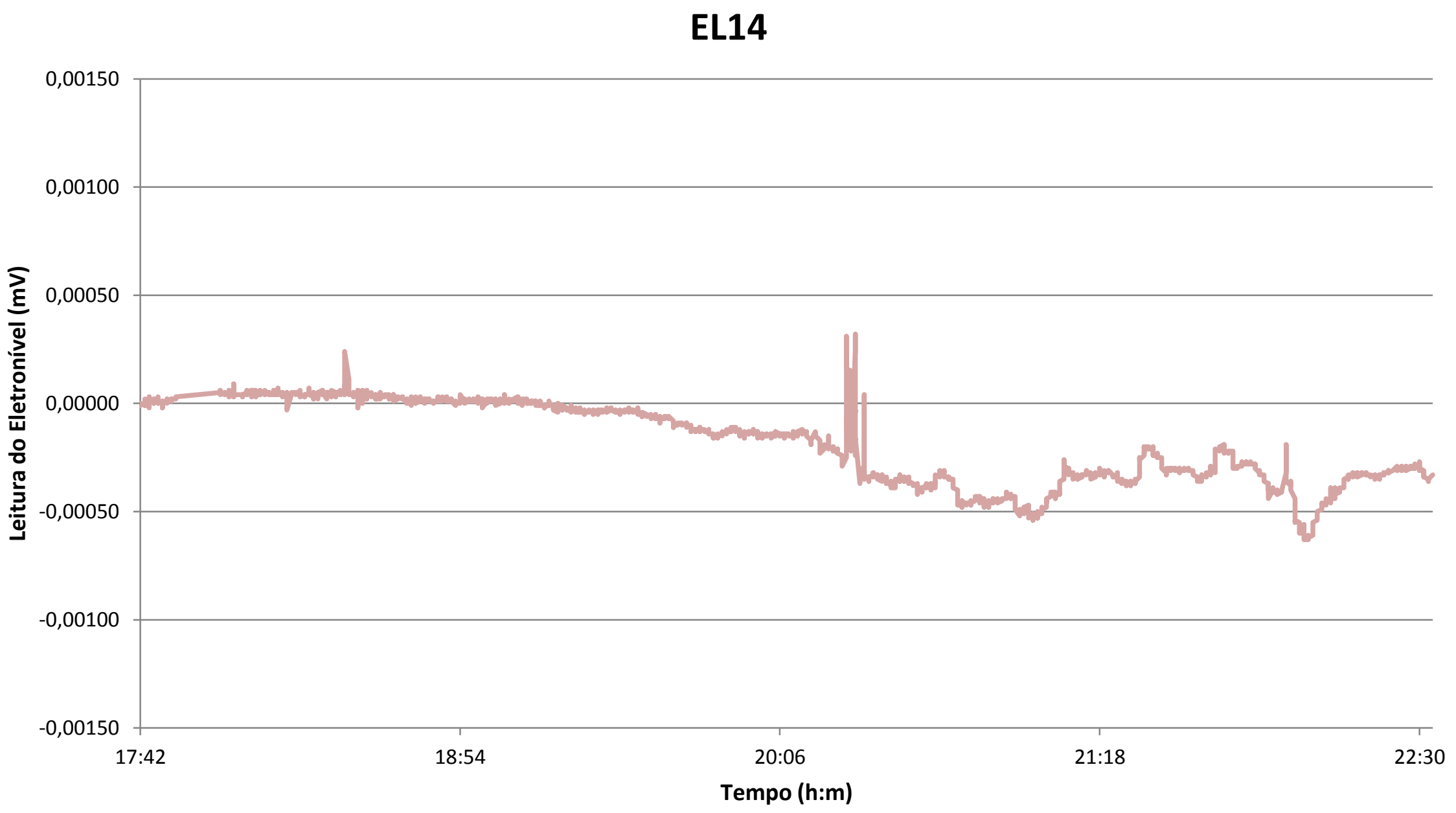

Figura A2.14 - Leituras do eletronível EL14. 
Apêndice 1

Curvas de calibração dos eletroníveis EL01 a EL16

EL15

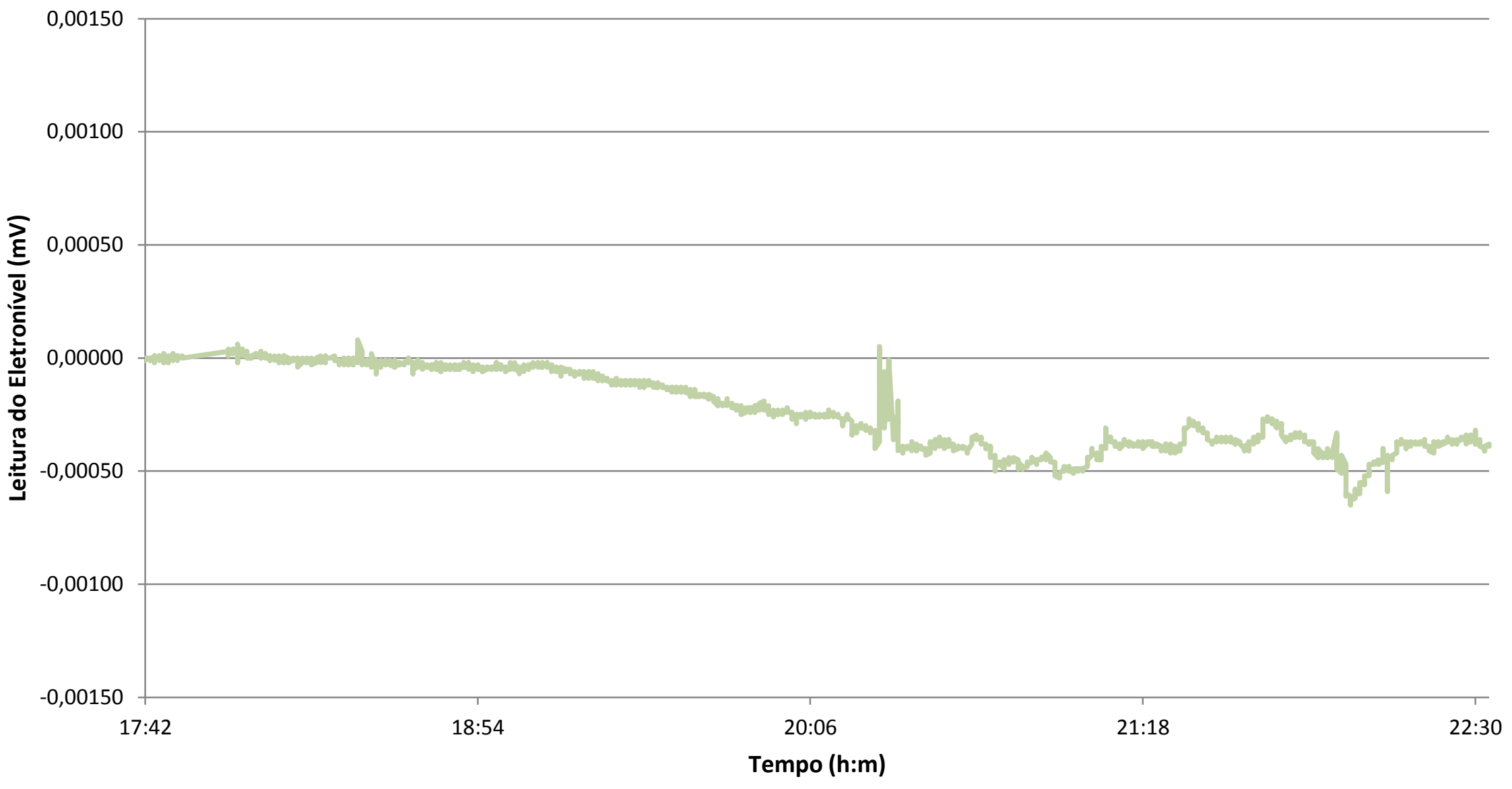

Figura A2.15 - Leituras do eletronível EL15. 
Apêndice 1

Curvas de calibração dos eletroníveis EL01 a EL16

\section{EL16}

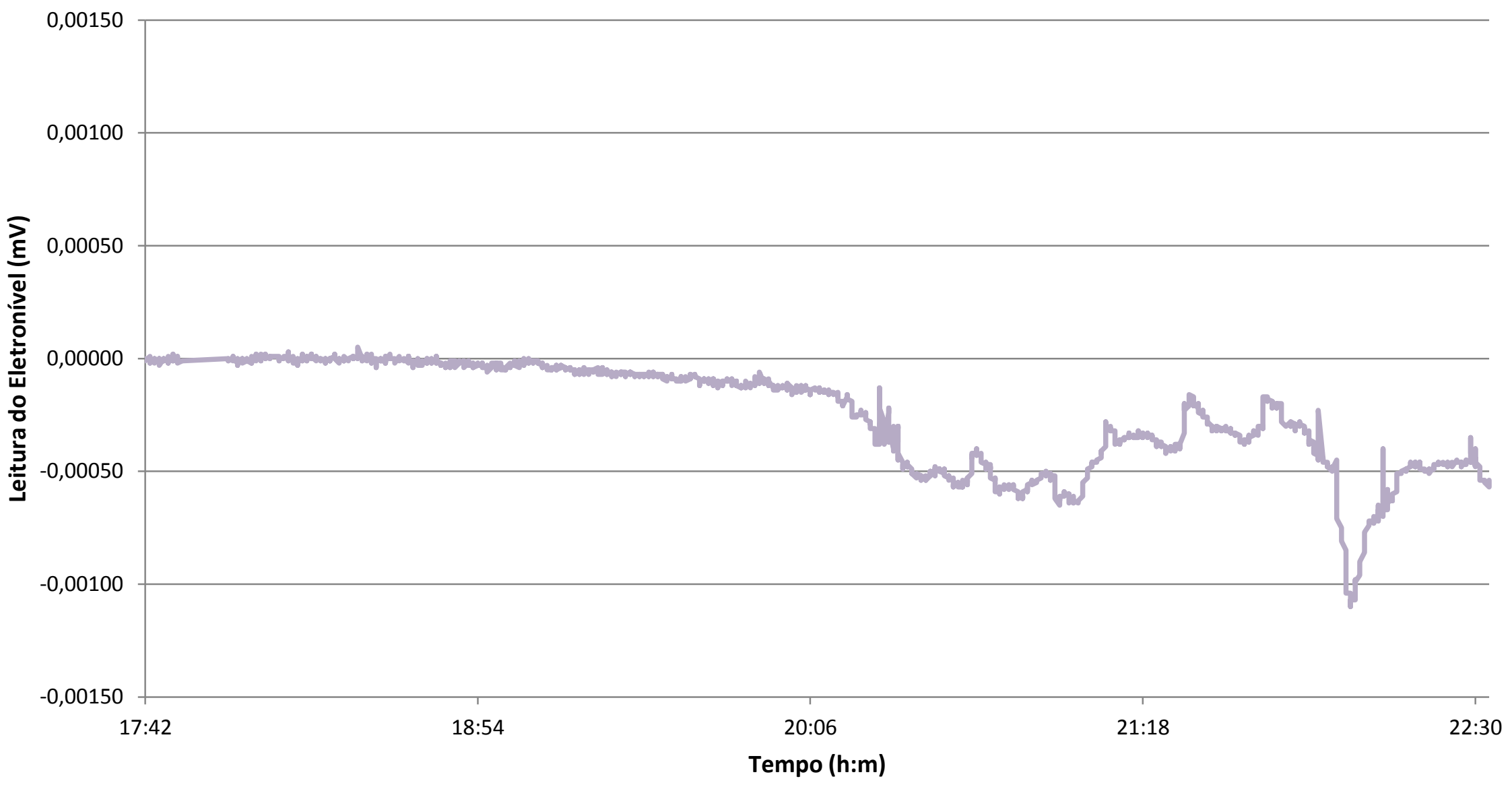

Figura A2.16 - Leituras do eletronível EL16. 